\title{
WestVirginiaUniversity
}

THE RESEARCH REPOSITORY @ WVU

Graduate Theses, Dissertations, and Problem Reports

2003

\section{Strengthening historic covered bridges to carry modern traffic}

Rex A. Cyphers

West Virginia University

Follow this and additional works at: https://researchrepository.wvu.edu/etd

\section{Recommended Citation}

Cyphers, Rex A., "Strengthening historic covered bridges to carry modern traffic" (2003). Graduate Theses, Dissertations, and Problem Reports. 1345.

https://researchrepository.wvu.edu/etd/1345

This Thesis is protected by copyright and/or related rights. It has been brought to you by the The Research Repository @ WVU with permission from the rights-holder(s). You are free to use this Thesis in any way that is permitted by the copyright and related rights legislation that applies to your use. For other uses you must obtain permission from the rights-holder(s) directly, unless additional rights are indicated by a Creative Commons license in the record and/ or on the work itself. This Thesis has been accepted for inclusion in WVU Graduate Theses, Dissertations, and Problem Reports collection by an authorized administrator of The Research Repository @ WVU. For more information, please contact researchrepository@mail.wvu.edu. 


\title{
Strengthening Historic Covered Bridges to Carry Modern Traffic
}

\author{
By \\ Rex A. Cyphers \\ Thesis submitted to the \\ College of Engineering and Mineral Resources \\ at West Virginia University \\ in partial fulfillment of the requirements \\ for the degree of \\ Master of Science \\ in \\ Civil Engineering
}

Hota V.S. GangaRao, Ph.D., P.E., Chair

Emory L. Kemp, Ph.D., P.E.

Udaya B. Halabe, Ph.D., P.E.

Samer H. Petro, P.E.

Department of Civil and Environmental Engineering

\author{
Morgantown, West Virginia \\ 2003
}

Key Words: Covered Bridges, Timber Bridges, Historic Preservation, GFRP 


\section{ABSTRACT \\ Strengthening Historic Covered Bridges to Carry Modern Traffic}

\section{Rex A. Cyphers}

The focus of this study was to develop means and methods to strengthen timber superstructural components of historic covered bridges using Glass Fiber Reinforced Polymer (GFRP) composite materials. The strengthening methodologies developed during this research project were designed to conform to the Secretary of the Interior's Standards for the Treatment of Historic Properties. More specifically, tension and bending tests were conducted to establish bond strength of GFRP rebars embedded in wood, and to establish bending strength and stiffness of large-scale beams reinforced with GFRP pultruded plates, and GFRP rebars. The GFRP rebars were developed to be used specifically as reinforcing materials for truss members, while the GFRP plates were developed to enhance the bending capacity of floor beams and stringers. The results showed bonded-in GFRP rebars performed very well in terms of pullout force and bond strength, and the strength and stiffness of GFRP reinforced timber beams improved significantly. Additionally, during this research several methods of concealing the reinforcement, thereby preserving the historic integrity of structural members were investigated. 
Dedicated to my wife Denise, without her patience, support and reassurance this would not have been possible. 


\section{ACKNOWLEDGMENTS}

The author would especially like to thank Dr. Hota V. S. GangaRao who was both the author's advisor and committee chairman. He provided too many contributions to mention; his understanding, wisdom and teachings will never be forgotten.

Special thanks are also owed to the remainder of the advisory committee. The author is thankful to have had the opportunity to learn from and interact with, Dr. Emory Kemp, whose knowledge and experience in the area of preservation of covered bridges in unequaled. Samer Petro served as both an advisory committee member and as the primary investigator for the project. He provided assistance on every aspect of the project. The author would also like to thank Dr. Udaya Halable for his insightful review and serving as a committee member and also Mr. Donald Tusing and Mr. Aaron Smith for their assistance with laboratory testing throughout the course of the project.

The author gratefully acknowledges the funding and support of the Federal Highway Administration and Sheila Duwadi and the Timber Bridge Research Council for their valuable review and comments. 


\section{Table of Contents}

Abstract

Acknowledgements ..................................................................................................................... iii

Chapter 1 - Introduction...........................................................................................1

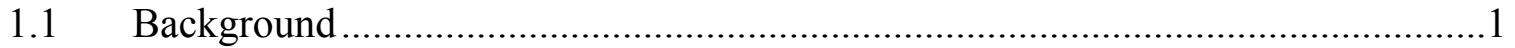

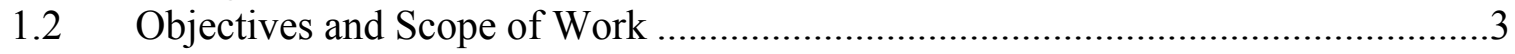

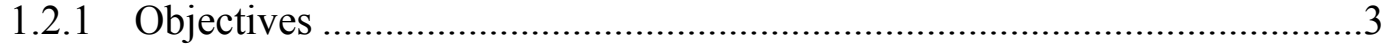

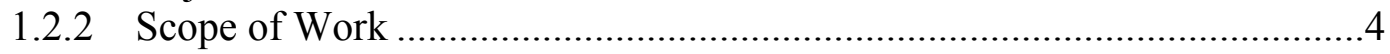

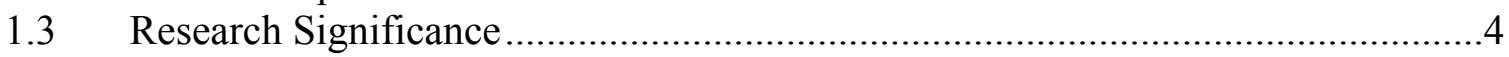

Chapter 2 - Literature Review .........................................................................................5

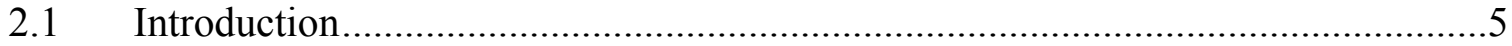

$2.2 \quad$ Historic Covered Bridges...............................................................................5

2.3 The Secretary of the Interior's Standards for the

Treatment of Historic Properties................................................................

$2.4 \quad$ Current Methods for Preserving Covered Bridges..................................................

2.5 Modern Methods for Preserving Covered Bridges ................................................13

2.5.1 Externally Bonded Repair....................................................................17

2.5.2 Philippi Covered Bridge .....................................................................18

2.5.3 Barrackville Covered Bridge ...................................................................18

Chapter 3 - Laboratory Experiments..................................................................20

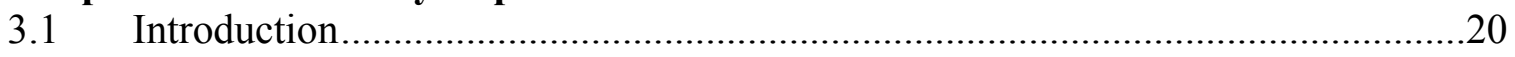

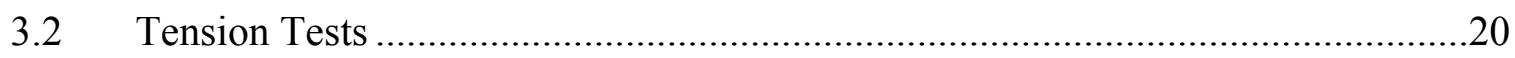

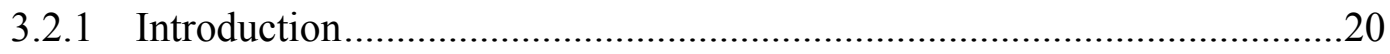

3.2.2 Preparation of Test Specimens.............................................................20

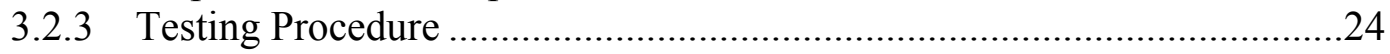

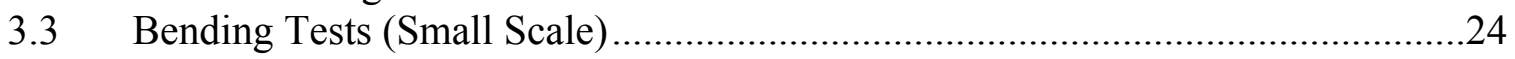

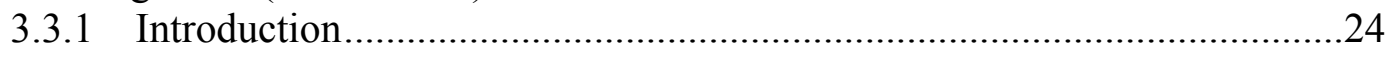

3.3.2 Preparation of Test Specimens.............................................................24

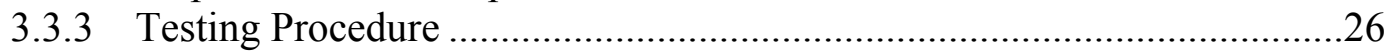

3.4 Bending Test (6" x 11 3/4") with GFRP Plates ..................................................27

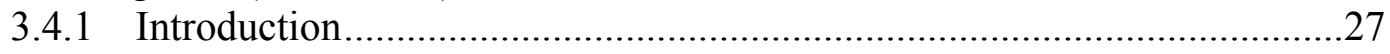

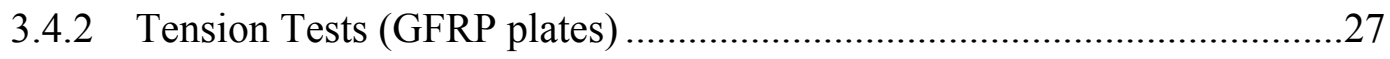

3.4.2.1 Preparation of Test Specimens...............................................27

3.4.2.2 Testing Procedure …………………………………….......28

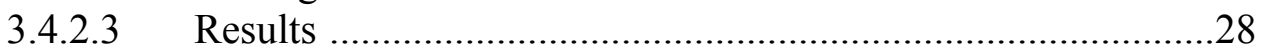

3.4.3 Preparation of Full Scale Bending Test Specimen ....................................29

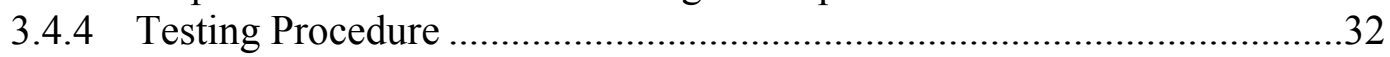

3.5 Bending Tests with GFRP Reinforcing Bars ....................................................33

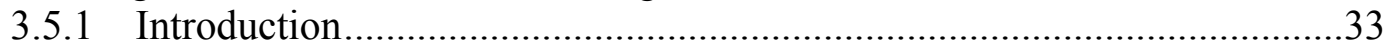

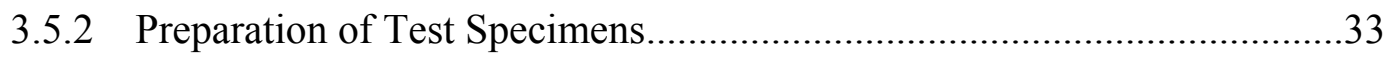

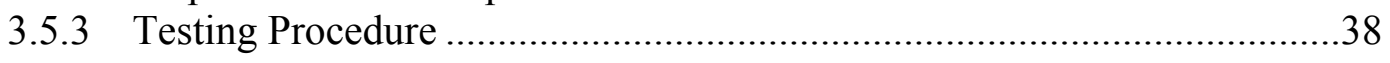




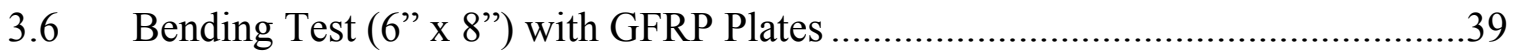

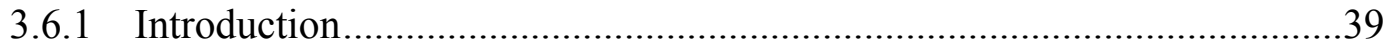

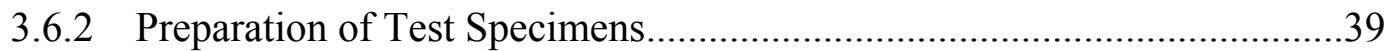

3.6.3 Testing Procedure ………………………......................................... 41

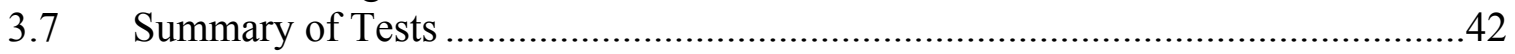

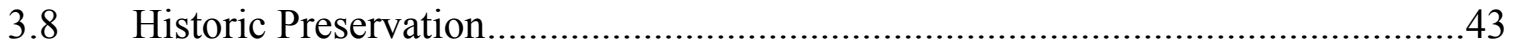

Chapter 4 - Results and Discussions ...................................................................................47

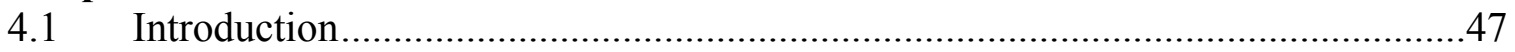

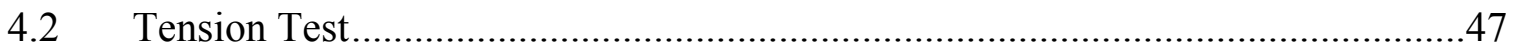

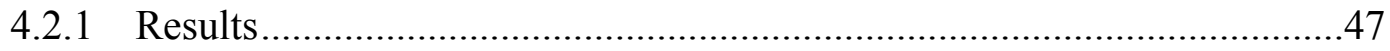

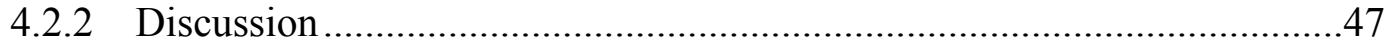

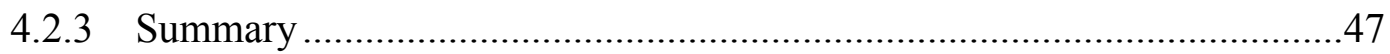

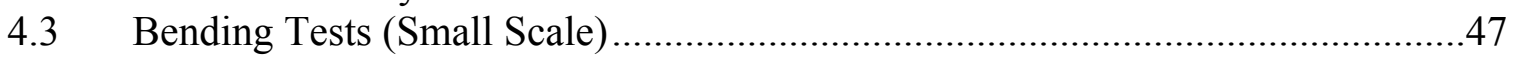

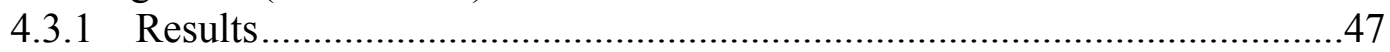

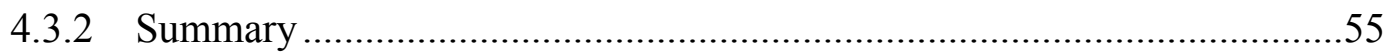

$4.4 \quad$ Bending Test $(6$ " x 11 3/4") with GFRP Plates ...................................................5

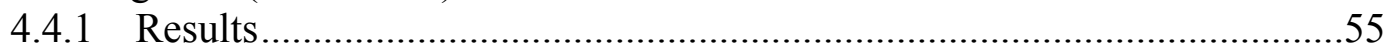

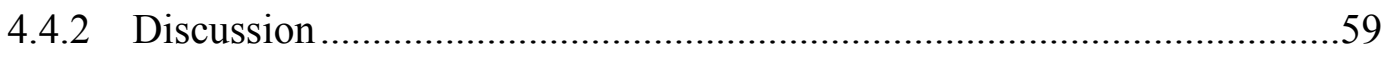

4.4.2.1 Prediction of Flexural Rigidity Using Rule of Mixtures ..............61

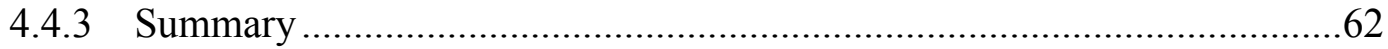

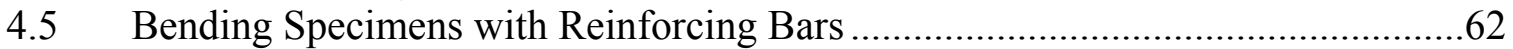

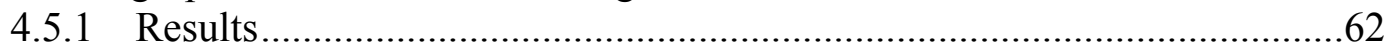

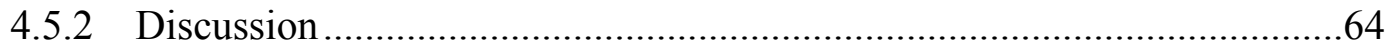

4.5.2.1 Prediction of Flexural Rigidity Using Rule of Mixtures ..............65

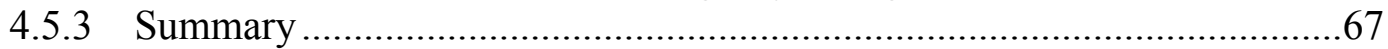

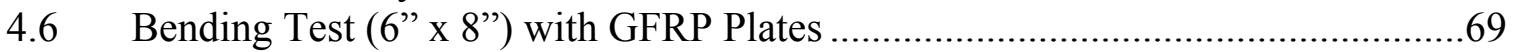

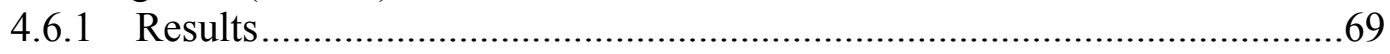

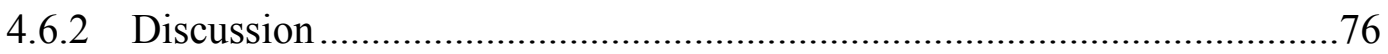

4.7 Theoretical Moment Capacity........................................................................

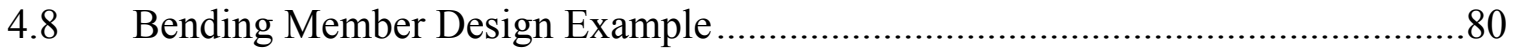

4.8.1 Bending Member Design without Factors ..................................................8

4.8.2 Bending Member Design with Factors ………….................................82

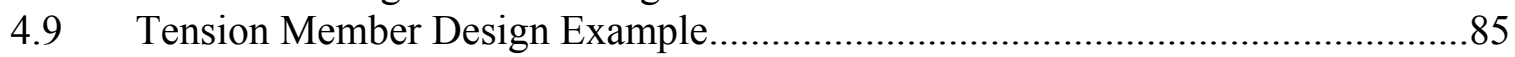

4.10 Prediction of Flexural Rigidity Using Rule of Mixtures .......................................8

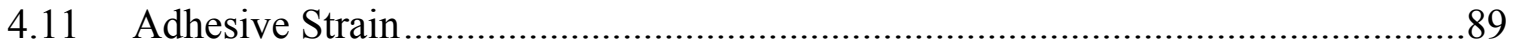

4.12 Bonding GFRP Plates to Timber Beams ………….........................................90

Chapter 5 - Conclusions and Recommendations...............................................................93

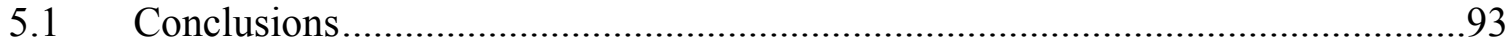

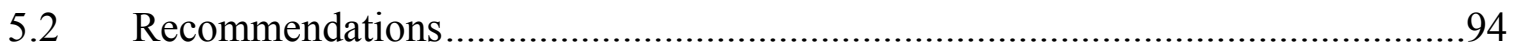

Bibliography ….........................................................................................................................96

Appendix A - Preliminary Testing.................................................................................98

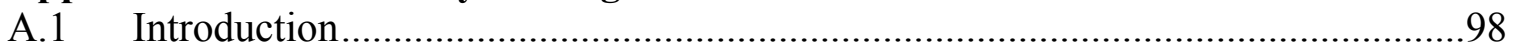


A.2 Void Test for Tension Members ………………...............................................98

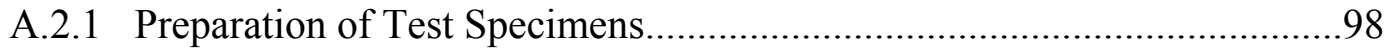

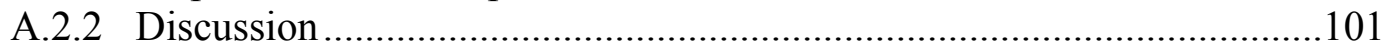

A.3 Preliminary Tension Tests ............................................................................. 102

A.3.1 Preparation of Test Specimens...........................................................102

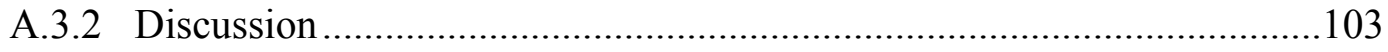

A.3.3 Conclusion .................................................................................

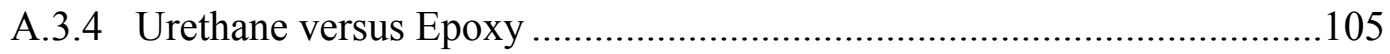

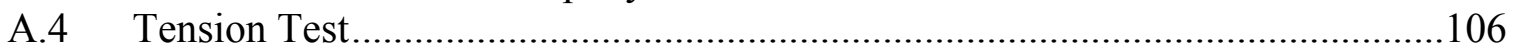

A.4.1 Preparation of Test Specimens...........................................................106

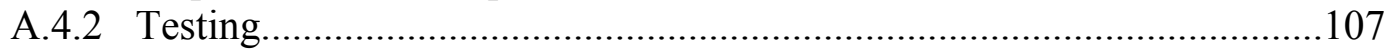

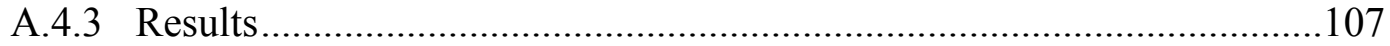

A.4.4 Discussion ...........................................................................................

Appendix B- Annotated Bibliography .............................................................................110

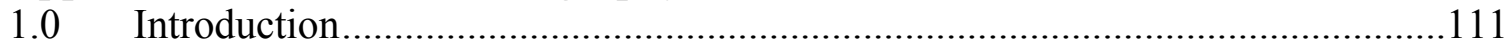

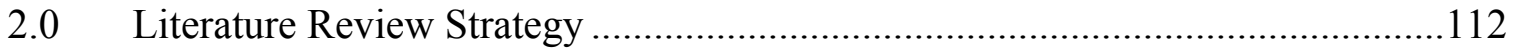

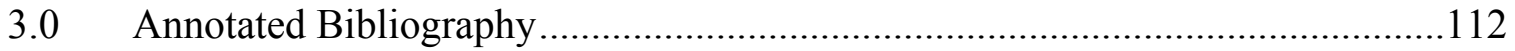

3.1 Composite Reinforcement of Timber Members .......................................113

3.2 Durability of FRP Reinforcement for Wood ..............................................117

3.3 Debonding of Beam Reinforced with FRP Plates.....................................118

3.4 Timber Joints with Composites ..........................................................118

3.5 FRPs in Bridge Applications .............................................................120

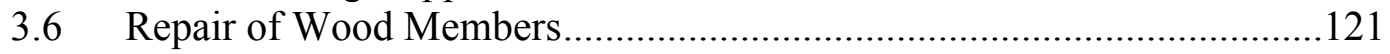

3.6 Nondestructive Evaluation of Timber Bridges .......................................122

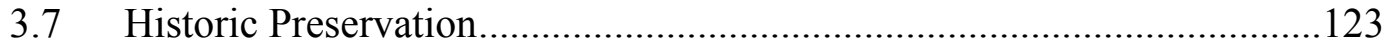

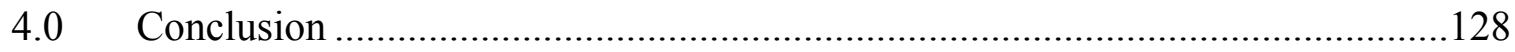




\section{List of Figures}

Figure 1. Barrackville Covered Bridge, Barrackville, W.Va........................2

Figure 2. Drawing of Barrackville Covered Bridge.....................................2

Figure 3. Roddy Road Covered Bridge Rehabilitated with Steel I Beams ....10 Frederick County, M.D.

Figure 4. Typical Clamping and Stitching of Timber Members....................12

Figure 5. Salt Creek Covered Bridge, Muskingum County, Ohio.................15

Figure 6. Tension Test Specimens ........................................................21

Figure 7. Countersunk Holes to Maintain Horizontal Alignment..................22

Figure 8. Tension Specimens ....................................................................23

Figure 9. Injection of PLIOGRIP in Tension Specimen............................23

Figure 10. Bending Test Specimen Dimension .............................................25

Figure 11. Bending Specimen Reinforcement ..........................................25

Figure 12. Four-Point Bending Test Set-Up ..............................................26

Figure 13. Specimen B-2 in Four-Point Loading......................................26

Figure 14. MOE Tension Test Specimens ..................................................28

Figure 15. End View of Test Specimens ...............................................29

Figure 16. Side View of Test Specimens .......................................................30

Figure 17. Routing of Test Specimen ........................................................30

Figure 18. Applying Adhesive on Test Member ......................................... 31

Figure 19. Steel Plates Used as Weights on Test Specimen ...........................32

Figure 20. Four Point Bending Test Setup...............................................33

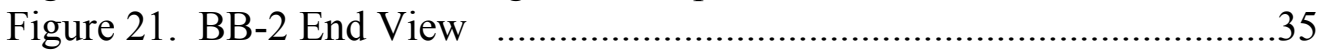

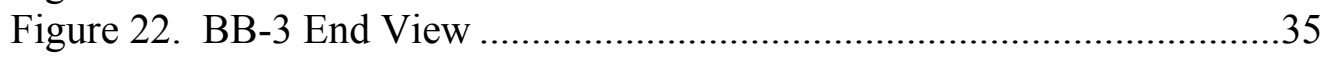

Figure 23. Bottom View BB-2 \& BB-3 ................................................... 35

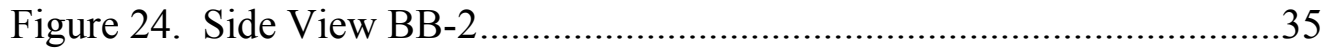

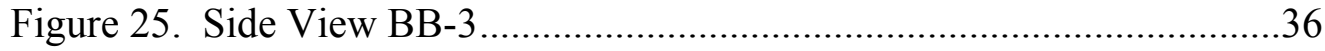

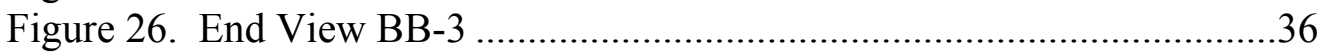

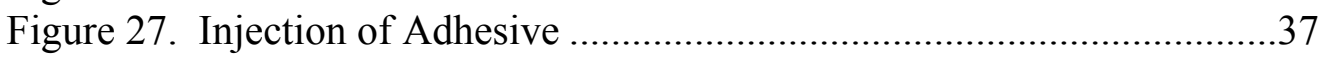

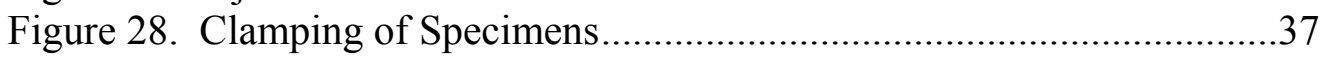

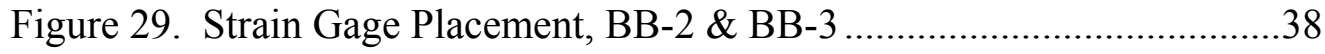

Figure 30. Four Point Bending Test Setup.................................................39

Figure 31. End View of Test Specimens ....................................................40

Figure 32. Side View of Test Specimens ................................................40

Figure 33. Plan View of Strain Gage Placement ......................................41

Figure 34. Four Point Bending Test Setup...............................................42

Figure 35. Side View of Reinforced Specimen ............................................44

Figure 36. Specimen Covered with Veneer .............................................45

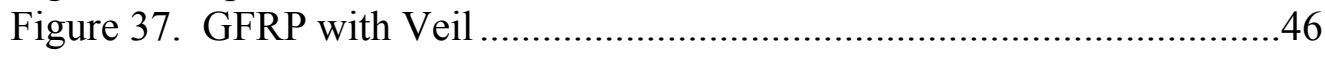

Figure 38. GFRP with Veil .................................................................46

Figure 39. Bond Strength vs. Development Length .................................48

Figure 40. Stress-Strain Diagram for the Unreinforced Specimen .................50

Figure 41. Stress-Strain Diagram for Specimen B-2 ..................................50

Figure 42. Failure Mode of Specimen B-2 ..............................................51

Figure 43. Actual and Transformed Section for B-2 …...........................52 
Figure 44. Stress-Strain Diagram for Specimen B-3 …............................53

Figure 45. Failure Mode of Specimen B-3 …...........................................54

Figure 46. Transformed and Actual Section for B-3 ...................................55

Figure 47. Load vs. Deflection for the Unreinforced Specimen.....................56

Figure 48. Failure Mode of GFRP Reinforced Beam ..................................57

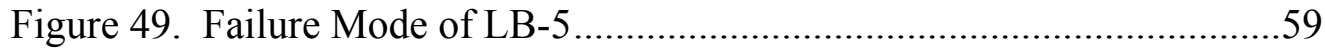

Figure 50. Transformed Section for LB-5 ..............................................60

Figure 51. Load vs. Deflection Between Reinforced and Unreinforced Beams.......................................................60

Figure 52. Specimen after Testing .........................................................63

Figure 53. Specimen after Testing ........................................................63

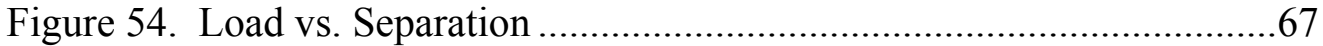

Figure 55. Arch Splice Repair Detail.........................................................68

Figure 56. Load vs. Strain for the Unreinforced Specimen ...........................70

Figure 57. Load vs. Deflection for Unreinforced Specimen..........................70

Figure 58. Failure Mode of Unreinforced Beam .......................................71

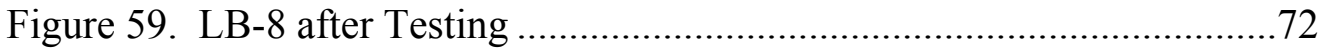

Figure 60. Partial Bond in LB-8 ............................................................... 72

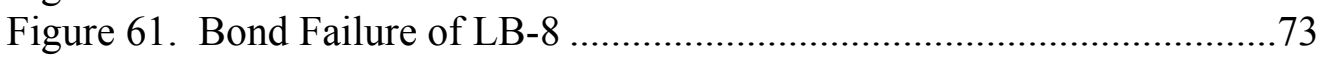

Figure 62. Failure Mode of LB-7, Tension Side Down...............................74

Figure 63. Load vs. Strain Diagram for LB-7 .......................................... 74

Figure 64. Transformed Section for LB-7 .................................................75

Figure 65. Strain Compatibility and Internal Moment Equilibrium ................77

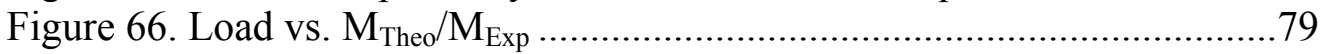

Figure 67. Bending Member Design Example ............................................8 80

Figure 68. Strain Compatibility and Internal Moment Equilibrium ..............81

Figure 69. Bending Member Design Example .............................................83

Figure 70. Strain Compatibility and Internal Moment Equlibrium ................84

Figure 71. Tension Member Design Example .............................................88

Figure 72. Diagram of Strain Gage Placement and Strain Profile..................89

Figure 73. Load vs. Microstrain in PLIOGRIP ............................................90

Figure 74. Side View of Test Specimens ...................................................99

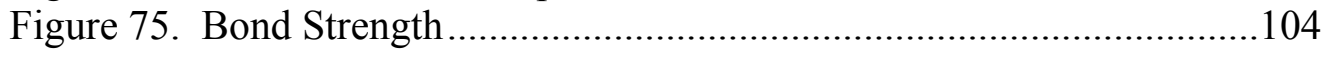

\section{List of Tables}

Table 1. Tension Test Specimens ..............................................................24

Table 2. GFRP Plate MOE Values ...........................................................29

Table 3. Observed Bond Strength................................................................47

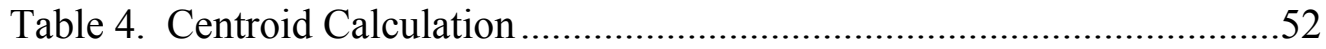

Table 5. Test Results ................................................................................5

Table 6. Test Results..............................................................................64

Table 7. Strain at Failure.......................................................................64 
Table 8. Test Results

Table 9. Tension Member Design Table.....................................................85

Table 10. Observed Strength and Stiffness

\section{List of Symbols}

\begin{tabular}{|c|c|}
\hline$A_{f}$ & Area of GFRP \\
\hline$A_{g}$ & Gross Cross Sectional Area \\
\hline$A_{h}$ & Area of Holes \\
\hline$A_{n}$ & Net-Cross Sectional Area \\
\hline$A_{w}$ & Area of Wood in Tension Block \\
\hline $\mathrm{C}_{\mathrm{D}}$ & Load Duration Factor \\
\hline $\mathrm{C}_{\mathrm{E}}$ & Environmental Reduction Factor of FRP \\
\hline $\mathrm{C}_{\mathrm{F}}$ & Size Factor for Sawn Lumber \\
\hline $\mathrm{C}_{\mathrm{L}}$ & Beam Stability Factor \\
\hline $\mathrm{C}_{\mathrm{M}}$ & Wet Surface Factor \\
\hline $\mathrm{C}_{\mathrm{t}}$ & Temperature Factor \\
\hline$\Delta$ & Deflection \\
\hline$\mu \varepsilon$ & Microstrain \\
\hline$\varepsilon$ & Strain \\
\hline $\mathrm{E}$ & Modulus of Elasticity \\
\hline EI & Flexural Rigidity \\
\hline $\mathrm{F}_{\mathrm{b}}$ & Bending Stress \\
\hline $\mathrm{F}_{\mathrm{b}}^{\prime}$ & Allowable Bending Stress \\
\hline$F_{f}$ & FRP Design Stress \\
\hline$f_{t}$ & Actual Tension Stress in Member \\
\hline$F_{t}$ & Tension Stress Parallel to Grain \\
\hline $\mathrm{F}_{\mathrm{t}}^{\prime}$ & Allowable Tensile Stress \\
\hline I & Moment of Inertia \\
\hline $\mathrm{I}_{\mathrm{T}}$ & Transformed Moment of Inertia \\
\hline M & Moment \\
\hline $\mathrm{M}_{\text {Theo }}$ & Theoretical Moment \\
\hline $\mathrm{M}_{\mathrm{Exp}}$ & Experimental Moment \\
\hline MOE & Modulus of Elasticity of the Beam \\
\hline MOR & Modulus of Rupture \\
\hline $\mathrm{P}$ & Load \\
\hline$\Phi_{\mathrm{b}}$ & GFRP Plate Reduction Factor for Bending \\
\hline$\Phi_{\mathrm{t}}$ & Reduction Factor for Tensile Bond Strength \\
\hline
\end{tabular}




\section{Chapter 1}

\section{Introduction}

\subsection{Background}

Many covered wooden bridges were hand built in the United States during the 1800s soon after the end of the Civil War. Many different types and designs comprise the once abundant population of covered wooden bridges, of which fewer than 1000 remain as an American icon of $19^{\text {th }}$ century bridge engineering and craftsmanship. Most of the remaining covered bridges are listed or eligible to be listed on the National Register of Historic Places and are of great importance to historians, engineers and the general public. In the State of West Virginia, covered bridges are not only a part of West Virginia's distinctive heritage, but also a tourist attraction to the region's most serene settings. Members of the National Society for the Preservation of Covered Bridges make annual trips to West Virginia and other states to see and photograph covered bridges.

Out of the remaining covered bridges, some must be bypassed, while others are being moved to local fairgrounds or parks to be used as pedestrian crossings. In some cases, new bridges are being built alongside the old to divert traffic away from the existing covered bridges. As a matter of integrity, the ideal preservation practice involves restoration and rehabilitation of the existing covered bridges, leaving them in place with the ability to carry modern loads, and at the same time preserving their historic and aesthetic values and national heritage ${ }^{1}$. Figure 1 is a photograph of what can happen if the right methods are developed to save these bridges. This photograph is of the Barrackville covered bridge, which is the 2nd oldest covered bridge still in service today in West Virginia. In 1987 a new bridge was built next to the Barrackville covered bridge to carry traffic. The Barrackville covered bridge was restored in 1999. Figure 2 is a drawing of the same bridge depicting "Burr-Arch" construction patented by Theodore Burr in $1817^{2}$. 


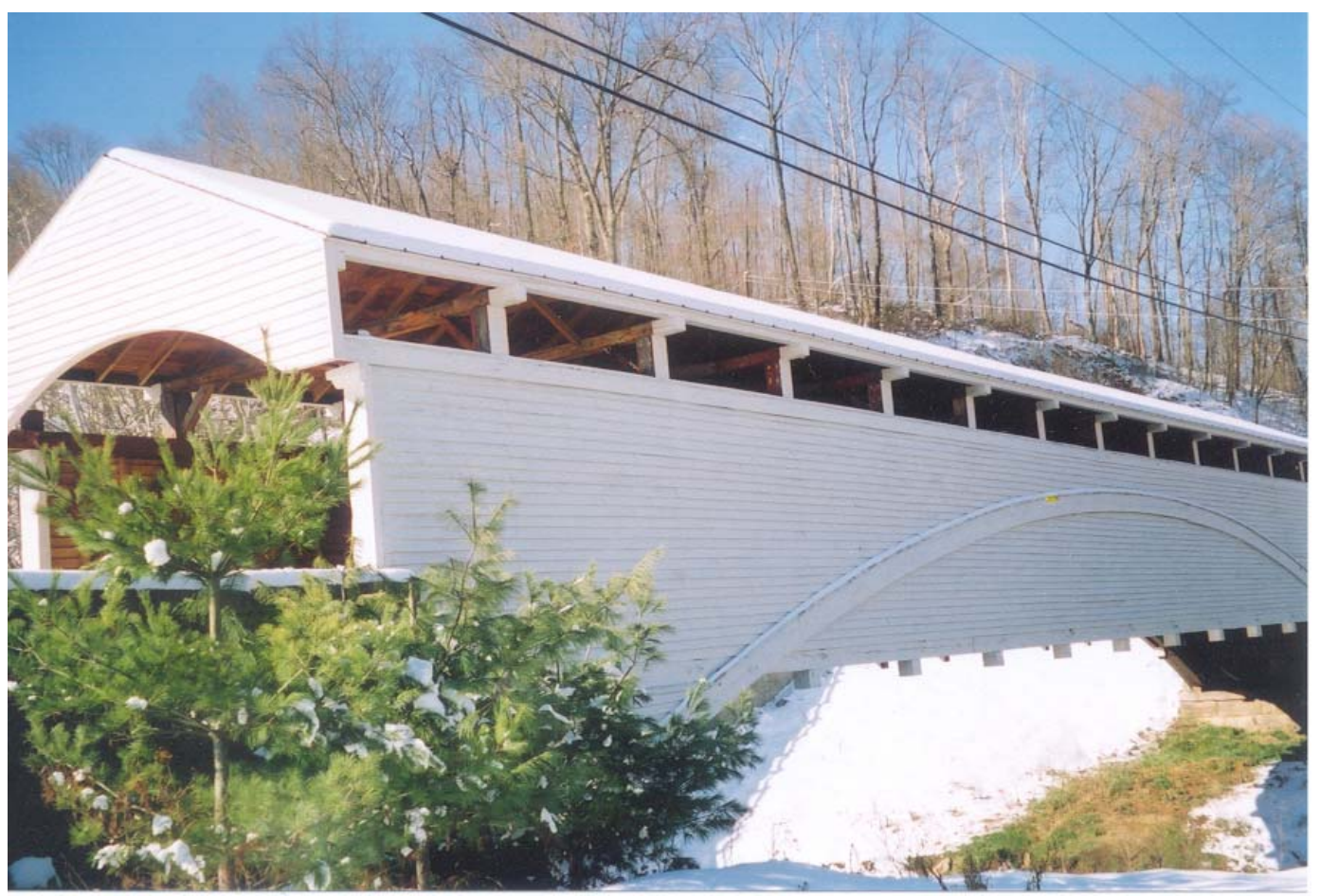

Figure 1. Barrackville Covered Bridge, Barrackville, W.Va. (Denise Cyphers)

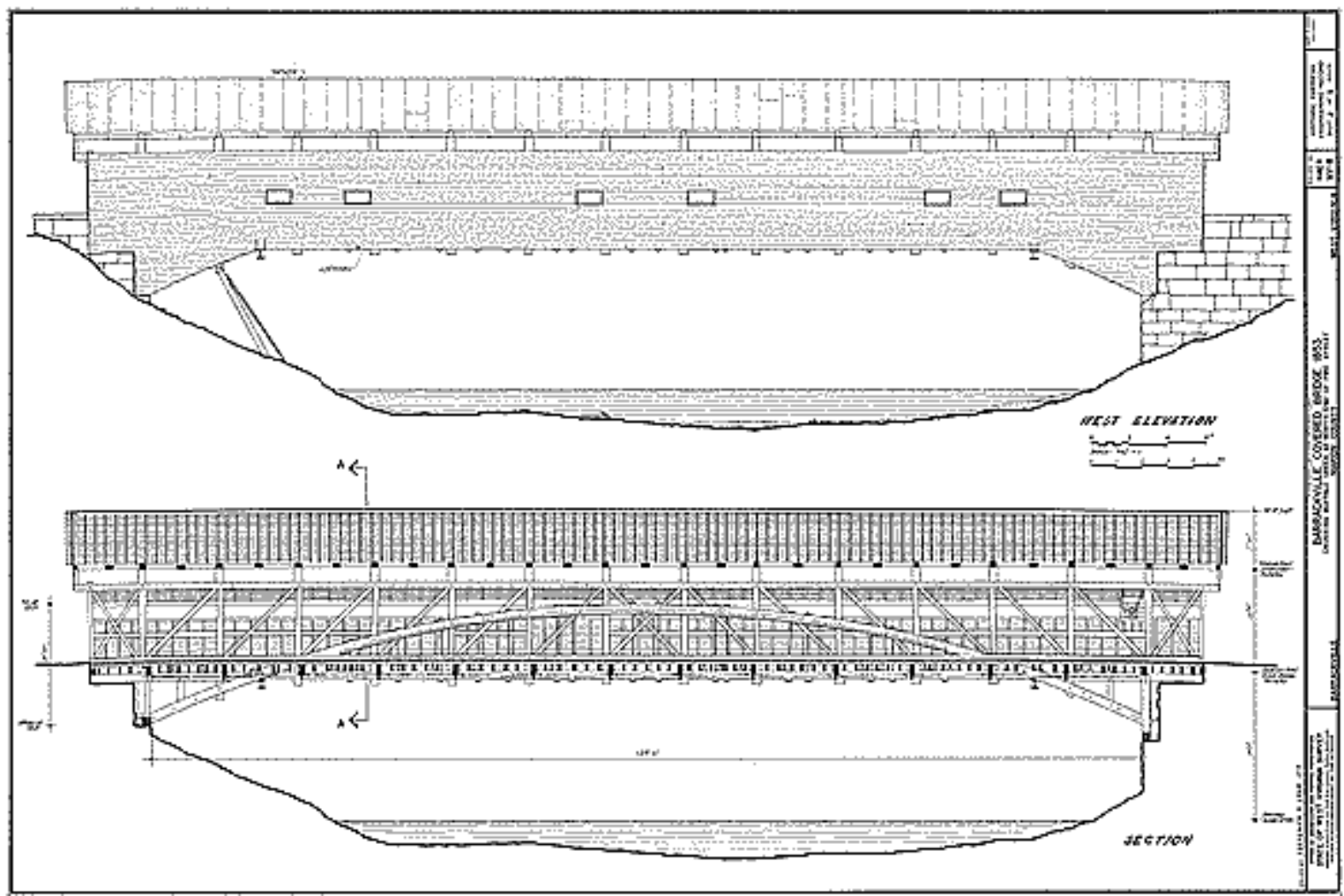

Figure 2. Drawing of Barrackville Covered Bridge

(Historic American Engineering Record) 
The Transportation Equity Act of the $21^{\text {st }}$ Century established the National Historic Covered Bridge Preservation Program (NHCBP). This program provides funding for conducting research to find improved means of restoring and protecting covered bridges, and for assisting the States in their efforts to rehabilitate, repair or preserve historic covered bridges. As a result, the Federal Highway Administration (FHWA) is funding a large number of bridges for rehabilitation, restoration and preservation, yet there is a lack of acceptable modern technologies for preserving the remaining historic structures if they are to continue to carry vehicular traffic.

This project at the CFC and Institute for the History of Technology and Industrial Archaeology (IHTIA) of West Virginia University was funded by FHWA to develop methodologies to preserve these historic structures using advanced composite materials and innovative techniques.

\subsection{Objectives and Scope of Work}

\subsubsection{Objectives}

The primary goals of this project are to develop means and methods to strengthen wooden superstructural components of historic covered bridges without compromising the structural and material integrity of the original structure and its heritage. The specific objectives are to:

- Develop methods to strengthen truss and arch members

- Develop methods to strengthen floor beams

- Develop simple analytical models to predict moment capacities of strengthened members

- Conduct a state-of-the-art literature review and compile an annotated bibliography 


\subsubsection{Scope of Work}

This research offers a new approach to the preservation of historic covered bridges. It is geared towards strengthening historic covered bridges to allow them to carry modern traffic. Chapter 2 provides a look at current and past methods that are being used to rehabilitate and preserve covered bridges. Innovative methods for strengthening were developed and tested in the laboratory for tension and bending members, and are described in Chapter 3, while Chapter 4 presents the results of the experimental tests, and Chapter 5 presents the conclusions and recommendations. Appendix A presents a description of some of the preliminary testing, while Appendix B presents an annotated bibliography.

\subsection{Research Significance}

Common preservation or repair methods for historic timber structures and covered bridges often use steel fasteners, additional wood members and steel components to strengthen the bridge. ${ }^{11}$ These techniques are not suitable for historic structures since they result in an intrusion, and are not compatible with the highest standards of preservation. $^{2}$

The goal of this research is to develop methods and techniques that revolve around the idea that historic preservation is part science and part art. In the view of the author(s), the proposed ways as described and discussed in length in the following chapters, of internally strengthening truss members and floor beams using advanced composite materials will serve to improve the member's load carrying capacity, and yet maintain its authenticity. The reason for this approach is that the beauty of the historic structure as created by previous generations of bridge engineers and craftsmen can be preserved for future generations. 


\section{Chapter 2}

\section{Literature Review}

\subsection{Introduction}

A detailed literature review was conducted to determine what methods are currently being used and what methods are being developed to preserve and strengthen historic covered bridges. Over 50 recent journal articles and technical papers were reviewed using sources such as MountainLynx (WVU Library and statewide library system), Compendex, Applied Science \& Technology databases, and the Internet. In addition, several reports and dissertations from different universities were reviewed. This review also highlighted areas such as current and modern methods of preserving covered bridges as described in the following sections. Also described in detail is the Secretary of the Interiors Standard which was followed for this project.

\subsection{Historic Covered Bridges}

Covered bridges represent our history frozen in time. 10,000 covered bridges were built during the 1800's in the United States. In 1950, there were 80 covered bridges in West Virginia alone. Today, there are only 17 left in West Virginia while there are 221 in Pennsylvania, 140 in Ohio, and 93 in Indiana. This is not a promising statistic. If the proper methods are developed, all of these bridges can be saved. Emory L. Kemp sums up the battle between stabilization, repair, restoration, and replacement by saying, "the engineer's chief concern is for the safety of the traveling public and this concern is pitted against the requirement to restore these structures according to well developed national standards for historic preservations". 2 One of the largest reasons for the replacement of bridges, instead of restoration, is attributed to the fact that few engineers have the background experience in the design of timber bridges. So it is easier to replace the bridge instead of finding an alternative solution to preserve the bridge. Although covered bridges are considered an American tradition the origins of covered bridge can be traced to Europe. Construction of covered bridges in America started in the 1800s and 
led to the development of the all-metal truss bridges. American covered bridges grew out of craft tradition, which had its roots in heavy timber construction as applied to barns, buildings and ships. For bridges over major river crossings, the timber truss covered bridge was developed where the simple trestle bridges were not sufficient. The covering served the practical purpose of protecting the main truss members from the environment. Such bridges were used for local roads as well as on turnpikes. In the early days of railroads, covered bridges were also used on railway lines.

An argument that is discussed much too often is that engineers are resisting restoring historic bridges because of the high fees involved. Engineers on the average usually receive $10 \%$ of the total construction value for design services. In some instances a new construction option might cost approximately more than 3 times that of a preservation alternative. ${ }^{3}$ This is highlighted by the argument over the cost of rehabilitating the historic Norridgewock concrete arch bridge. ${ }^{3}$ Most say that the engineers inflated the cost for the rehabilitation option, because of lack of knowledge or they wanted the new design option. ${ }^{4}$

Abba Lichtenstein also discusses the issues between replace and rehabilitate, "On one side of the conflict is the owner who must, with limited funds, protect the safety of the public by making sure that the structure is up to code. On the other is the preservation community whose members want to retain the bridge at any cost. Emotions run high and many issues enter this conflict." ${ }^{5}$ Unless there is clear danger to the public, historic bridges should not be neglected. Solutions for their preservation should be found and the bridge engineer / historian should make a major contribution in this endeavor. This is where the research that is being conducted at the (CFC) and (IHTIA) at WVU and elsewhere really comes into play. Methods are being developed to save the lives of these bridges while keeping public safety and modern usages in mind.

Nearly 50,000 of the 575,000 bridges nationwide might have some historical significance. Of these bridges, approximately 1600 are listed on the National Register and 900 more are eligible for listing. Until recently relatively few of the historic bridges have been rehabilitated to carry modern vehicular traffic. Many challenges await the engineers who have an understanding of the materials and techniques used to construct the bridges of the past. The balance between preservation principles demanding 
authenticity and codes requiring safety, strength and stability is hinging in the balance of future innovations. ${ }^{6}$ The Cultural Resource Management (CRM) lists ten (10) high profile historic bridge rehabilitation projects in one of it supplements. All of the projects use external strengthening techniques or replacement of members as a method of rehabilitation. Not a single project rehabilitated and strengthened existing members using methods that would not interfere with the historic integrity of the member.

Emory L. Kemp also discusses methods of preservation other than full restoration of an existing structure. ${ }^{7}$ For example, preservation through recording is a tool to document and study a structure that does not meet the safety or use requirements. A recording is a means of preservation since the record has been preserved, while structural stabilization is a method to temporarily make a structure safe until funding is available for the project or new methods are developed. Adaptive reuse is another method that is widely used in buildings, but not readily used in bridges. This could mean taking a covered bridge out of service, moving it to a park, and using it for pedestrian traffic. Partial restoration is also another method to restore or rehabilitate portions of a structure at a time. When funding is available or it is feasible to restore one part of the historic structure, other parts of the structure can be restored at a later date. This could also be used to only restore the portions of a structure that are absolutely necessary.

Another document that offers substantial information on historic structural preservation is the Secretary of the Interior's Standard for the Treatment of Historic Properties, from this point forward know as the Secretary of the Interiors Standard, that recommends among other things described in Section 2.3, that if preservation or repair of historic timber structures necessitates member replacement, a replacement timber of the same species and quality must be used. ${ }^{8}$

\subsection{The Secretary of the Interior's Standards for the Treatment of Historic Properties}

One of the goals of this project is to develop means and methods to rehabilitate, strengthen and preserve covered bridges by complying with the Secretary of the Interior's Standards for the Treatment of Historic Properties with Guidelines for Preserving, 
Rehabilitating, Restoring, and Reconstructing Historic Buildings. ${ }^{8}$ As the title suggests, these guidelines are more for use with historic buildings and not for historic covered bridges. The Secretary's guidelines can provide guidelines that make a person use proper stewardship while dealing with any historic property. The guidelines define rehabilitation as, "the process of returning a property to a state of utility, through repair or alteration, which makes possible an efficient contemporary use while preserving those portions and features of the property which are significant to its historic, architectural, and cultural values". The use of the terms "alteration" and "contemporary" in the definition gives the sense that major changes can be made to achieve the desired end use of the property. This is far from the truth, no changes or alterations can be made that will influence the significance of the property. In other words, placement of steel or concrete beams under an existing covered bridge does not contribute to the preservation of the historic or cultural value of the historic property. The design and construction of the original timber truss and arch members along with the siding, covering and other elements are what makes covered bridges significant. The Secretary's Guidelines give ten (10) rules for rehabilitation of historic properties. These ten (10) rules were the guiding principles for this project: ${ }^{8}$

1. A property will be used as it was historically, or be given a new use that maximizes the retention of distinctive materials, features, spaces, and spatial relationships.

2. The historic character of a property will be retained and preserved. The replacement of intact or repairable historic materials or alteration of features, spaces, and spatial relationships that characterize a property will be avoided.

3. Each property will be recognized as a physical record of its time, place and use. Changes that create a false sense of historical development, such as adding conjectural features or element from other historic properties, will not be undertaken.

4. Changes to a property that have acquired historic significance in their own right will be retained and preserved.

5. Distinctive materials, features, finishes, and construction techniques or examples of craftsmanship that characterize a property will be preserved. 
6. Deteriorated historic features will be repaired rather than replaced. Where the severity of deterioration requires replacement of a distinctive feature, the new feature will match the old in design, color, texture, and, where possible, materials. Replacement of missing features will be substantiated by documentary and physical evidence.

7. Chemical or physical treatments, if appropriate, will be undertaken using the gentlest means possible. Treatments that cause damage to historic materials will not be used.

8. Archeological resources will be protected and preserved in place. If such resources must be disturbed, mitigation measures will be undertaken.

9. New additions, exterior alterations, or related new construction will not destroy historic materials, features, and spatial relationships that characterize the property. The new work shall be differentiated from the old and will be compatible with the historic materials, features, size, scale and proportion, and massing to protect the integrity of the property and its environment.

10. New additions and adjacent or related new construction will be undertaken in such a manner that, if removed in the future, the essential form and integrity of the historic property and its environment would be unimpaired.

\subsection{Current Methods for Preserving Covered Bridges}

Past methods of strengthening historic covered bridges were not really strengthening the bridge they were turning the bridge into a timber shell over steel or concrete beams. Steel-I beams are usually placed underneath a new deck to support the entire structure. ${ }^{10}$ The original bridge members would be replaced as needed and would no longer serve the purpose that the original designer had intended. Examples of this type of preservation are all around us, it was used here in West Virginia and everywhere covered bridges were built. Figure 3 is an example of a covered bridge that was rehabilitated with steel beams. Timber glulam beams are also used in this method of strengthening. 


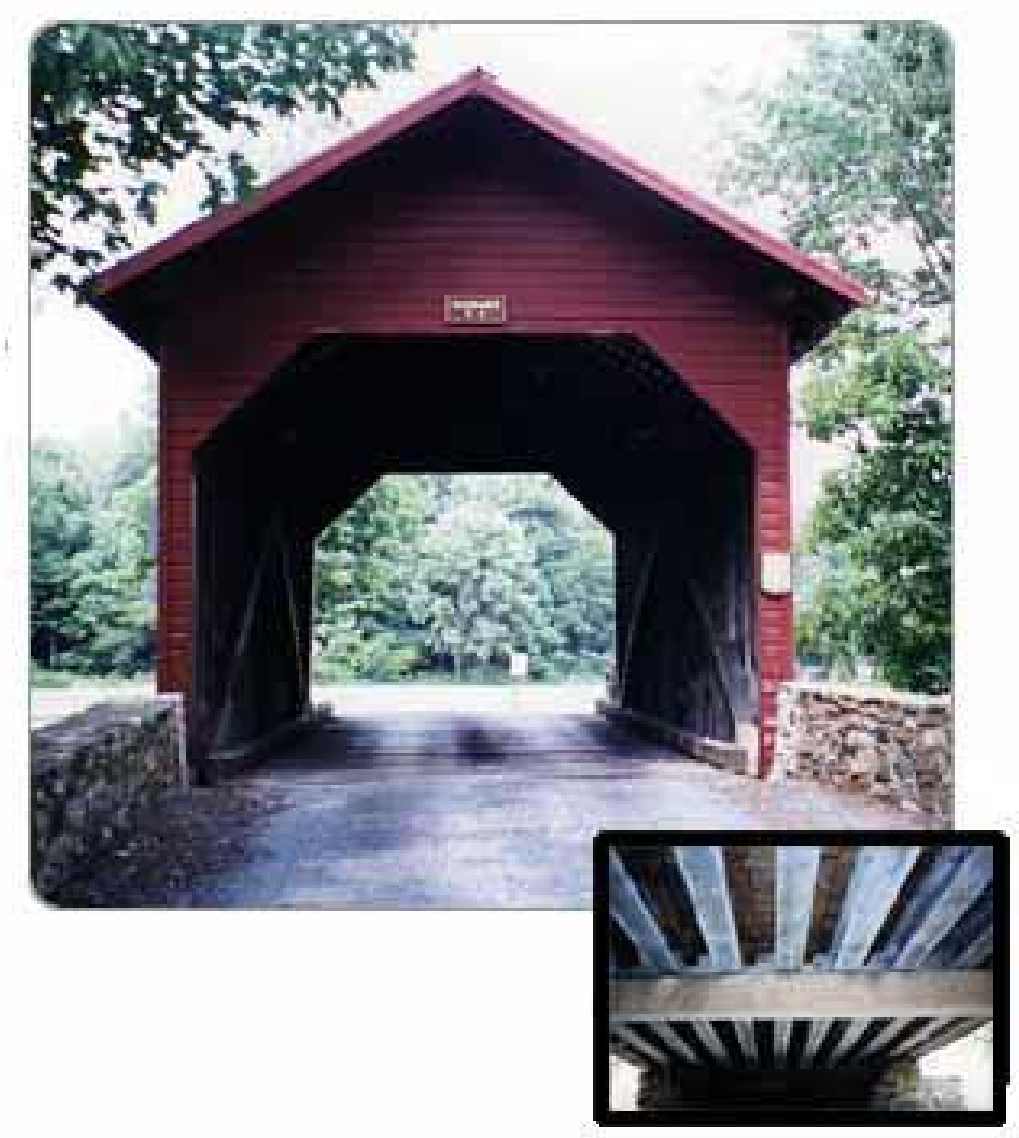

Figure 3. Roddy Road Covered Bridge Rehabilitated with Steel I Beams, Frederick County, MD

The Roddy Road Covered Bridge is a king post design, originally constructed in 1856. The structure spans $40^{\prime}-0^{\prime \prime}$ and is $16^{\prime}-0$ " wide with $12^{\prime}-8^{\prime \prime}$ clearance. The wooded deck stringers were replaced with steel in 1964-65 to strengthen the structure and to increase load capacity. This steel was replaced again in 1979-80 because the stringers had completely corroded and finally replaced by galvanized steel stringers and diaphragms in 1995.

Another method used to rehabilitate is to replace original members with wood of the same type. A detailed evaluation and load rating must be conducted on the bridge to determine which members must be replaced and which ones can be salvaged. Members exhibiting moderate to heavy insect infestation, splitting, rotting, charring, weather worn and water damage will be replaced. ${ }^{11}$ 
There are other common strengthening methods for deteriorated wooden members, such as, the use of steel fasteners, additional wood members, and steel components. ${ }^{11}$ The following sections describe some of these strengthening methods namely: (1) member augmentation; (2) clamping and stitching; (3) stress laminating; and (4) Epoxy repair. The information is extracted from the USDA Forest Service publication entitled "Timber Bridges: Design, Construction, Inspection, and Maintenance", by Mike Ritter. $^{11}$

Member augmentation involves the addition of material to reinforce or strengthen existing members. The additional pieces, commonly wood or steel plates attached with bolts, serve to increase the effective section and thus load capacity. The two most widely used methods of member augmentation are splicing and scabbing while efficient, they are to be avoided in restoration work. Splicing generally applies to a defined location where load transfer is restored at a break, split, or other defect. Traditional splicing methods for both tension and compression splices can be augmented with glued scarf joints, lapped joints, and mortice and tenon joints, and/or the insertion of FRP bars. In most cases, a thorough structural analysis is required to ensure the capacity of the repair and to verify stress distribution in the members. Situations that introduce eccentric loads or tension perpendicular to grain must be avoided.

A typical problem associated with timber members is the development of longitudinal splits and checks. These checks commonly develop in sawn lumber as the member seasons. To a lesser degree, splits or checks may also develop in glulam decks if delamination occurs at the glue lines, although this problem has become very rare with the introduction of waterproof adhesives. In sawn members splits can also develop from overloads or poor design details that introduce tension perpendicular to grain at connections. When splitting is detected it must be determined whether the splits are the result of normal seasoning or the result of structural problems.

Stitching is another strengthening operation that uses treenails to arrest cracks, splits, or delaminations in timber members. An example of stitching is shown in Figure 4. These methods are most commonly used for buildings, but also apply to some bridge components, particularly truss members or other structures with a high number of small members or fastened connections. The objective is not to close the split or check, but 
rather to prevent further progression of splitting by drawing the two parts together. Aside from fastener design requirements, there are no specific design criteria for stitching, and the configuration, number, and size of treenails must be based on magnitudes of forces to be transferred and also on designer judgment, which may be site specific. ${ }^{9}$
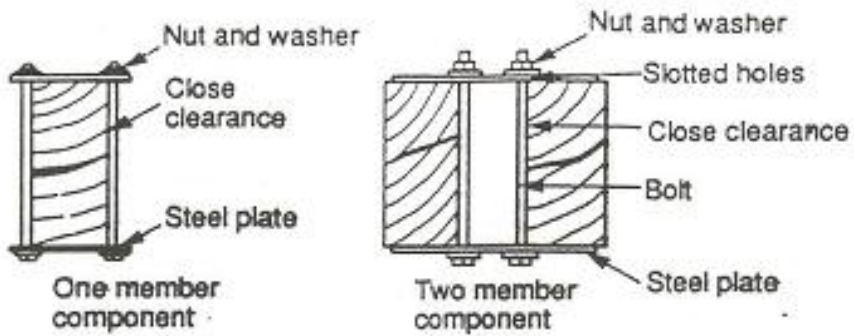

Clamping in Connection with Epoxy Injection

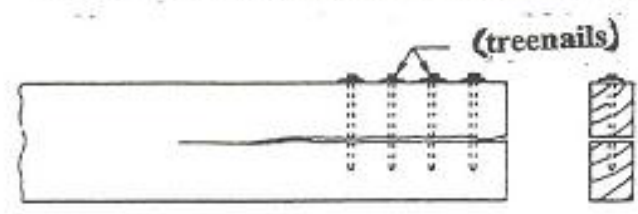

Stitching

Figure 4. Typical Clamping and Stitching of Timber Members

Stress laminating is probably the most effective method for the mechanical repair of existing nail-laminated decks. Nail-laminated decks frequently separate and delaminate from repeated loading, causing breakup of asphalt wearing surfaces, water penetration through the deck, and loss in live load distribution width. In these cases, the static strength and condition of the deck are generally maintained, but the deck's serviceability and ability to distribute loads between individual laminations is greatly reduced. In this situation, the laminations no longer act together to distribute loads, and could lead to local failures. This condition could increase the rate of deterioration, eventually leading to failures that require complete deck replacement.

Epoxy is used for timber repair as a bonding agent (adhesive) and/or grout (filler) in structural repairs. It is commonly injected under pressure but it is also manually applied as a gel or putty. Epoxy is most effective when used as a bonding agent to provide shear resistance between members for structural repairs in dry locations. 
For structural repairs, it is used to fill voids or repair bearing surfaces. Four basic types of epoxy repairs for structural repairs are: epoxy injection of cracked and split members at truss joints; epoxy injection and reinforcement of decayed wood; and splicing and epoxy injection of broken members; epoxy injection of delaminated beams. Another two basic types of epoxy repairs for semi-structural repairs are: epoxy injection of longitudinal cracks and splits in truss members away from joints; and repair of bearing surface using epoxy filler such and ground walnut shells. The use of epoxies in timber repairs is well established and accepted by preservation architects. Preservation Brief 26, The Preservation and Repair of Historic Log Buildings detail the use of epoxies to consolidate and repair deteriorated timbers.

\subsection{Modern Methods for Preserving Covered Bridges}

The first portion of the modern methods for preservation of covered bridges is developing modern methods of evaluation. These methods are being developed to determine if a member needs to be replaced or if it has enough capacity to resist required loads. This will allow members that would once be replaced to remain in service. One of these methods is stress wave timing in wooden members. ${ }^{12}$ Stress wave timing consists of timing stress waves propagating through a material. Areas of decay can be readily identified and compared to sound wood. Typical stress wave transmission times for different species at different moisture contents are known. This test is carried out by striking the specimen using a special hammer and an accelerometer to measure the time it takes the wave to propagate through the specimen. This is a very valuable tool; especially in a large member where conventional methods can only reach short distances into the member.

One of the most exciting uses of modern technology in historic preservation is laser scanning. A laser scanner is similar to a total station in land surveying, except the laser scanner can develop highly accurate 3-D drawings of structures. At a range of 50 meters the laser scanner's accuracy is within millimeters. This technology has already been used on a courthouse located in northwestern Pennsylvania that was built circa 1876 that has very intricate architecture, and also on a historic bridge located in Rhode Island. 
Laser scanning can provide some of the most accurate drawings possible. This technology could not only be used for historic buildings and bridges, but also the recording of historic landscapes. ${ }^{13}$ One of the keys to historic preservation is recording and with this technology sites that in the past have been lost due to long recording times can now be recorded in a matter of hours.

Another method of modern analysis that provides a better understanding of the historic structure is the use of finite element analyses. ${ }^{14}$ Finite element models can be updated by direct field measurements such as strains and deflections. An updated model can provide very accurate simulated responses and can be used in the overall structural evaluation. These methods can start to tell the current "story" of the structure. Such as, how much load is the structure carrying, how the loads are being transferred from a structure to the ground, and what are the current material strengths and properties. These are all-critical in the evaluation and decision making process to determine if the structure can be rehabilitated.

There is an amazing amount of information available on nondestructive testing (NDT) methods and tools at engineers' fingertips to help them conduct an accurate evaluation of historic structures that provide a wealth of information. NDT methods can be used to locate defects, determine material properties, locate reinforcing steel, depth of foundation, locate delamination, and evaluate the quality of materials. These methods include: ultrasonic pulse velocity, impact echo, sonic echo, infrared thermography, radar, covermeter, and electric half - cell. ${ }^{15}$ Fiber optic borescopes can also be used to look inside of walls and other cavities without removing any material.

The application of the ultrasonic NDT method has also been widely and successfully used to test historic structures. For example, The CFC of West Virginia University developed state-of-the-art portable field instrumentation to conduct ultrasonic testing of historic bridges. The CFC tested the Barrackville historic covered bridge (Figures 1 and 2) and the Salt Creek covered bridge located in Muskingum County, Ohio. The Salt Creek covered bridge, built in 1876 using White Oak with Warren truss type construction, spans 104 feet, which makes it as one of the longest clear span timber bridge in the State of Ohio (Figure 5). 


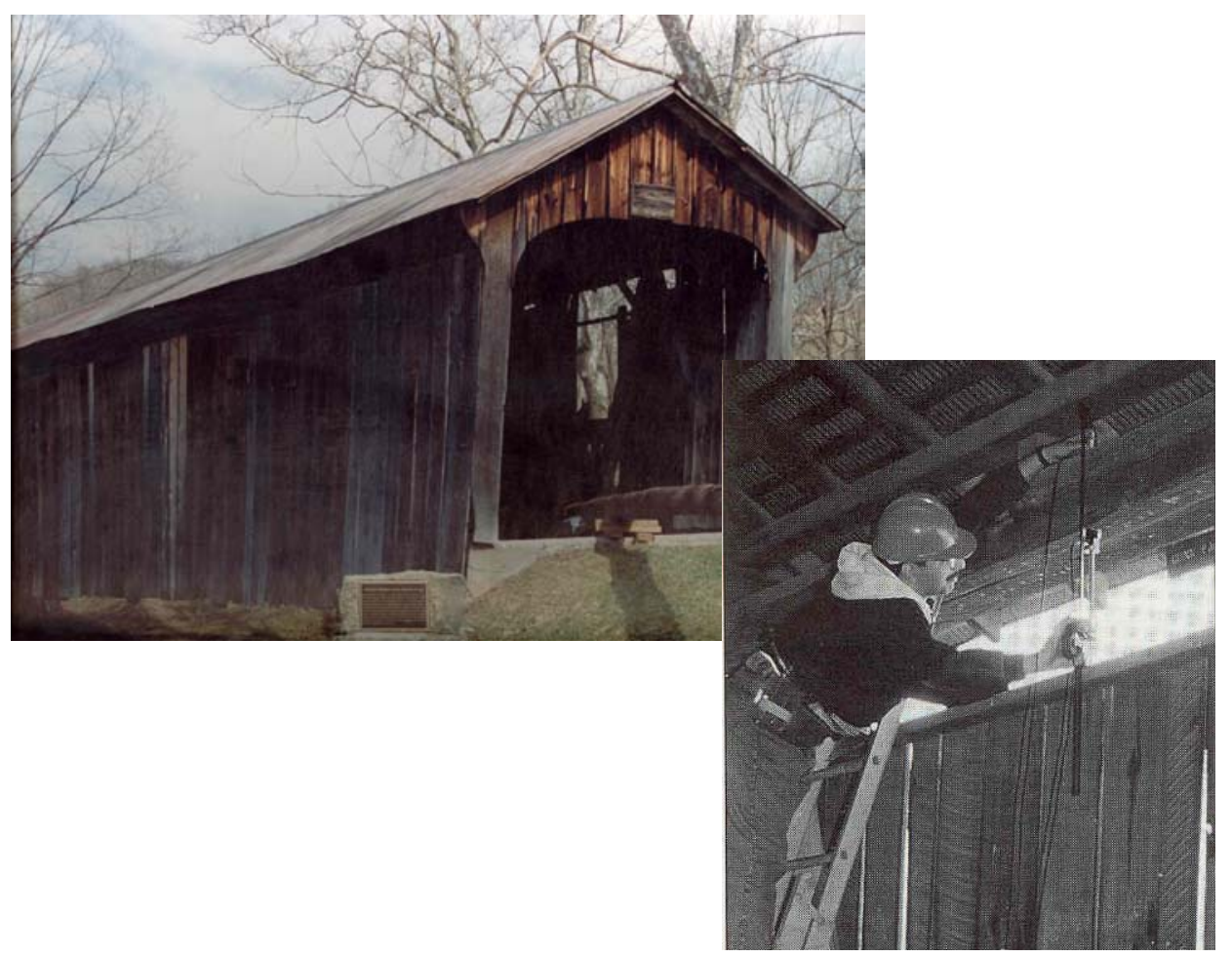

Figure 5. Salt Creek Covered Bridge, Muskingum County, Ohio

The Salt Creek ultrasonic field-testing was performed to assess the integrity of the upper truss chords for repair and renovation. Figure 5 also shows the sensor positions for the ultrasonic through-transmission mode and the spring loaded quick grip clamp. The results of the field-testing indicated that seventeen members in the bridge had defects needing immediate rehabilitation. The CFC also developed a NDT manual for bridge superstructures for the West Virginia Department of Highways.

The most promising modern method of preservation is through the use of fiberreinforced polymers (FRP) to strengthen structural members. FRP materials are composed of fibers embedded in a polymeric matrix. They are characterized by high tensile strength in the direction of fibers, the fibers make an excellent structural reinforcement. The concept of FRP materials dates back to the Israelites in 800 B.C. when they reinforced bricks with straw. ${ }^{16}$ The FRP matrix consists of a polymer or resin 
used as a binder for the reinforcing fibers. The matrix has two main functions. It enables the load to be transferred among the fibers and it protects the fibers from degradation and environmental effects. The three (3) main types of commonly used resins include epoxy, vinylester, and phenolic. In an FRP composite material, the fibers have the role of load bearing. For structural applications glass, carbon, and aramid fibers have been used. Glass and carbon are the most common in infrastructure applications. FRPs can also be fabricated into many different shapes. Individual fibers can be wound, pultruded, or laidup in the final shape. Filament winding entails the wrapping on resin-impregnated fibers around a mandrel. Pultrusion entails the continuous production of a composite shape through a die. Lay-up fabrication consists of the placement of multiple layers of resinimpregnated fibers or fabrics onto a designed shape. FRP composites are used in the construction industry in various forms and shapes such as:

- Sheets of fibers with resin applied in-place

- Laminates formed from sheets stacked with resin

- Unidirectional and multidirectional sheets or fabrics with resin applied in place

The following are just some of the reasons to consider FRP composites: ${ }^{17}$

- Tensile strength: FRP composites tensile strength can range from about the strength of mild reinforcing steel to stronger than that of prestressing steels.

- Low mass: FRPs have densities which are in the range of 75 to $162 \mathrm{lb} / \mathrm{ft}^{3}$, which is substantially less than that of steel, which is about $490 \mathrm{lb} / \mathrm{ft}^{3}$.

- Other advantages: Ease of fabrication, custom geometry, color and coating, construction and transportation cost, reduce environmental toxicity, and resistance to corrosion. FRPs can be recycled and made from recycled plastics.

Some of the disadvantages are high first cost, creep rupture, and shrinkage. The designs also require highly trained and specialized engineers. ${ }^{17}$

FRPs have been used in the strengthening of timber, concrete, steel, masonry, and stone structural members. Some specific types of applications where these materials are used include column-beam connections, seismic retrofitting, repair of corrosion damaged 
beams and columns, bridge decks, piles, precast prestressed concrete shells, chimney stacks, lighthouses, roof structures, and prestressed water tanks. ${ }^{18}$

\subsubsection{Externally Bonded Repair}

FRP composites bonded externally can be used to strengthen members in several different ways. The process usually includes surface preparation, resin application, and the adhesion of an FRP sheet or fabric. The fiber direction in the FRP sheet or fabric allows for the possibility to increase mechanical properties such as strength and stiffness in different directions depending on the application.

One of the most popular uses of FRPs is the reinforcement of bending members or FRP plate bonding. Applying a laminate or a fabric wrap is one of the most popular approaches, but in historic structures this cannot be done due to the altering of the exterior of the member in order to achieve the desired effect. The strengthening must be done in a non-intrusive manner. In most cases, structural repair of wood beams by bonding FRP enhances the bending capacity by $40-100 \%$ when compared to an unreinforced specimen. ${ }^{19}$ This wide range of results can be attributed to the variability of the wood itself. Researchers have investigated the influence of factors such as FRP plate thickness, type of adhesive, and type of fibers.

When creep is an issue in a timber beam and laminates are used to reinforce the member, it does not matter which type of FRP is used. In most cases, the creep of wood and not the FRP is the dominating mechanism. ${ }^{20}$ It has been proven that a small quantity of shear reinforcement can lead to substantial increases in shear capacity. ${ }^{21} \mathrm{~A}$ key point to the shear reinforcement is that the theoretical capacity in lab testing environments were very accurate compared to the experimental. This accuracy leads to a more accurate prediction can be made when designing FRP reinforcement for shear.

An important aspect of using FRPs is that they are very sensitive to the resin combinations. For example, the resins used in the FRP itself have to be compatible to the resin in the adhesive used and most importantly both of these have to be compatible to the substrate that it is being bonded to.

For example, to date, FRPs have not had widespread use in restoring and rehabilitating cast and wrought iron bridges. The most widely accepted method to restore 
these bridges is to recast a damaged member with ductile iron or to weld the member. ${ }^{22}$ This is not to say the FRPs will not be widely used in the future for iron bridges.

\subsubsection{Philippi Covered Bridge}

Philippi Covered Bridge has a double-barreled arch truss design and has two spans, each about 139 feet. On February 2, 1989, in a bizarre accident the Philippi Covered Bridge was nearly consumed by a gasoline fire. The bridge was heavily damaged due to this fire. The State of West Virginia and the local residents of Philippi decided that the bridge should be rebuilt to its original shape and appearance. The restoration work was undertaken by the researchers in cooperation with the West Virginia Department of Transportation-Division of Highways (WVDOT-DOH).

The engineering work was primarily dependent on the structural analysis of main arch truss members. Based on analytical results the bridge components were strengthened to carry specialized live loads. The restoration work of the bridge was based on an extensive amount of historical research to establish its original condition. The work involved modern engineering in which the intersection and drainage was considerably improved to ensure a better flow of traffic and long-term durability of the bridge. In addition, a fire sprinklers system and lighting were installed to preclude recurrence of fire and vandalism. The entire bridge and approaches were finished in September of 1991.

\subsubsection{Barrackville Bridge}

The second extant covered bridge structure restored by the researchers is the bridge at Barrackville on the Fairmont and Wheeling Turnpike in the State of West Virginia (Figures 1 and 2). The bridge spans about 131 feet from spring line of one abutment to spring line of other abutment. The trusses are of multiple king post, sandwiched between pairs of arched frames into the trusses, creating an indeterminate composite timber structure. The Barrackville covered bridge was being used as a pedestrian bridge due to its deterioration and inability it to carry modern traffic.

The restoration of the Barrackville covered bridge had two phases: development of a preservation plan; and stabilization of the main structure of the bridge. During the spring of 1993, the first phase of the work was completed in cooperation with the 
WVDOT-DOH. The information gained thorough inspection served as the basis for the development of plans and specifications, which constituted the second phase of the project. The second phase of the work was completed in 1999. The bridge, restored to its original capacity, is in a stable condition. The second phase of the work mainly involved removal of the sidewalk or wart on the downstream side, installation of the new downstream siding, removal of extraneous floor support members which were added over time, repair of deck beams and installation of a new timber deck, and renewal of the entire roof. Thus, Barrackville covered bridge was restored to its original appearance just after the Civil war, including hand-forged bolts and other advanced materials such as bulk adhesives and Fiber Reinforced Polymer (FRP) rebars, at a cost of $\$ 1$ million. Beginning with the restoration of the Meems Bottom Bridge in Virginia, and currently with four covered bridges in the design and restoration stages, in addition to the Philippi and Barrackville covered bridges restoration techniques for members, joints and secondary components have been developed and are being used. Included in these restoration projects were consolidating cracked members using thixotrophic epoxy under pressure. By using a mixture of epoxy and walnut shells or sawdust, areas of rot were replaced by this mixture to match the original wood in color and texture while restoring the strength and dimensions of the original component. Critical to the restoration work was the development of splices and joints, in deteriorated members augmented with steel and FRP bars discreetly inserted in the member. Only when rot was so severe that repairs in compliance with the best preservation techniques could not be made without unsightly member modern intrusions dictated that members in question be replaced with other wood, preferably from old structures which have been demolished.

Advanced methods for historic preservation have made tremendous gains over the past several years. They still have not come far enough. Implementation of these new methods and materials for structural repair and preservation is ultimately contingent upon availability of standards of practice and familiarity of owners, engineers, and contractors with appropriate preservation techniques. See Appendix B, Annotated Bibliography, for more articles pertaining to the use of FRPs and modern methods of strengthening timber bridges. 


\section{Chapter 3}

\section{Laboratory Experiments}

\subsection{Introduction}

The laboratory experimental program carried out during this research project included internally reinforcing wooden members with Glass Fiber Reinforced Polymer (GFRP) composite materials (Figures 7, 10, 15, 26, and 31). The strengthening schemes developed and tested in this research were designed to comply with the Secretary of the Interior's Standard as described in Chapter 2. Tension specimens were developed and tested to reinforce truss members subjected to direct loads. The tests were conducted to determine the bond strength and development length of the GFRP bars adhesively bonded to the wood. Bending specimens were also developed and tested to improve the bending capacities of floor beams and stringers. The following sections describe all of the specimens tested and the experimental tests conducted for this project.

\subsection{Tension Tests}

\subsubsection{Introduction}

Preliminary tension tests were conducted to determine the appropriate adhesive / matrix combination and specimen preparation methods. These initial sets of experiments are described in great detail in Appendix A. For this research, nine tension specimens were prepared and tested. The tension tests were conducted as a continuation of the preliminary tension tests conducted as described in Appendix A.

\subsubsection{Preparation of Test Specimens}

The tension specimens consisted of White Oak wooden members at $8-10 \%$ Moisture Content (MC) that were air-dried at the West Virginia University Forest saw mill. The test specimens were cut into a dog-bone shape with dimensions prorated to ASTM 198 test standards for tensile strength parallel to the grain. The ends of the test specimens were $1 \frac{1}{2}$ " $\times 3$ " tapering down to a constant cross-section of $1 \frac{1 / 2}{2}$ x $1 \frac{1 / 2}{2}$ × 6 " with an overall specimen length of 36 inches (Figure 6). 


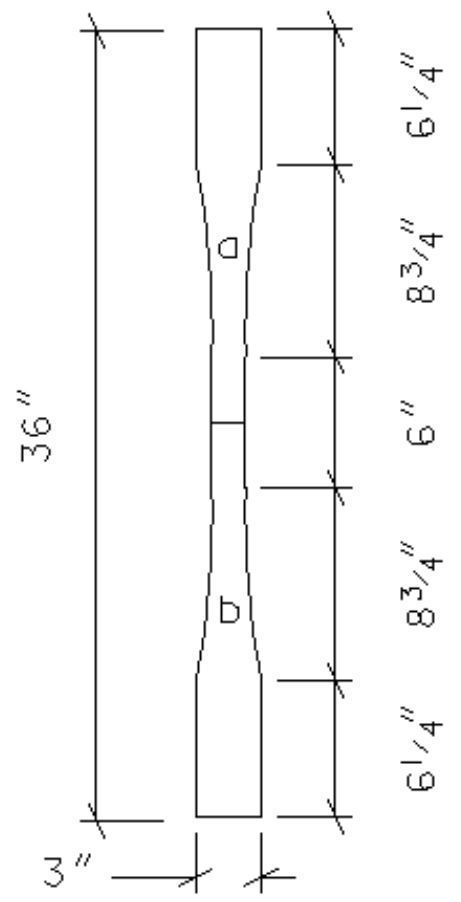

Figure 6. Tension Test Specimens

In order to insert the GFRP bars into the specimens, the specimens were cut in two halves (sides a and b) and holes drilled into each end. 5/8-inch diameter holes were drilled to accommodate a \# 4 bar (i.e., 1/2" diameter bar). The hole size was drilled slightly larger than the diameter of the bar to allow for $1 / 16$ inch of resin adhesive on all sides of the composite bar. To maintain alignment of the GFRP bar in-wood and to ensure that the bar is fully surrounded by adhesive, a 1/2-inch countersink was drilled to the exact diameter of the bar (i.e., 1/2" bar diameter $+1 / 16$ " allowance for sand coating) in side a. On side b, a 1"(O.D.) x 5/8" (I.D.) x 1/8" thick washer was countersunk as seen in Figures 7 and 8 . 

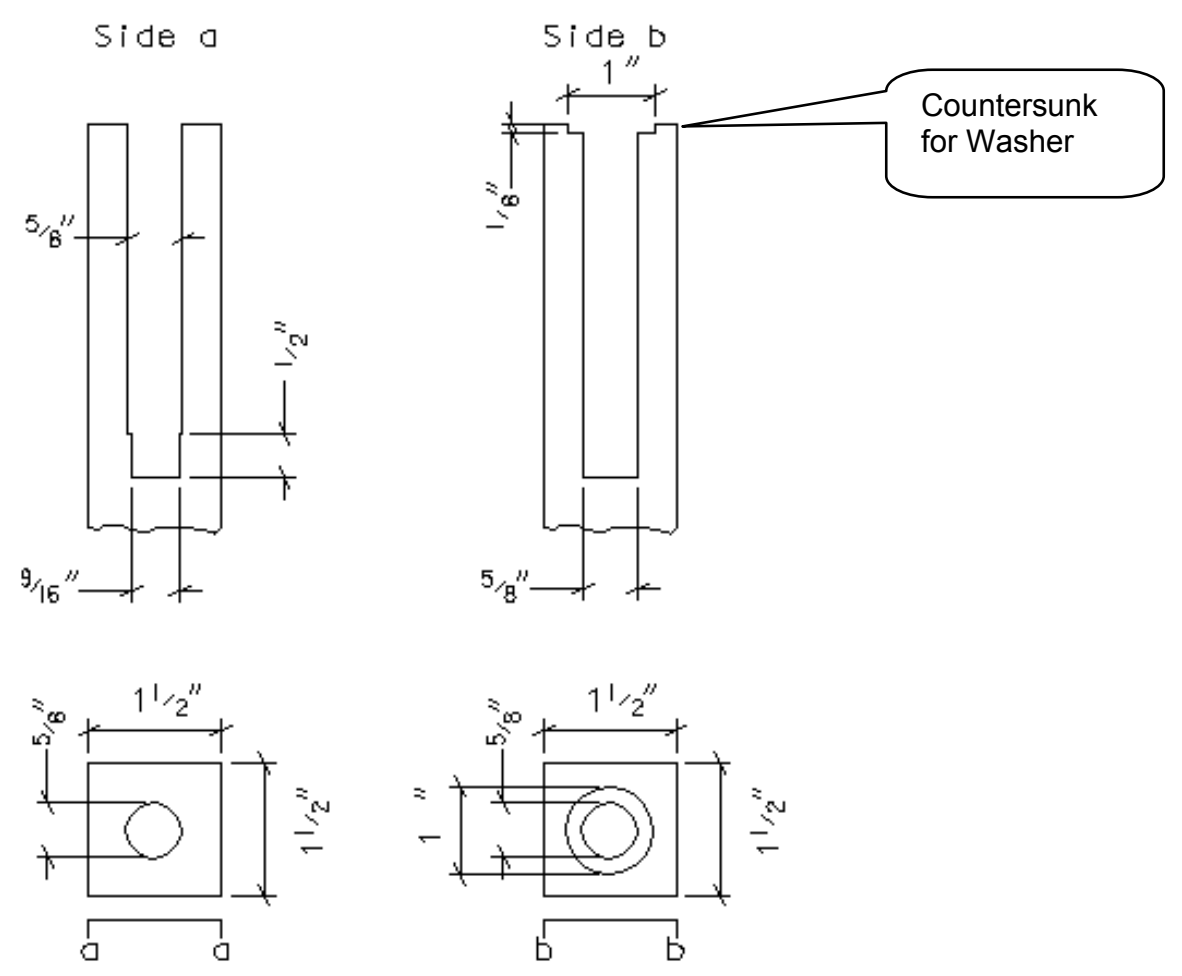

Figure 7. Countersunk Holes to Maintain Horizontal Alignment

Four (4) different depths (1, 2, 4, and 8 inches) were also drilled into different specimens so that four different bond lengths $(1,2,4$, and 8 inches) could be tested. Two specimens of each bond length were tested. The GFRP bars were placed in the predrilled holes and the specimens were then clamped at the joint by a C-clamp and placed into a bar furniture clamp. The properties of the bars and adhesive used are:

Bars: $\quad$ Sand-coated Glass Fiber Reinforced with a vinylester matrix Adhesive: $\quad$ Urethane based PLIOGRIP, manufactured by the Ashland Chemical Company 


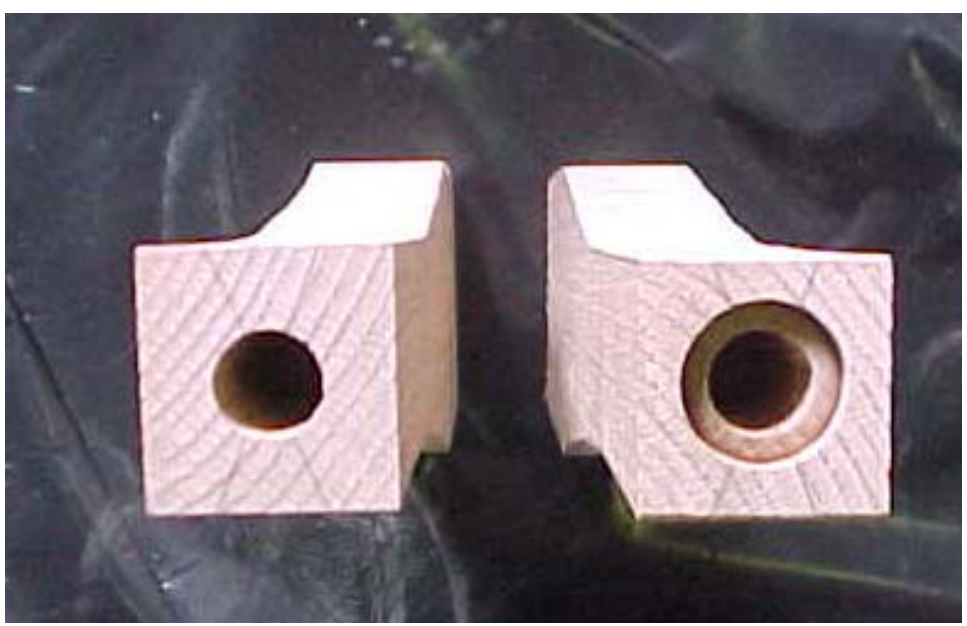

Figure 8. Tension Specimens

Two 7/32" holes were drilled on the sides a \& b (Figure 8) to pressure-inject the PLIOGRIP adhesive. The specimens were left for another 48 hours to cure before testing (Figure 9).

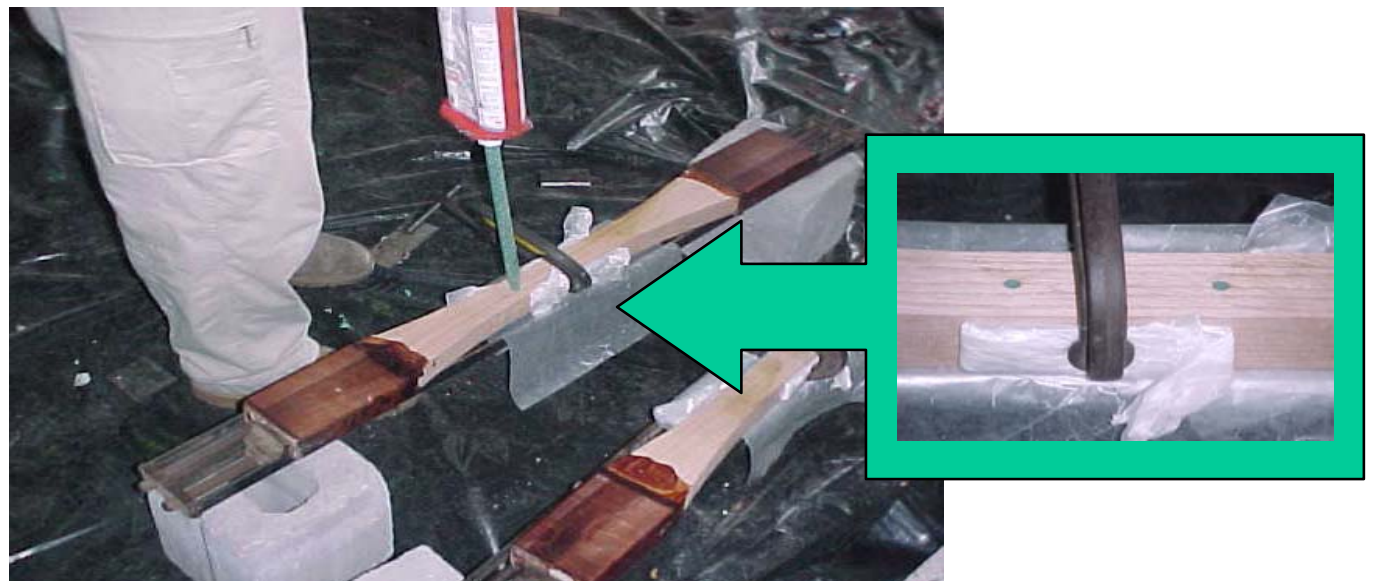

Figure 9. Injection of PLIOGRIP in Tension Specimen 


\subsubsection{Testing Procedure}

Uniaxial tension tests were performed on the GFRP reinforced wood samples using a 200 kip capacity Baldwin Universal Testing Machine. Strain gages were mounted on the test specimen at mid height on both faces. Strain and load measurements were taken manually every 500 pounds from the Baldwin Machine. Table 1 presents the different specimens tested.

Table 1. Tension Test Specimens

\begin{tabular}{|l|l|l|l|l|}
\hline Specimen & Rebar Type & $\begin{array}{l}\text { Rebar } \\
\text { Diameter }\end{array}$ & $\begin{array}{l}\text { Rebar } \\
\text { Length }\end{array}$ & Bond Length \\
\hline T1 & None (Control) & N/A & N/A & N/A \\
\hline T2 & Sand-Coated GFRP & $1 / 2$ inch & 4 inch & 2 inch \\
\hline T3 & Sand-Coated GFRP & $1 / 2$ inch & 4 inch & 2 inch \\
\hline T4 & Sand-Coated GFRP & $1 / 2$ inch & 2 inch & 1 inch \\
\hline T5 & Sand-Coated GFRP & $1 / 2$ inch & 2 inch & 1 inch \\
\hline T6 & Sand-Coated GFRP & $1 / 2$ inch & 8 inch & 4 inch \\
\hline T7 & Sand-Coated GFRP & $1 / 2$ inch & 8 inch & 4 inch \\
\hline T8 & Sand-Coated GFRP & $1 / 2$ inch & 16 inch & 8 inch \\
\hline T9 & Sand-Coated GFRP & $1 / 2$ inch & 16 inch & 8 inch \\
\hline
\end{tabular}

\subsection{Bending Tests (Small Scale)}

\subsubsection{Introduction}

No preliminary bending tests were conducted, since the adhesive and the GFRP matrix used are the same as in the tension test. The bending specimens tested in this section were the first step in developing methods of strengthening, which could be used on full-scale members, as described in section 3.4.

\subsubsection{Preparation of Test Specimens}

The bending specimens consisted of White Oak wooden members at 8-10\% Moisture Content (MC) that were air-dried at the West Virginia University Forest saw mill. The test specimen dimensions were prorated to ASTM 198 bending test standards. A cut-out section was removed to place a GFRP reinforcement plate. This method of 
GFRP placement was selected so that the GFRP plate can be easily hidden to comply with the Secretary of the Interior's Standards. Three $31 / 2$ " x $11 / 2$ " x 36 " specimens were cut and surfaced. Also, a $31 / 8$ " x 1/2" section was routed for the entire length of all the specimens as shown in Figure 10.

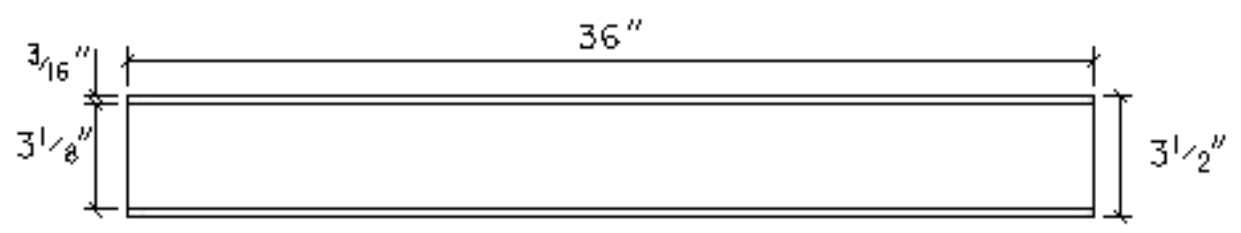

Plan View (Tension Side)

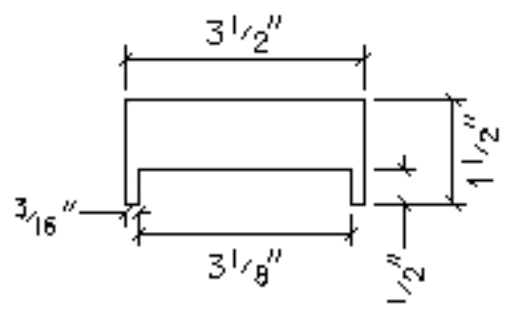

Cross-Section

Figure 10. Bending Test Specimen Dimension

One control specimen without GFRP plate reinforcement and two specimens with GFRP plate reinforcement were tested to failure. A 3" x 1/4" GFRP $\left(E_{L}=2.4 \mathrm{msi}\right)$ with vinylester matrix plate was used to reinforce Specimen B-2. One side of the GFRP plate was lightly sanded to remove a thin layer of protective coating to provide an adequate bonding surface. PLIOGRIP was applied to the wood surface and the specimen was clamped and left to cure for 2-4 days (Figure 11). Specimen B-3 was reinforced using a 3 " x $3 / 8$ " GFRP $\left(E_{L}=3 \mathrm{msi}\right)$ with vinylester matrix plate. A peel ply was removed from this GFRP plate to provide an adequate bonding surface (Figure 11).

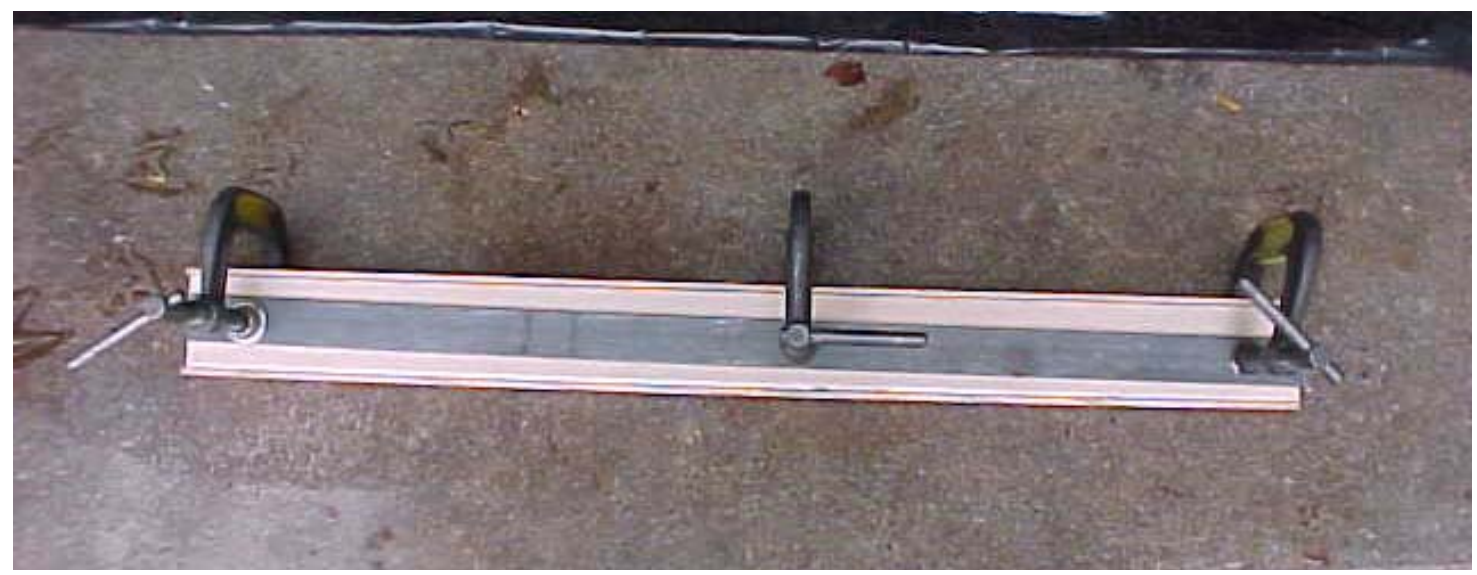

Figure 11. Bending Specimen Reinforcement 


\subsubsection{Testing Procedure}

The specimens were tested in 4-point loading as shown in Figure 12. All the specimens were instrumented with electrical strain gages placed at midspan. Stress/strain curves were developed and modes of failure identified.

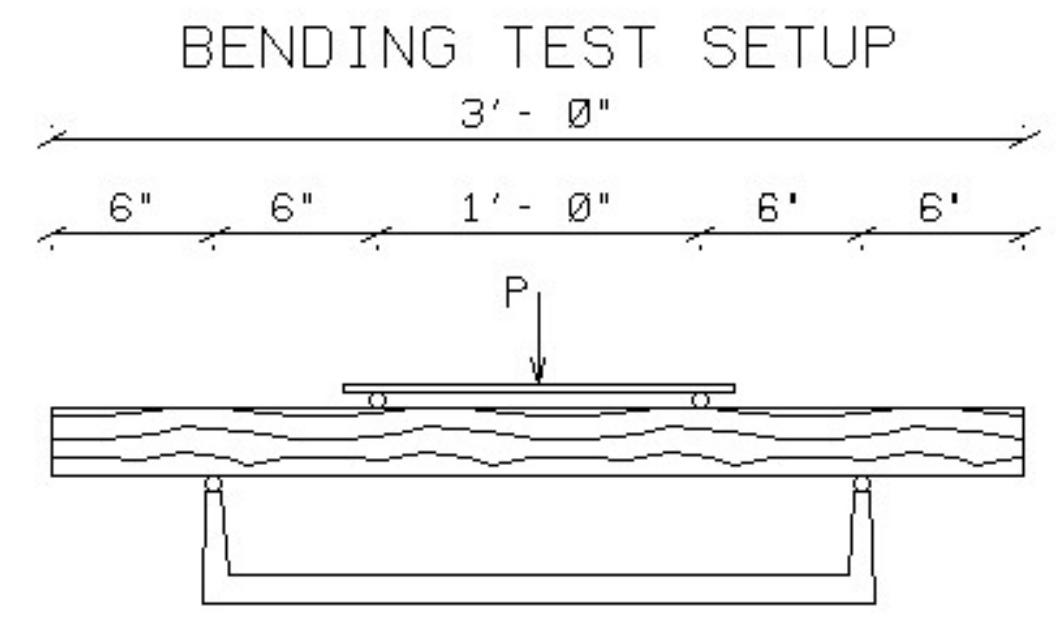

Figure 12. Four-Point Bending Test Set-Up

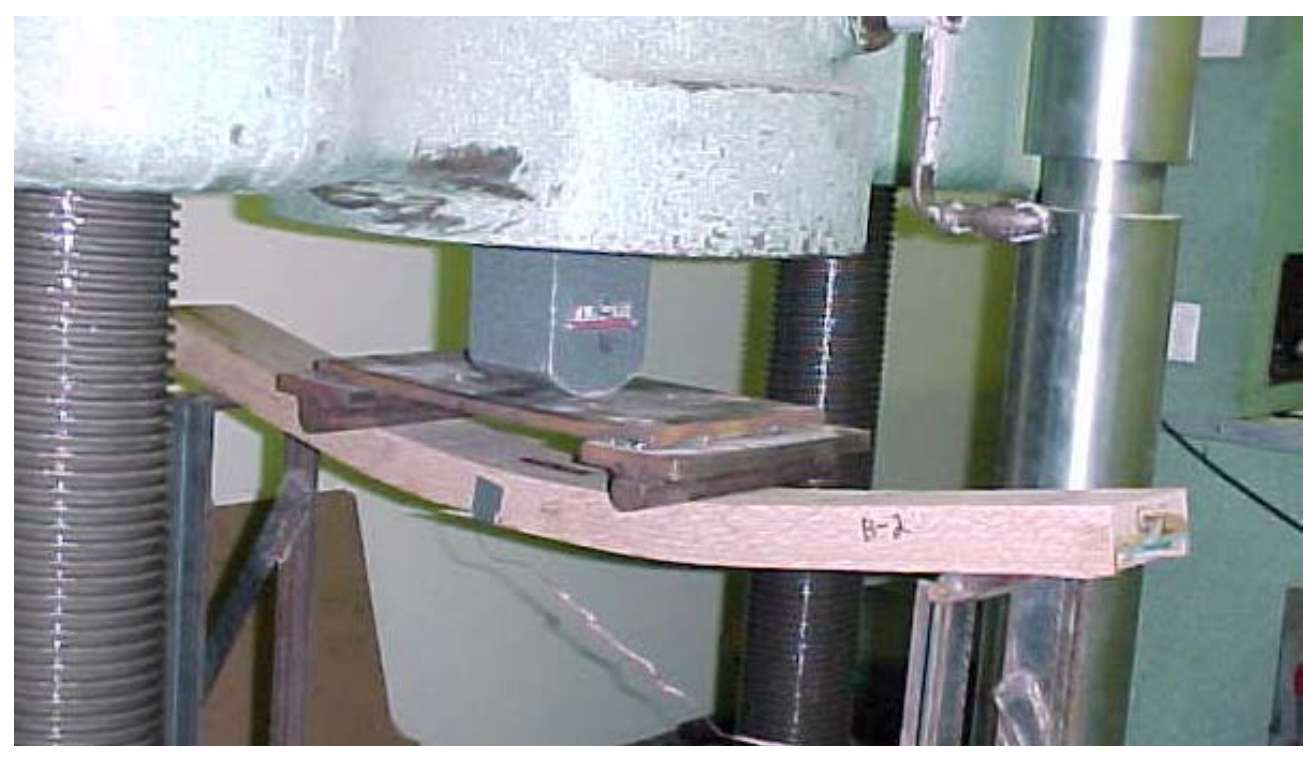

Figure 13. Specimen B-2 in Four-Point Loading

The control specimen test was conducted to determine the ultimate moment capacity, flexural stiffness, and to identify the failure mode of the unreinforced wood. The GFRP 
reinforced wood specimens (B-2 and B-3) were also tested to failure. The strain gages on the GFRP specimens were bonded to the composite surface at midspan.

\subsection{Bending Test (6" x $113 / 4$ ") with GFRP Plates}

\subsubsection{Introduction}

Bending tests were conducted on large-scale wooden structural members reinforced with GFRP composite plates. An additional set of bending tests on large-scale wooden members reinforced with GFRP reinforcing bars was also conducted. These tests are a continuation of the findings and results of earlier tests to investigate the behavior of reinforcement and rehabilitation methods on field size members. Also, tension tests were conducted to determine engineering properties of GFRP plates. Tension tests of GFRP plates are also presented in this section due to the fact that the tension tests were only conducted to determine properties needed for analysis of the full scale bending members. Description of the preparation of specimens and tests are presented in this section and preliminary findings are presented in later sections of this report.

\subsubsection{Tension Tests (GFRP plates)}

\subsubsection{Preparation of Test Specimens}

Tension tests were conducted on the GFRP plates that were used to reinforce the large scale bending members in order to determine their modulus of elasticity (MOE) values. Samples were cut from the two different size plates (i.e., 3/8" and 1/4" thick). The test specimens were $3 / 8$ " x 1 " x 12" and 1/4" x 1" x 12". Additional plates were bonded at the ends of the specimen to prevent failure at the grip location as shown in Figure 14. The plates were bonded to the test specimens using the same adhesive that was used for the large scale bending test as described in the following sections of this report. 


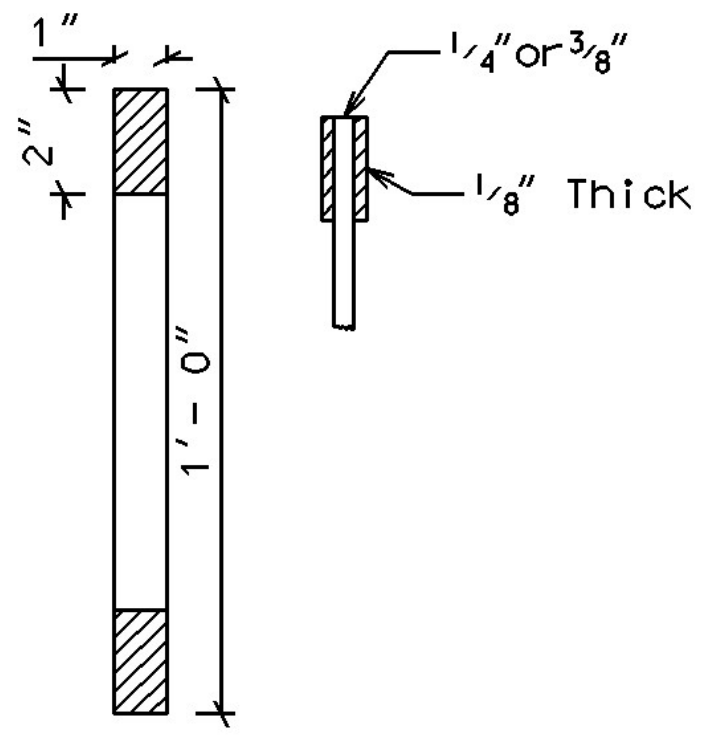

Figure 14. MOE Tension Test Specimens

\subsubsection{Testing Procedure}

Uniaxial tension tests were conducted on the GFRP plate samples using a 200 kip capacity Baldwin Universal Testing Machine. A strain gage was attached at the center of the test specimen. Strain and load measurements were taken manually every 500 pounds using a strain indicator and the Baldwin Machine.

\subsubsection{Results}

Since these tests were conducted to determine only the properties for analysis they are presented in this section. The MOE values used for the transformed section analysis of the full scale bending, presented in Chapter 4, test were taken as the average of the best three tests for each thickness of plates. This was determined by the mode of failure, i.e. pure tension failure in the middle of the plate. Table 2 shows the test results. 
Table 2. GFRP Plate MOE Values

\begin{tabular}{|c|c|c|}
\hline Test & $\begin{array}{c}\text { MOE }\left(1 \times 10^{6}\right) \mathrm{psi} \\
3 / 8{ }^{\prime} \times 1{ }^{\prime} \times 12^{\prime}\end{array}$ & $\begin{array}{c}\text { MOE }\left(1 \times 10^{6}\right) \mathrm{psi} \\
3 / 8{ }^{\prime} \times 11^{\prime} \times 1\end{array}$ \\
\hline 1 & 3.422 & 2.676 \\
\hline 2 & 3.422 & 2.810 \\
\hline 3 & 3.550 & 3.270 \\
\hline Average & $\mathbf{3 . 4 6 4}$ & $\mathbf{2 . 9 1 9}$ \\
\hline
\end{tabular}

\subsubsection{Preparation of Full Scale Bending Test Specimens}

The full-scale bending test specimens consisted of White Oak wooden members at $8-10 \%$ Moisture Content (MC) that were obtained from West Virginia University Forest saw mill. These specimens were chosen to closely replicate earlier tests that were conducted on small-scale wooden members. The members were rough-cut cants 6" x 11 3/4" x 8', Figure 16. Four specimens were reinforced with a GFRP plate bonded flatwise on the tension side of the member. One specimen was tested without GFRP reinforcement and used as a control specimen. The plate was recessed into the member by routing an area large enough to accommodate the plate plus an additional 1/16" for the adhesive and 1/16" for added tolerance. Two different thicknesses of plates were used, $3 / 8$ " and 1/4" as shown in Figure 15.

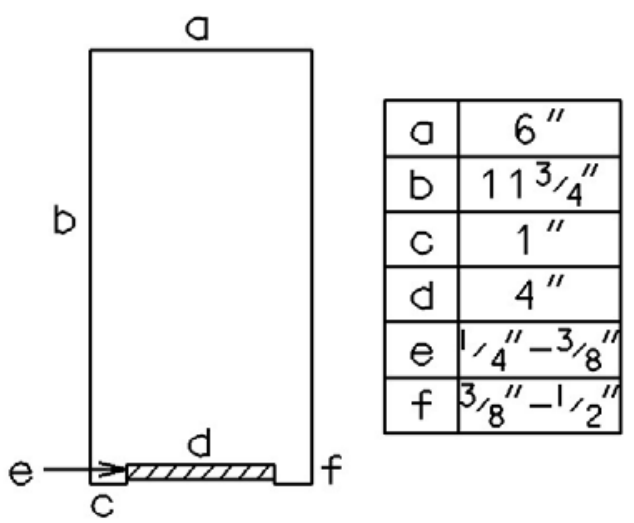

Figure 15. End View of Test Specimens 


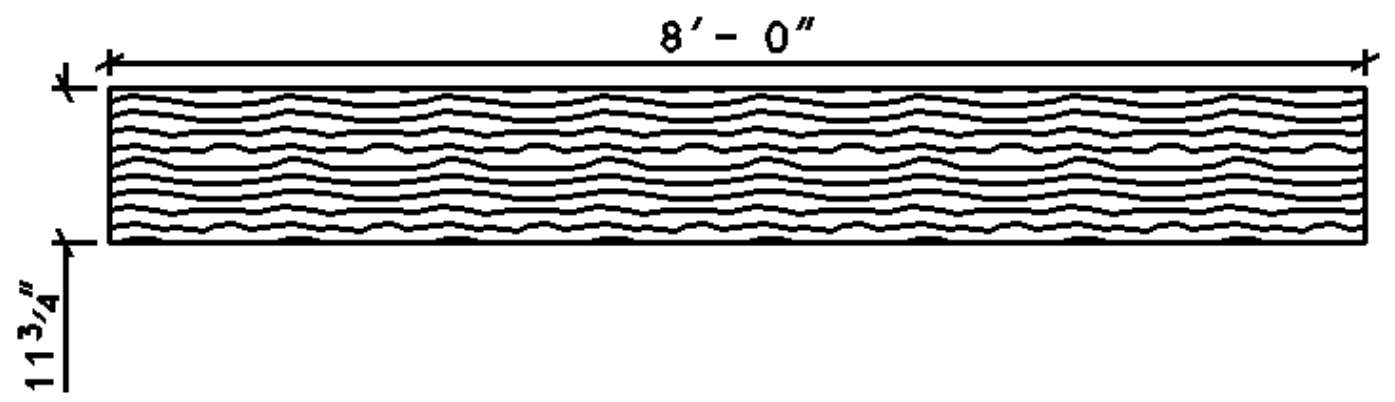

Figure 16. Side View of Test Specimens

The typical rehabilitation method of wood beams using polymer composites utilizes FRPs bonded directly to the tension side of the member. However, in order to hide the reinforcement to comply with the Secretary of the Interior's Standards, the GFRP plate had to be recessed into the member. This was accomplished by routing a 4 " $\times 3 / 8$ " or $1 / 2$ " section depending on the thickness of the GFRP plate used. The specimens were routed the entire length of the member as shown in Figure 17.

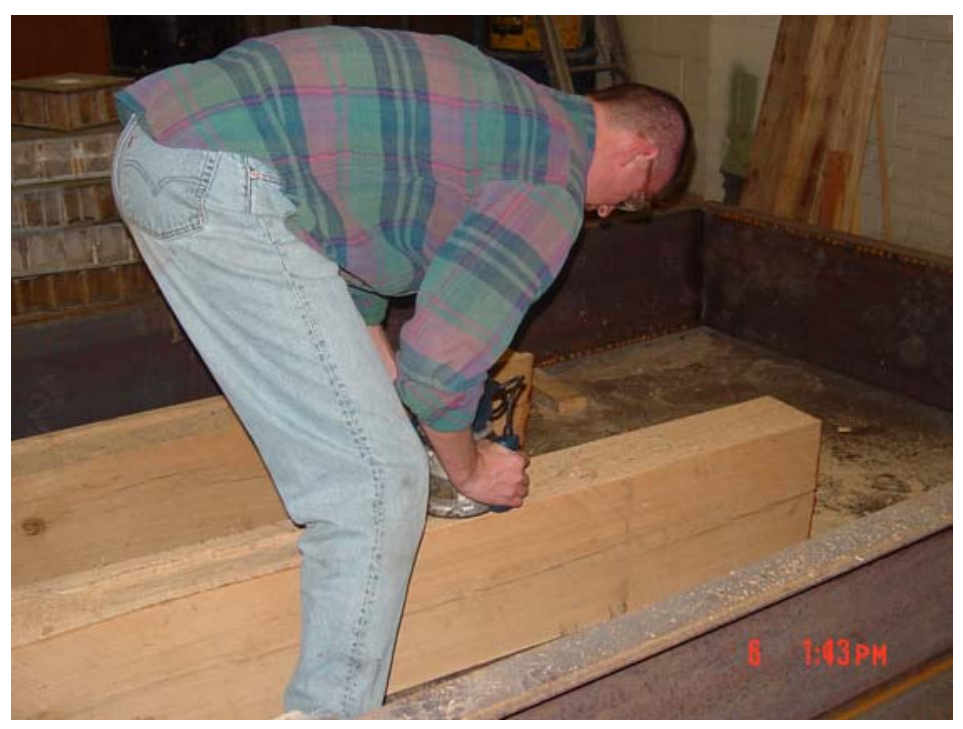

Figure 17. Routing of Test Specimen 
Once the routing was completed, the GFRP plate was prepared by sanding the protective coating from the side to be applied to the member to provide an adequate bonding surface. The adhesive used was the Urethane based PLIOGRIP, manufactured by the Ashland Chemical Company. After the plate was sanded the adhesive was applied directly to the member as shown in Figure 18.

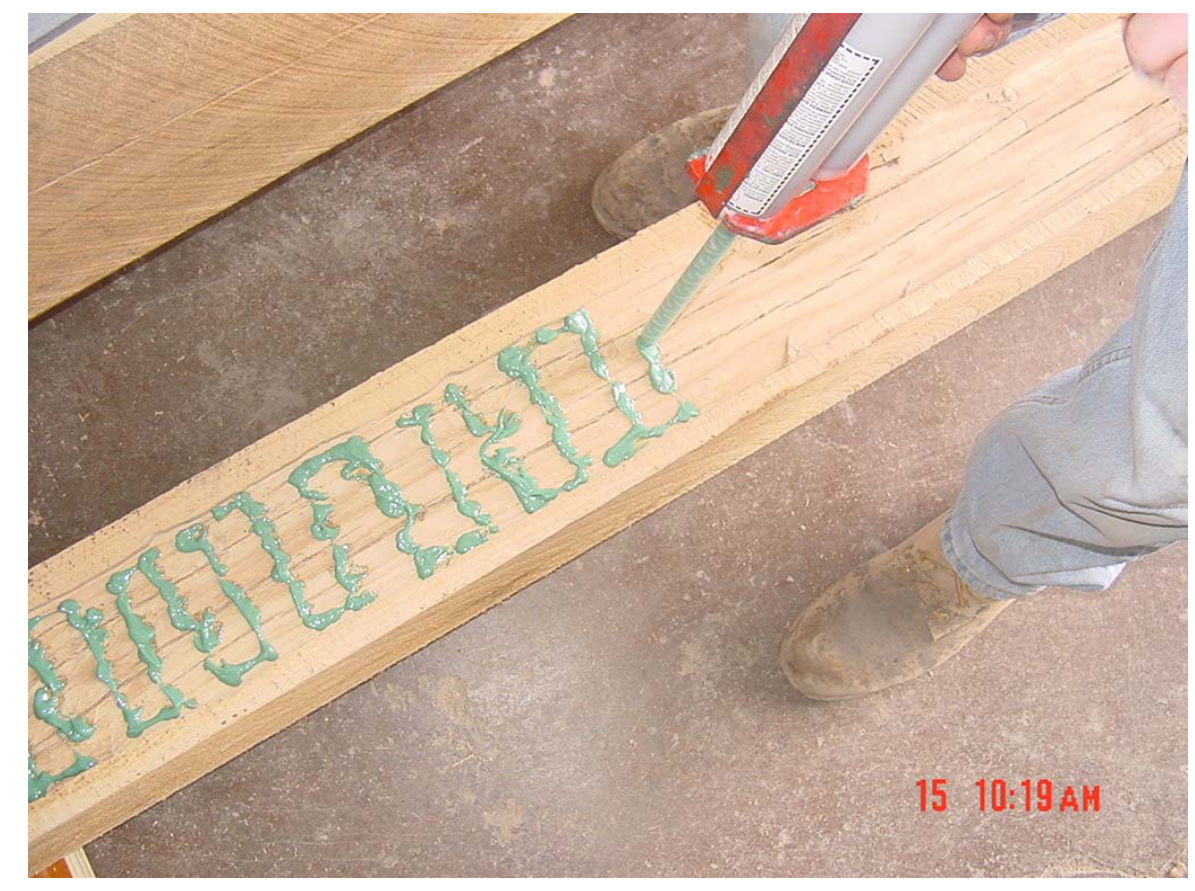

Figure 18. Applying Adhesive on Test Member

The plate was then placed in the recessed area and put under pressure to ensure proper bond between the plate and wooden member (Figure 19). 


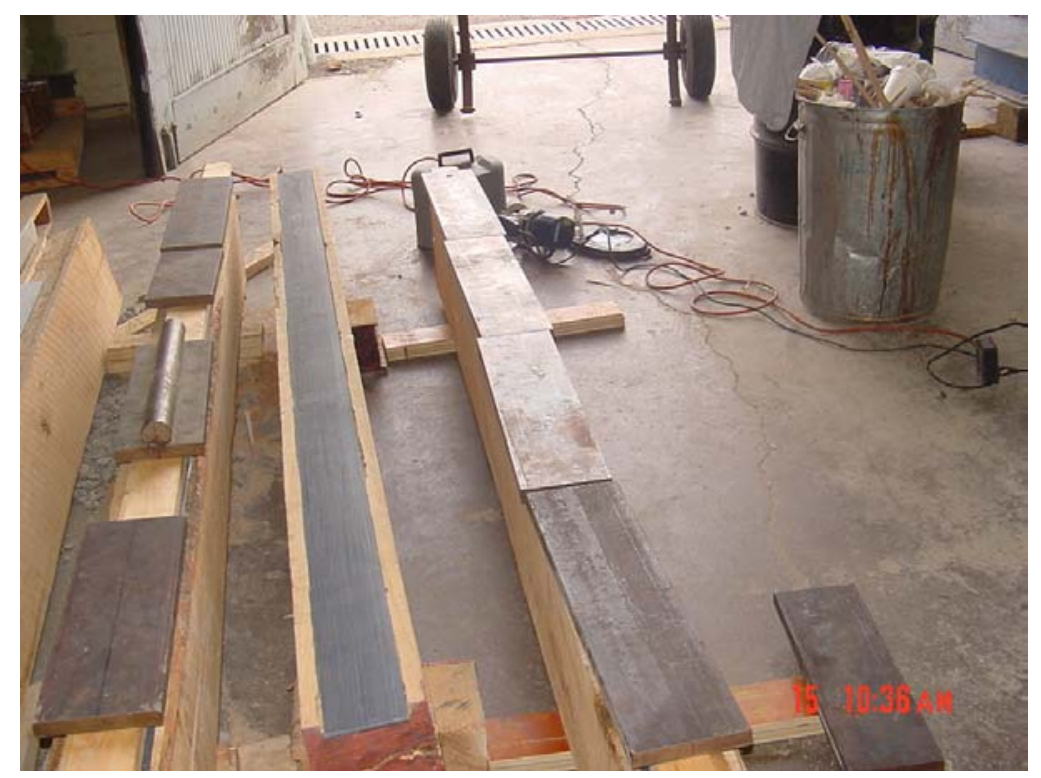

Figure 19. Steel Plates Used as Weights on Test Specimen

\subsubsection{Testing Procedure}

The specimens were tested in 4-point loading as shown in Figure 20. All specimens were instrumented with electrical strain gages placed at the midspan, compression and tension sides, and at the support on the tension side. Deflection was measured using an LVDT and the loading was measured using a load cell. A data acquisition system was used for data collection. The specimens were tested to failure and stress/strain curves were developed and modes of failure identified. One (1) control specimen was tested with no reinforcement, two (2) were tested with $1 / 4$ " $\times 4$ " $\times 8$ ' GFRP plates, and two (2) were tested with $3 / 8$ " $\times 4$ " $\times 8$ '. 


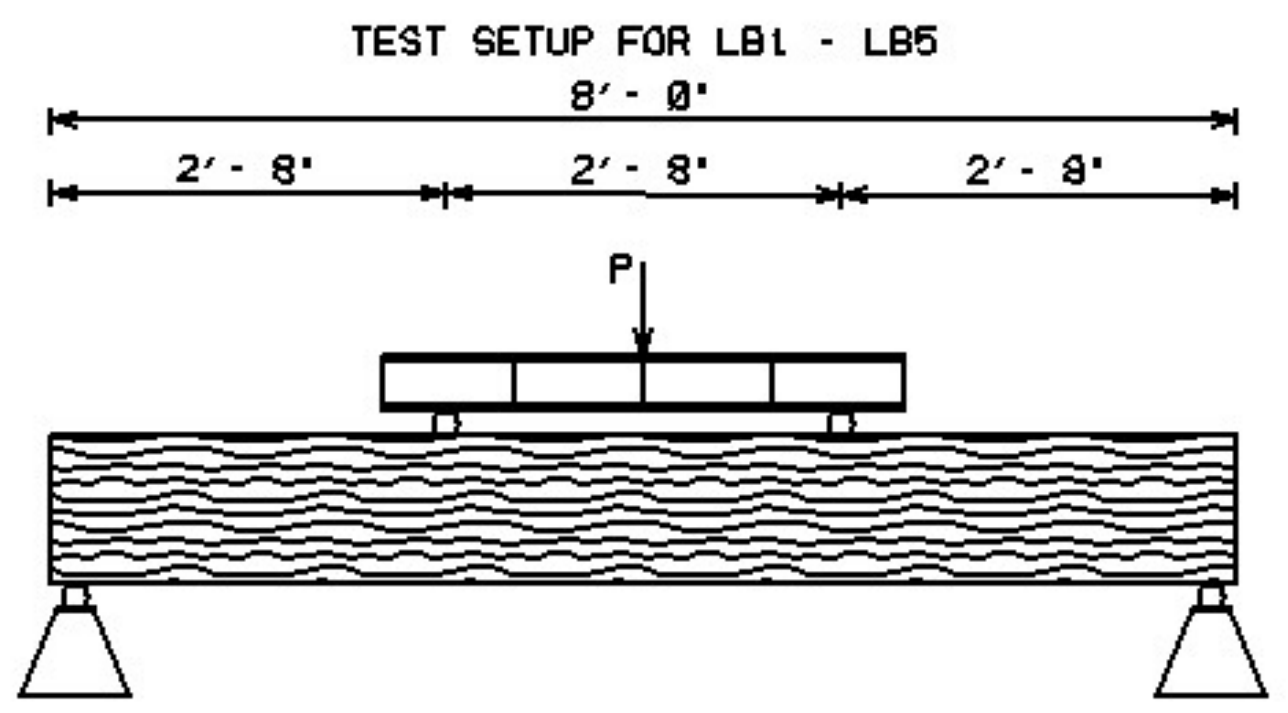

Figure 20. Four Point Bending Test Setup

\subsection{Bending Tests with GFRP Reinforcing Bars}

\subsubsection{Introduction}

The intent of the method developed for these tests would be to only remove the portion of an existing member that was deteriorated and allow the rest of the member to remain in service. In covered bridges, the members themselves are a historic resource that must be preserved. Through the methods developed in this project, we are honoring the techniques developed by previous generations by preserving and reinforcing these members in a concealed manner.

\subsubsection{Preparation of Test Specimens}

The bending test specimens consisted of White Oak wooden members at 9\% Moisture Content (MC) that were obtained from West Virginia University Forest saw mill. These specimens were chosen to closely replicate a floor beam in a covered bridge. The members were rough-cut cants $53 / 4$ " x 5 5/8"x 7'. The specimens were stored in the laboratory until the desired MC was reached. The MC of $9 \%$ was used to closely replicate the $\mathrm{MC}$ of an existing covered bridge. Once the desired $\mathrm{MC}$ was reached the 
specimens were then cut in half. The specimens were cut in half to develop the method that could be used to rehabilitate a partially deteriorated member and allow the intact portion to remain in place. The deteriorated portion would be removed and replaced with a new piece of the same size and species of wood as the original. The pieces would then be joined together by drilling holes and inserting GFRP reinforcing bars to bridge between the new and old members. The GFRP reinforcing bars used were sand coated with a diameter of $9 / 16$ " and $81 / 2$ inches long. The bars were standard $\# 4$ 's, but because of the sand coating an additional 1/16" was added to the diameter.

After the specimens were cut transversely into two halves, $5 / 8$ " diameter holes were drilled into the ends of the specimens. The holes were drilled in accordance with the design requirements of NDS ${ }^{24}$, Section 8.5. Two (2) specimens were prepared and tested, BB-2 and BB-3. BB-2 was reinforced with two (2) GFRP reinforcing bars and BB-3 was reinforced with four (4) GFRP reinforcing bars, Figures 21- 27. After the holes were drilled to accommodate the reinforcing bars, a 7/32" hole was drilled into the side of the members to allow for the injection of the adhesive. PLIOGRIP was also used as the adhesive for these members. An injection process was used because earlier experiments conducted to determine the best method to achieve the desired bond, injection proved the best method to get to as close to perfect bond as possible. The 9/16" diameter sand coated GFRP bars were then placed into the holes and the two pieces were joined together. Bar clamps were used to secure the two halves in place while the adhesive was injected, Figure 28. The bar clamps were also used to provide pressure on the specimens while the adhesive had time to cure properly. The specimens were clamped for approximately 48 hours. It should be noted that BB- 2 was put together with improper alignment. To avoid problems while testing, the holes on one side of the specimen were enlarged to $7 / 8$ " diameter. The GFRP reinforcing bars were then wrapped with a GFRP fabric that had been soaked in PLIOGRIP. The bars were then placed into the specimen in same manner as BB-3. 


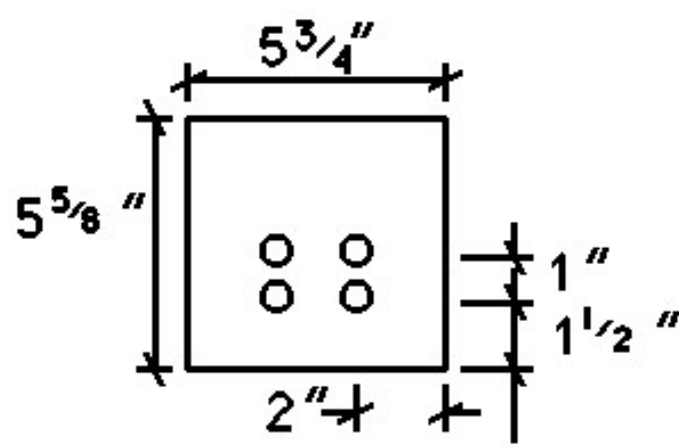

Figure 21. BB-2 End View

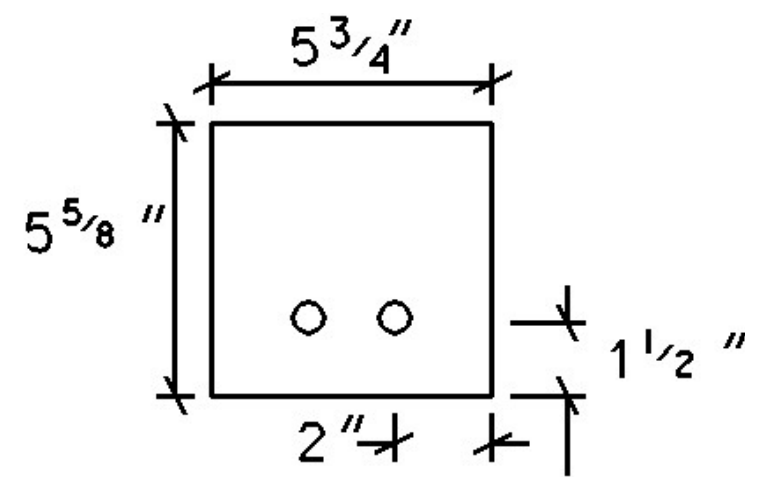

Figure 22. BB-3 End View

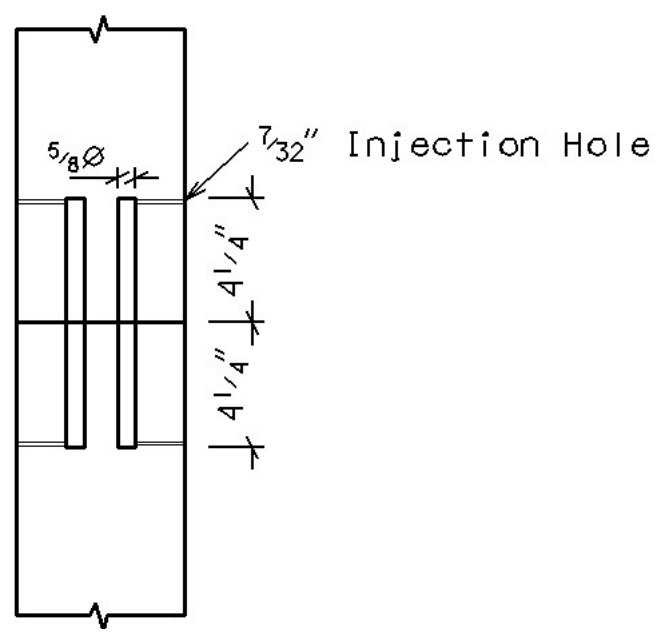

Figure 23. Bottom View BB-2 \& BB-3

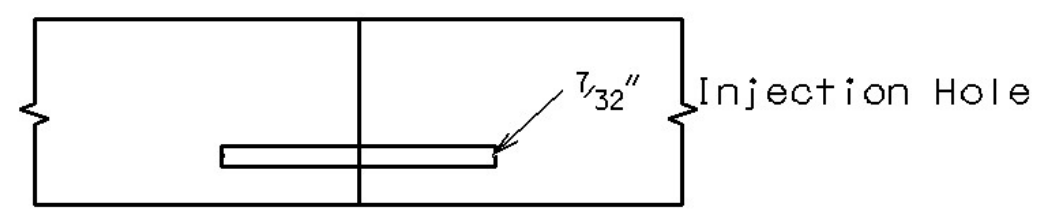

Figure 24. Side View BB-2 


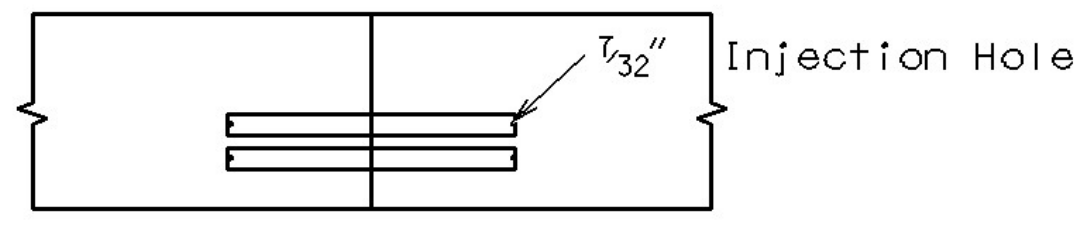

Figure 25. Side View BB-3

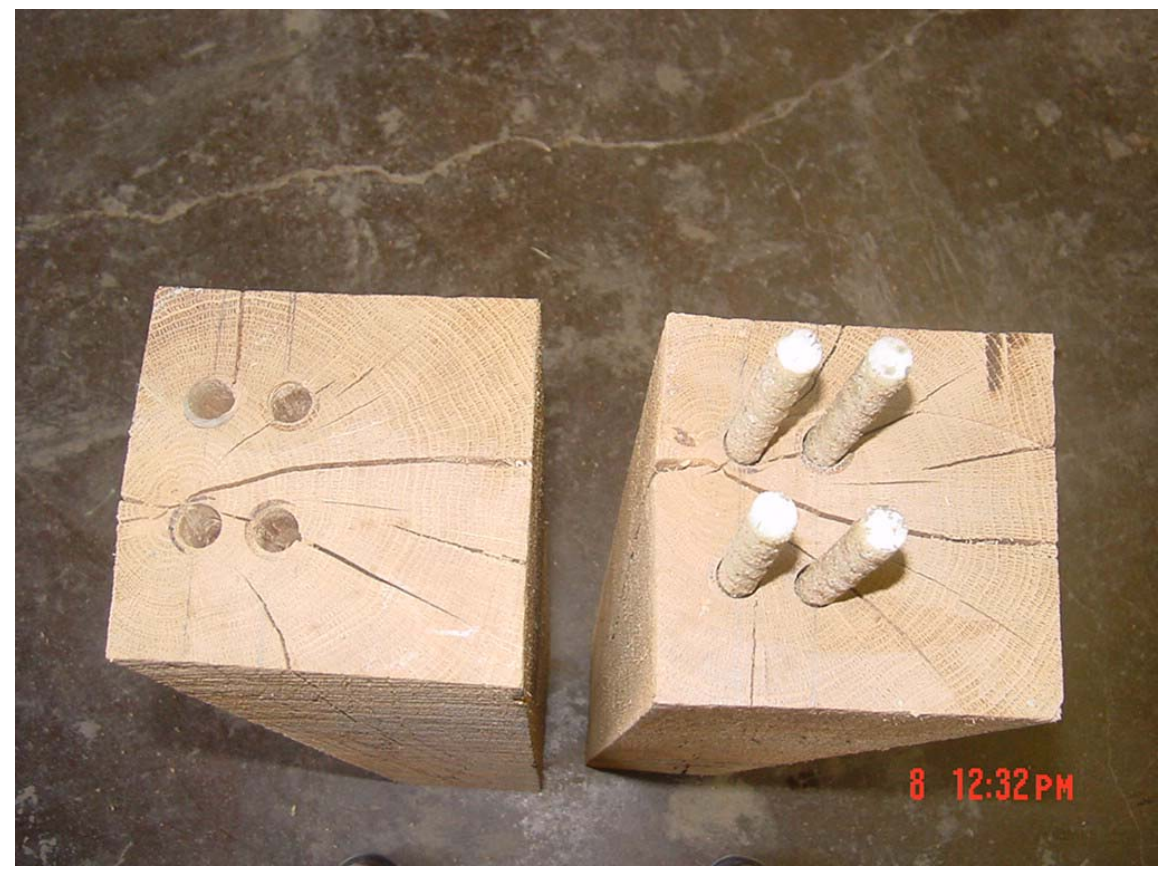

Figure 26. End View BB-3 


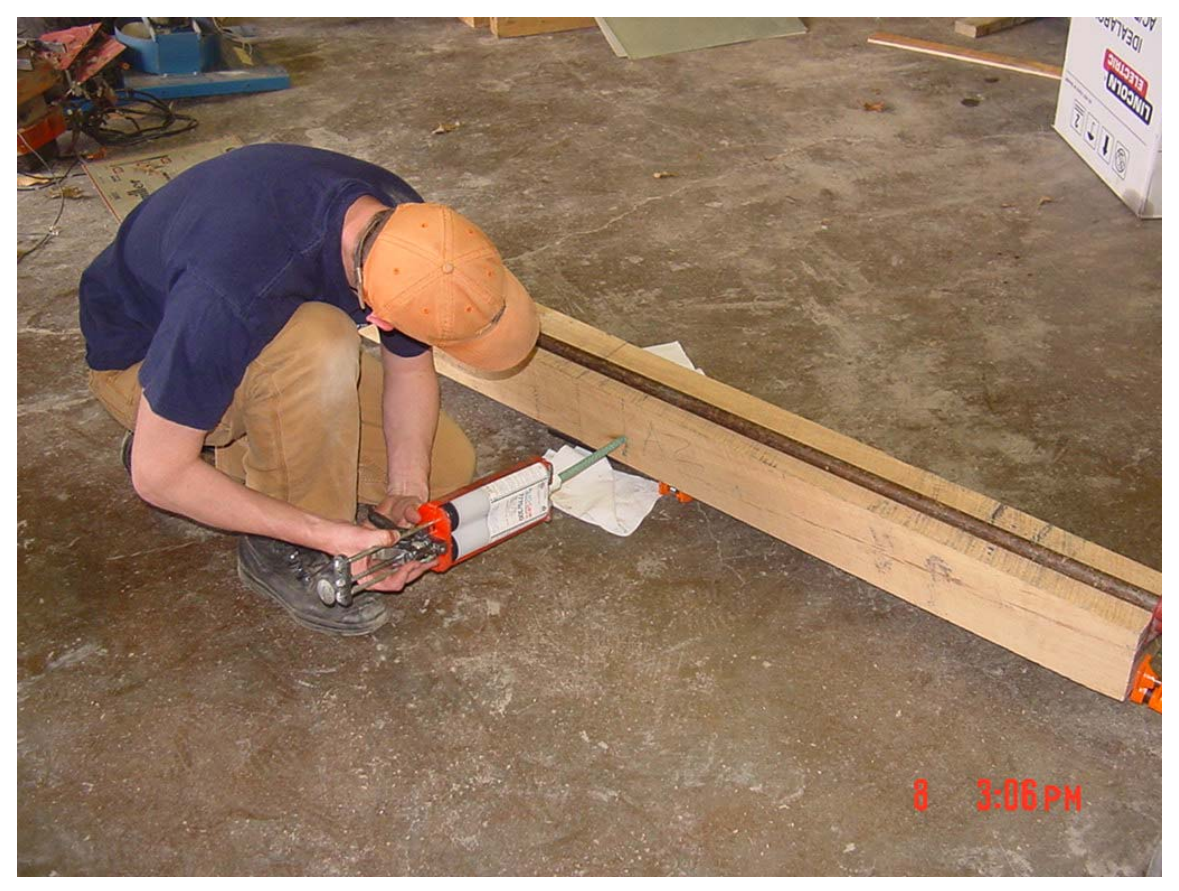

Figure 27. Injection of Adhesive

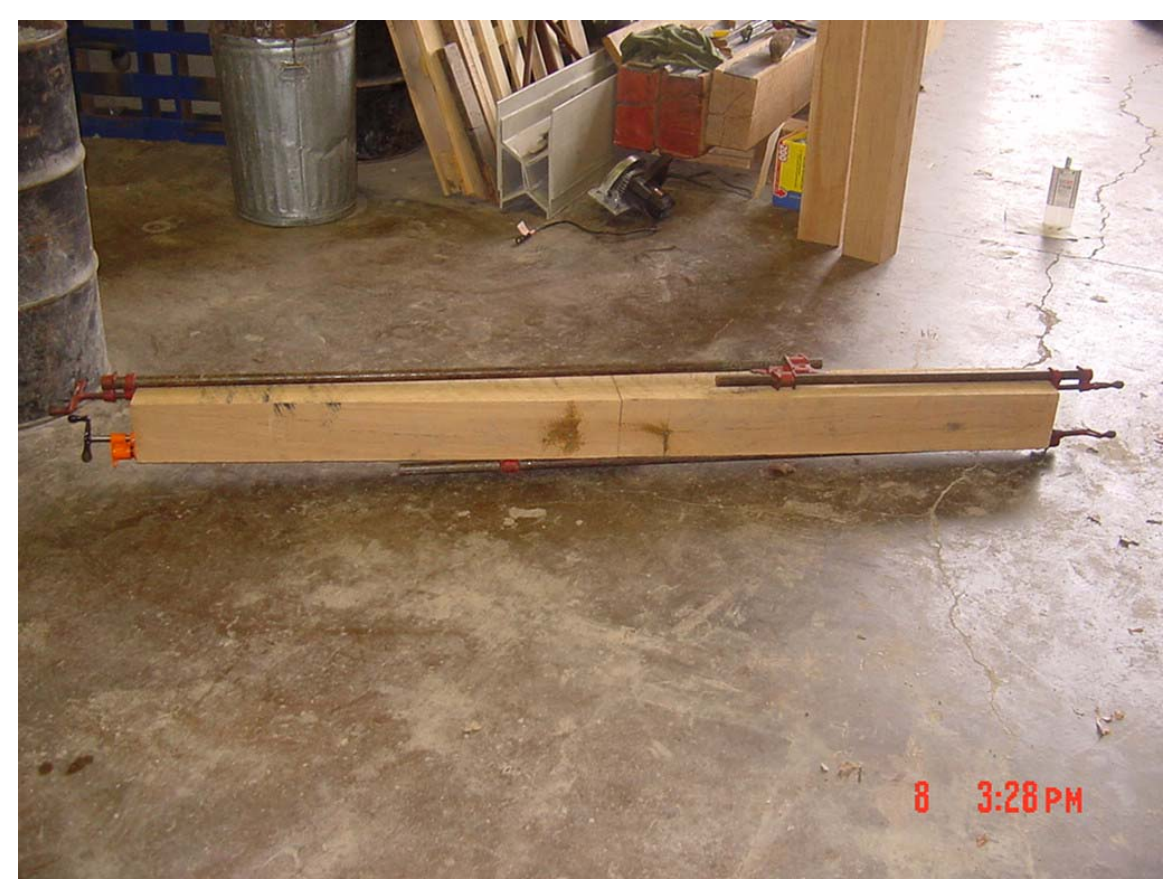

Figure 28. Clamping of Specimens 
The specimens were prepared for testing and removed from the clamps. Strain gages were placed on the tension and compression sides of the specimens and also on the left and right sides of the joint.

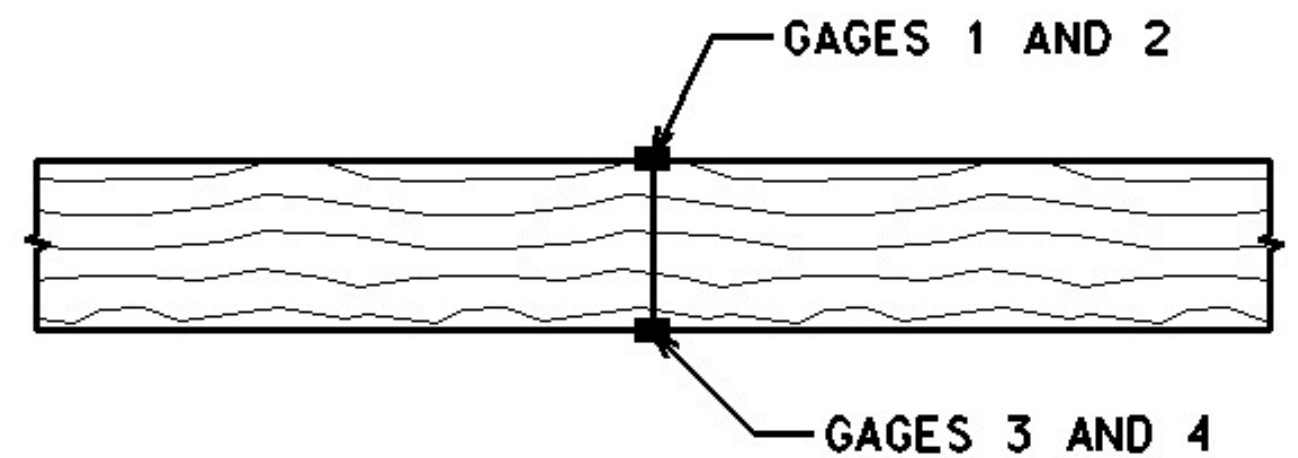

Figure 29. Strain Gage Placement, BB-2 \& BB-3

\subsubsection{Testing Procedure}

The specimens were tested in 4-point loading as shown in Figure 30. Both specimens were instrumented with strain gages and deflections were measured using a dial gage. A load cell was used to determine the applied load. The joint opening was measured with a digital caliper on the tension side of the member. A data acquisition system was used for data collection of the strain and load measurements. The specimens were tested to failure, and theoretical data were developed to compare to the experimental data. The mode of failure was identified. Normally, a control specimen would be tested and the test specimens would be compared to a control specimen. Due to the nature of the methods used, it can easily be seen that the test specimens would not have an increase in strength and stiffness over a whole specimen. Therefore, test data was compared only to theoretical data. 


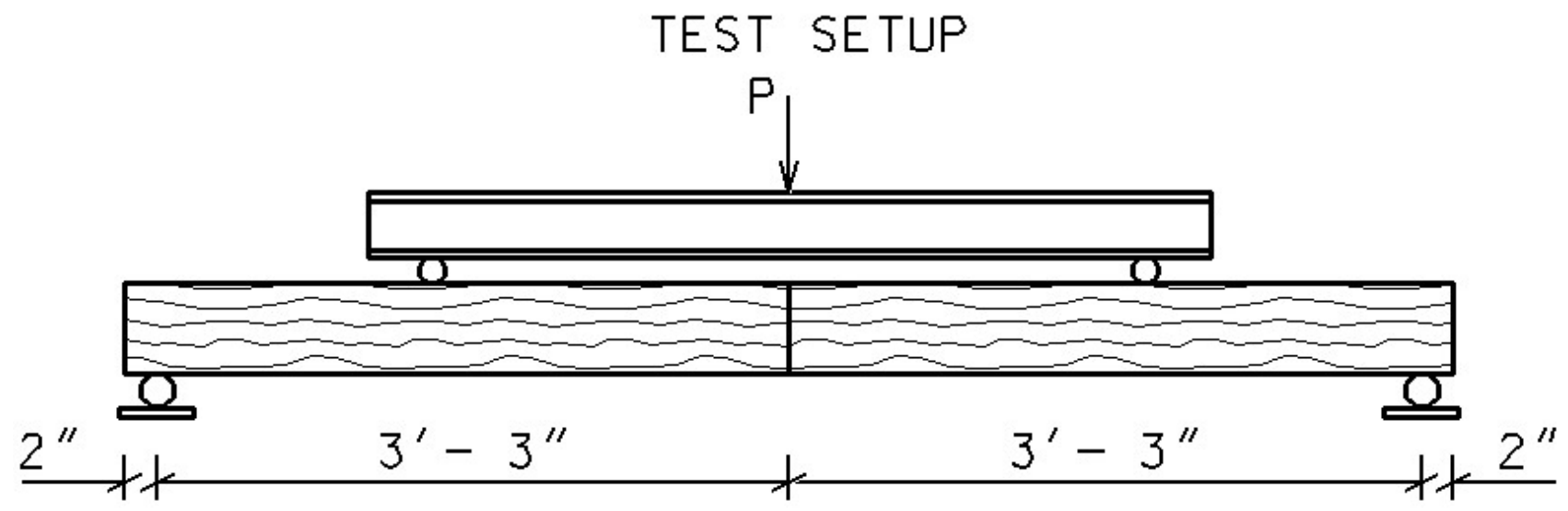

Figure 30. Four Point Bending Test Setup

\subsection{Bending Test (6" x 8") with GFRP Plates}

\subsubsection{Introduction}

Several tests were conducted on full-scale wood members reinforced with GFRP composite plates. These tests are a continuation of earlier tests to investigate the behavior of wooden members reinforced with GFRP plates bonded to the tension side. A total of three (3) 6" x 8" x 10" white oak wooden members with and without GFRP plates were tested to failure.

\subsubsection{Preparation of Test Specimens}

The full-scale bending test specimens consisted of White Oak wooden members at $8-10 \%$ Moisture Content (MC) that were obtained from the Greenbrier Forest Products in Lewisburg, WV. These specimens were chosen to closely replicate earlier tests that were conducted on small-scale wooden members. The specimens ( 6 ' $\left.\times 8^{\prime} \times 10^{\prime}\right)$ are also rough-cut cants, but the cross-section and span length were altered to ensure bending failure and evaluate the flexural behavior of GFRP reinforced wooden beams, see Figures 31 and 32. The specimens were reinforced with GFRP plates that were placed flat-wise 
on the tension side of the member. The shear span-to-depth ratio $(\mathrm{a} / \mathrm{h})$ for these beams was approximately 5. According to ASTM 98 , if $\mathrm{a} / \mathrm{h} \geq 5$, a bending failure will be induced and if $\mathrm{a} / \mathrm{h} \leq 5$ shear failure will be induced, where the shear span is defined as the distance from the support to the loading point. In past specimens the plates were recessed into the member by routing an area large enough to accommodate the plate plus an additional $1 / 16$ " for an adhesive and a 1/16" for added tolerance. An improved method to prepare these specimens was used. This method involved cutting a recessed area of the member out with a table saw (as opposed to routing) to achieve a more accurate and consistent cut, while still allowing for the 1/16" added thickness for the adhesive. A $3 / 8$ " thick GFRP plate was used to reinforce the specimens.
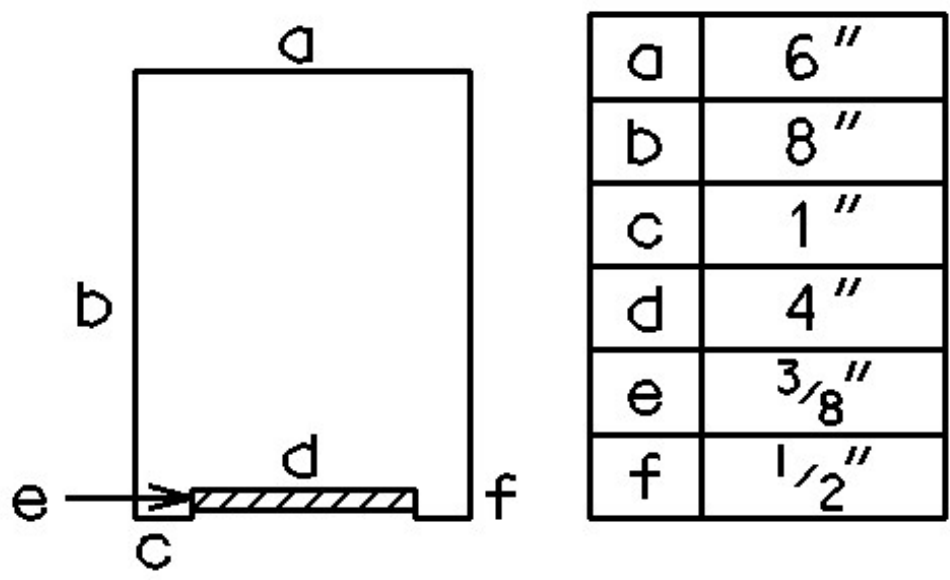

Figure 31. End View of Test Specimens

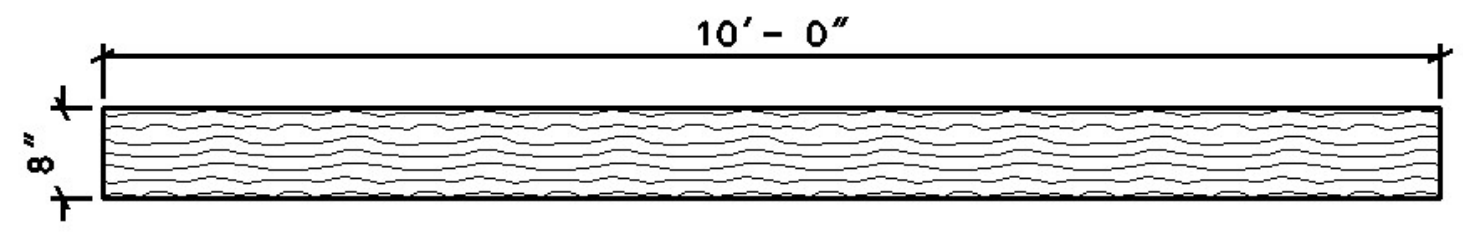

Figure 32. Side View of Test Specimens 
A key difference between these specimens and earlier bending specimens is that after the members were obtained from the saw mill they were stored in a humidity chamber at a constant temperature and humidity level $\left(68^{\circ} \mathrm{F}\right.$ and $70 \%$ relative humidity) until they were ready for assembly and testing. Splits and checks have developed in the past due to excessive in-situ drying in our laboratory. Once the groove was cut, a strain gage was placed internally at the midsection to get accurate measurements of strain on the wood beam under the adhesive. A strain measurement on the wood section and a strain measurement on the GFRP section at the same location will "expected" provide an idea about the strain in the PLIOGRIP adhesive at various loads. The GFRP plates were then sanded on the side that was to be bonded to the wood member. PLIOGRIP was then applied directly to the member. Once the cut out area of the member was adequately covered with PLIOGRIP to ensure proper bond, the sanded plate was placed into the cutout section. Weights were then placed on the plate to provide pressure that from past testing has shown to create proper bond between the member and the plate. Additional strain gages were then placed externally on the GFRP from the center of the member to the edge at 1-foot intervals to observe how the strain varies along the length of the member (Figure 33).

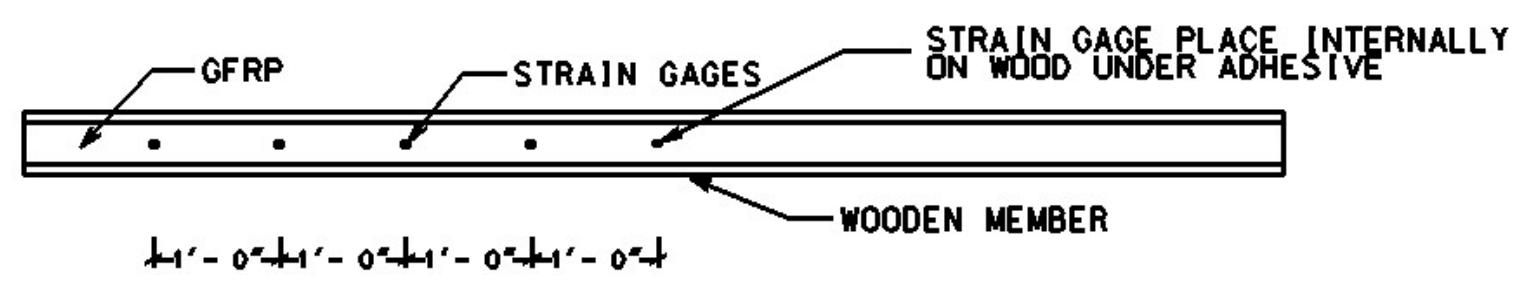

Figure 33. Plan View of Strain Gage Placement

\subsubsection{Testing Procedure}

The specimens were tested in 4-point loading as shown in Figure 34. All specimens were instrumented with electrical strain gages placed at midspan, on the compression and tension sides, and at 1-foot intervals along one half of the member on the tension side. Deflection was also measured using an LVDT and dial gages. The 
applied load was measured using a load cell. A data acquisition system was used for data collection. The specimens were tested to failure. Load/deflection, load/strain, and stress/strain curves were developed and modes of failure were identified. One (1) control specimen was tested with no reinforcement and two (2) specimens were tested with $3 / 8$ " thick GFRP plates. The percent reinforcement of the GFRP to the total cross-section of the member was $3.125 \%$.

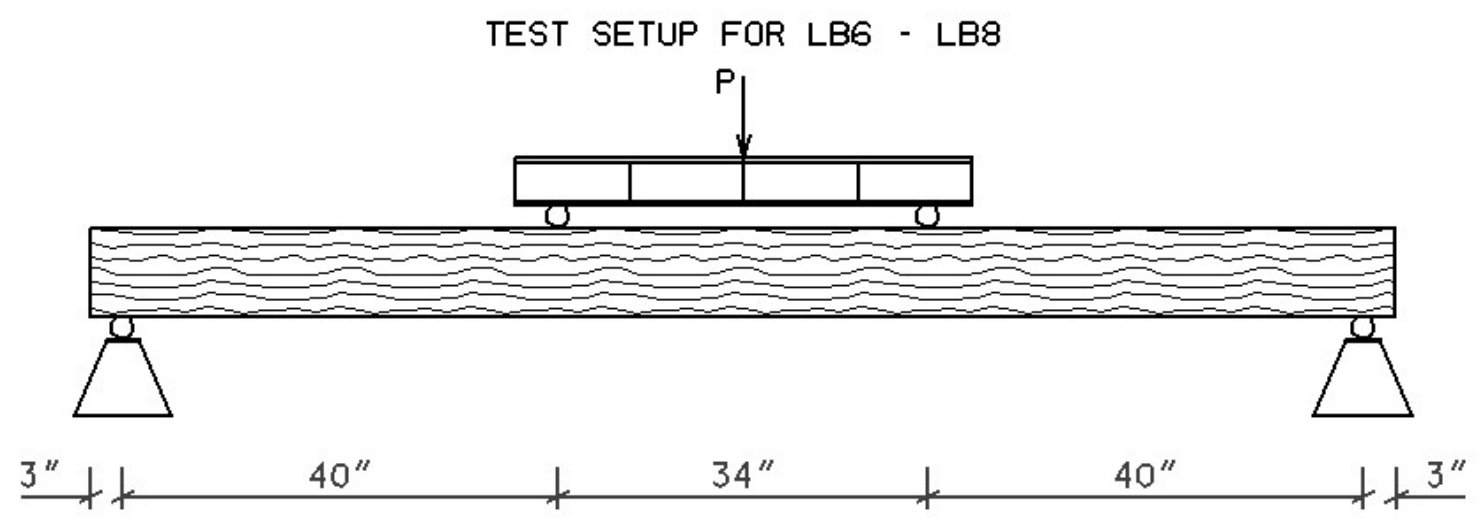

Figure 34. Four Point Bending Test Setup

\subsection{Summary of Tests}

This section summarizes all tests that are presented in this report and is not the summarization of all tests conducted for this research project.

Tension Tests:

Void Test $=3$, to determine the best method to apply adhesive to GFRP

Preliminary Tension Tests $=7$, to determine the best material combination to use Uniaxial Tension Tests $=2$, final comparison made between the two most desirable adhesive/ GFRP combination 
Uniaxial Tension Tests $=9$, testing of preferred material combination and application process for tension splices

Tension Tests of GFRP Plates $=3$, to determine MOE values of GFRP plates used to reinforce bending specimens

Bending Tests:

Small Scale $=3$, to determine if recessing GFRP plate flat-wise on tension side of beam would provide increase strength and stiffness

Bending Member w/ GFRP Bars $=2$, to determine if placing GFRP reinforcing bars on the inside a member that has been spliced can be used as viable method to reinforce deteriorated beams

$6 " \times 113 / 4 "$ "' $\times 8$ " $=3$, continuation of small scale tests on full-size members

$6 " \times 8^{\prime \prime} \times 10^{\prime}=3$, continuation of other bending test on a longer and smaller depth member

\subsection{Historic Preservation}

During these set of experiments two different methods of concealing the reinforcement and preserving the historic integrity of the member were investigated. Both methods take advantage of routing the member in order to place the reinforcement inside of the member and not on the bottom. From the top and side, the GFRP plates cannot be seen (Figure 35). 


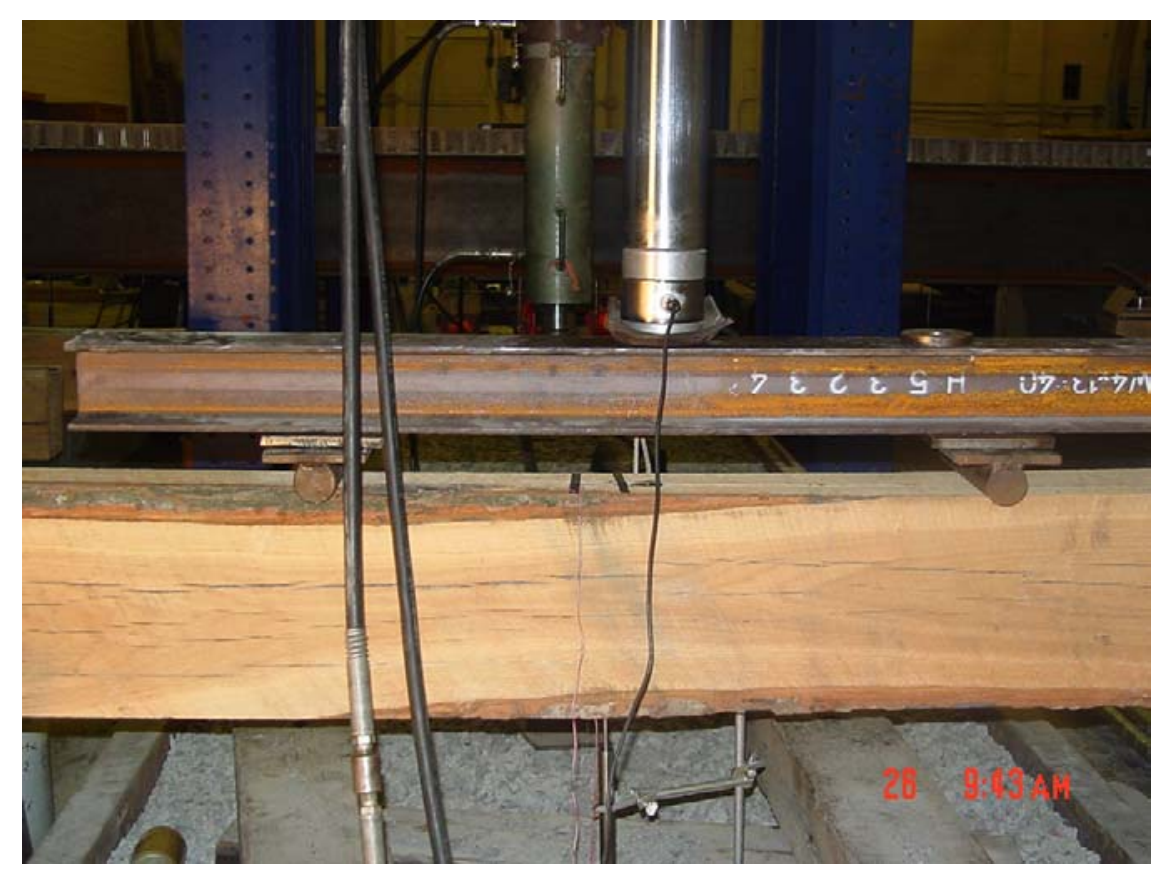

Figure 35. Side View of Reinforced Specimen.

Without being able to view the GFRP from the top and sides, only the bottom had to be concealed. The first method was to use a white oak veneer and bond it to the bottom of the specimen as shown in Figure 36. The entire specimen was then stained; there are several proven methods to make new wood look like old, that could be used to match the existing color. 


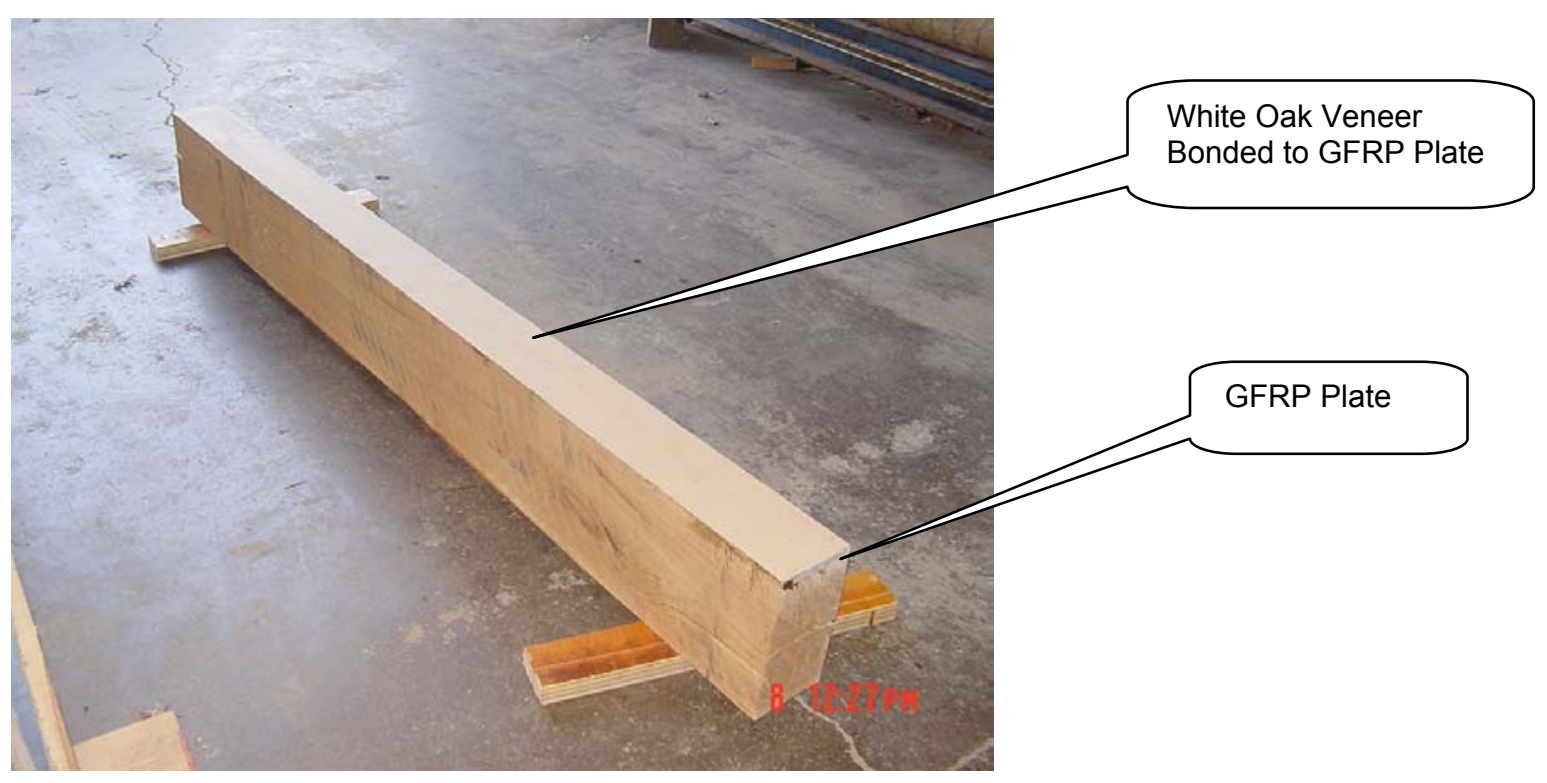

Figure 36. Specimen Covered with Veneer

The next method investigated to conceal the reinforcement is by making the GFRP look like wood. The idea is not to add a layer or ply to the GFRP which could degrade with time and peel off. Instead, a veil integrated at the Pultrusion process is added to the GFRP plate to match existing wood or grain. Since the Constructed Facilities Center has an excellent working relationship with a polymer composite manufacturer (Bedford Reinforced Plastics, Inc., Bedford, PA), several samples were manufactured. A sample of a $100^{+}$year old wood was given to Bedford Reinforced Plastics, and they used a computer generated image to create a veil to match the existing wood. A few samples of the GFRP with wood grain veils are shown in the Figures 37 and 38 . 


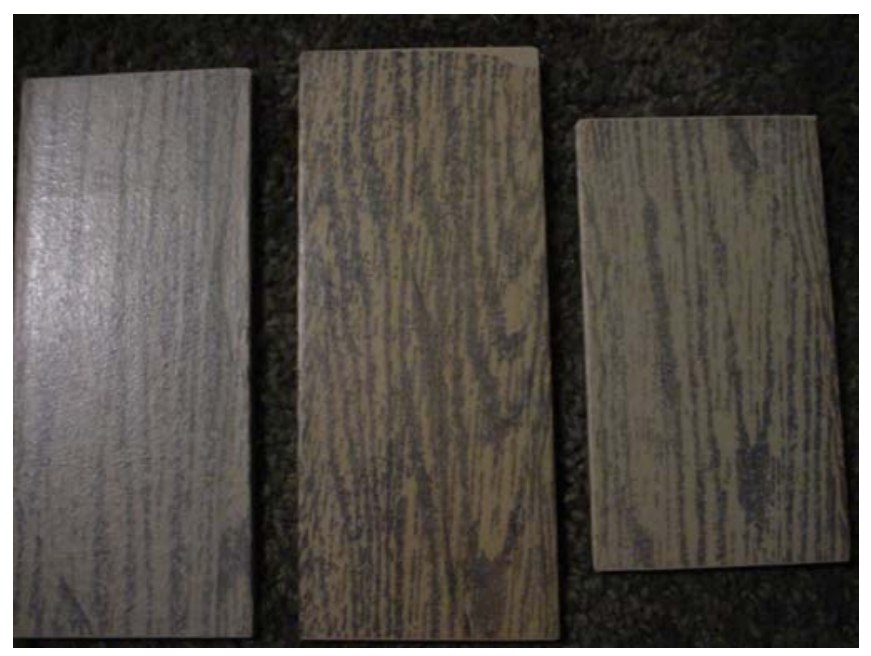

Figure 37. GFRP with Veil

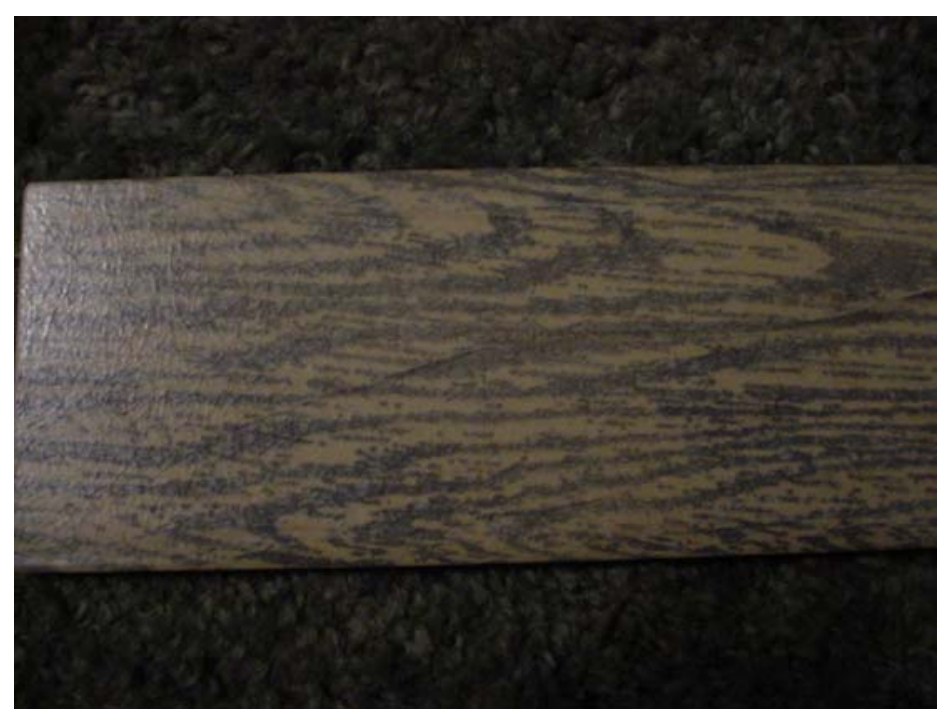

Figure 38. GFRP with Veil 


\section{Chapter 4}

\section{Results and Discussions}

\subsection{Introduction}

This chapter presents the results of the experimental testing described in Chapter 3. Also presented are analysis and discussion of these results, such as the bond strength and approximate development length of truss members, and strength and flexural rigidity improvements due to the addition of GFRP reinforcement.

\subsection{Tension Test}

\subsubsection{Results}

The tension test results of the GFRP reinforced wood specimens revealed that there was adequate chemical cross-linking (a.k.a., bond) between the GFRP rebars and the wood substrate using the PLIOGRIP adhesive and the vinylester matrix of the GFRP rebar. The results of the tension tests and bond strengths are presented in Table 3.

Table 3. Observed Bond Strength

\begin{tabular}{|c|c|c|c|c|c|}
\hline Specimen & $\begin{array}{c}\text { Rebar Length } \\
\text { (in) }\end{array}$ & $\begin{array}{c}\text { Bond Length } \\
\text { (in) }\end{array}$ & $\begin{array}{c}\text { Bond Area } \\
\text { in }^{2}\end{array}$ & $\begin{array}{c}\text { Max Load } \\
\text { (lb) }\end{array}$ & $\begin{array}{c}\text { Bond } \\
\text { Strength (psi) }\end{array}$ \\
\hline$\underline{\mathrm{T}-4^{*}}$ & $\underline{2}$ & $\underline{1}$ & $\underline{1.571}$ & $\underline{1950}$ & $\underline{1241.25}$ \\
\hline $\mathrm{T}-5$ & 2 & 1 & 1.571 & 2565 & 1632.72 \\
\hline$\underline{\mathrm{T}} 3^{*}$ & $\underline{4}$ & $\underline{2}$ & $\underline{3.142}$ & $\underline{2809}$ & $\underline{894.02}$ \\
\hline $\mathrm{T}-2$ & 4 & 2 & 3.142 & 4225 & 1344.68 \\
\hline$\underline{\mathrm{T}-6^{*}}$ & $\underline{8}$ & $\underline{4}$ & $\underline{6.284}$ & $\underline{9730}$ & $\underline{1548.38}$ \\
\hline $\mathrm{T}-7$ & 8 & 4 & 6.284 & 7310 & 1163.27 \\
\hline$\underline{\mathrm{T}-8^{*}}$ & $\underline{16}$ & $\underline{8}$ & $\underline{12.568}$ & $\underline{11900}$ & $\underline{946.85}$ \\
\hline $\mathrm{T}-9$ & 16 & 8 & 12.568 & 10000 & 795.67 \\
\hline
\end{tabular}

$*=$ misalignment (marked red)

$* *=$ premature failure (marked red)

\subsubsection{Discussion}

The bond strength or failure was defined as the load divided by the circumferential area of the embedded length of the GFRP rebar in one side (loaded end) 
of the test specimen, while bond failure (i.e., failure in wood) was defined as the load at which the specimen could not sustain any additional loading.

Based on the test results, the alignment of the GFRP rebar was found to be extremely important to eliminate any eccentricity while applying tension. The countersinking and the washer were found to work well and provide the required alignment. However, several test specimens (marked red and underlined in Table 3) exhibited misalignment of the GFRP rebar as evidenced by strain gage reading. The results from the misaligned GFRP rebars and premature failure tests (specimen T-3) were not used in further analysis. Figure 39 shows the relationship between bond strength and development length. As shown in Figure 39, the bond stress decreases in a nearly parabolic manner to a bond length of 2" and decreases in a nearly linear manner to a bond length of 8 ". This figure is will be the basis for future design requirements.

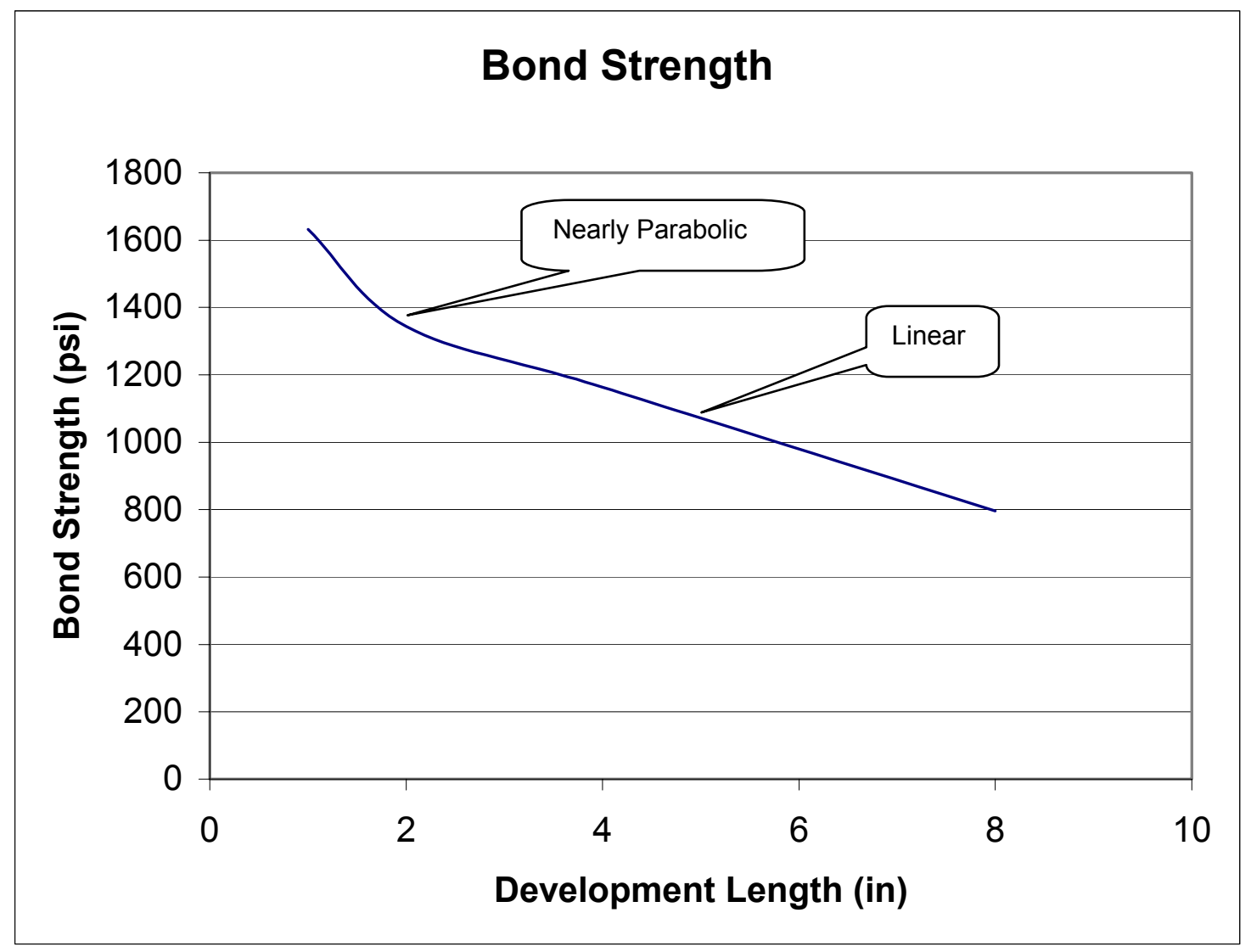

Figure 39. Bond Strength Versus Development Length 


\subsubsection{Summary}

The tension test results appear to be promising. The reinforcement of wood with GFRP is like most other types of reinforcement; i.e., the more reinforcement is not necessarily better. The desired bond strength could be reached in a relatively short distance; this will save immensely when it comes to the cost of materials and man-hours to conduct the strengthening. Another advantage of this behavior may be that a longer than needed bond length can be used to improve joint ductility with a view to extend the strain to failure of the adhesive thus avoiding a sudden joint failure. A major advantage of using GFRP reinforcement over more conventional steel is the strength to weight ratio. With steel, more reinforcement cannot be added because of the self-weight of the steel. The E values between wood and FRP are also more compatible than those of steel.

\subsection{Bending Tests (Small Scale)}

\subsubsection{Results}

The unreinforced specimen (control specimen) described in section 3.3, was tested to failure under four-point bending. As the load increased, horizontal cracks were first observed at the notched cut-out located at the bottom side of the member below the loading points. A loud cracking noise occurred at 2,000 lbs and failure was sudden. The bending stress at this load level was computed as 4800 psi. The non-linear behavior beyond this load level was continued until failure to determine the ultimate strength or load carrying capacity as shown in Figure 40. The ultimate mode of failure was a bending failure, which in a wood beam is a tensile failure. The failure load was recorded. The initial flexural rigidity (EI) of the control specimen was computed as $0.93 \times 10^{6} \mathrm{lb}$ $\mathrm{in}^{2}$ and the ultimate strength or Modulus of Rupture (MOR) was computed as $5600 \mathrm{psi}$. The strain at failure of the control specimen measured at the extreme fibers of the midspan tension side was $11,936 \mu$. 


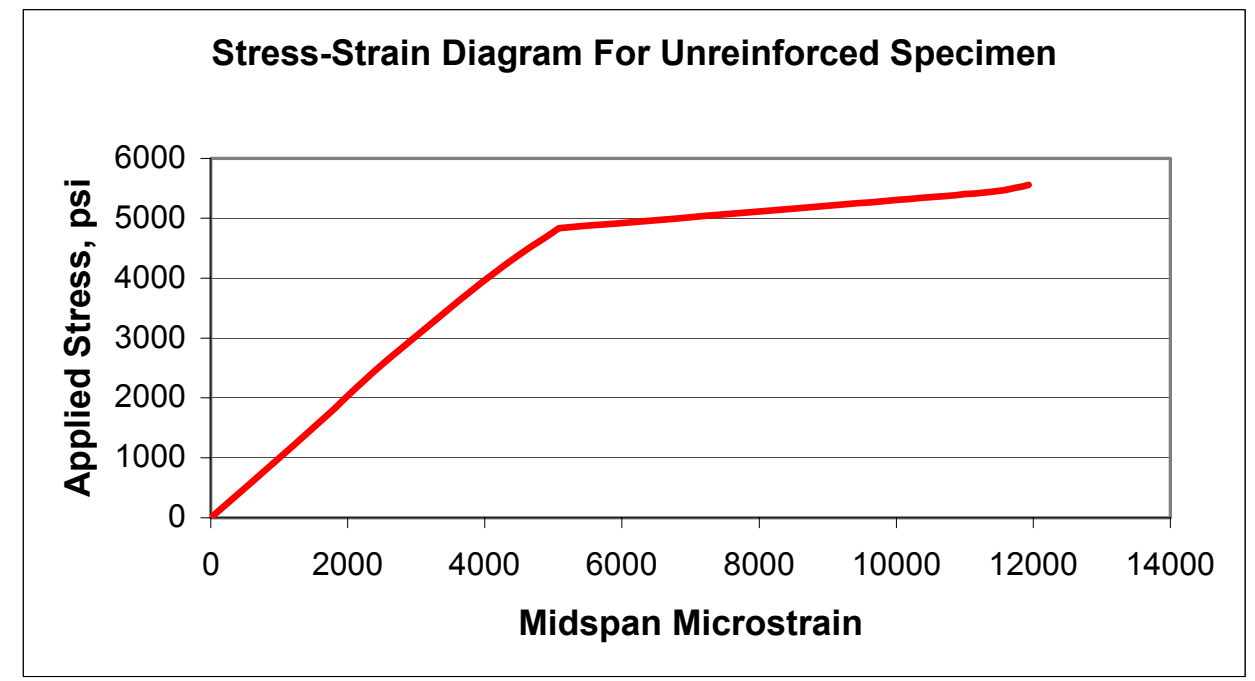

Figure 40. Stress-Strain Diagram for the Unreinforced Specimen

To demonstrate the effectiveness of GFRP reinforcement, specimen B-2 was reinforced using a 1/4" thick GFRP plate with vinylester matrix and tested to failure. This specimen exhibited a stiffer behavior as compared to the unreinforced specimen and had a bi-linear behavior as clearly shown in the stress/strain curves in Figure 41.

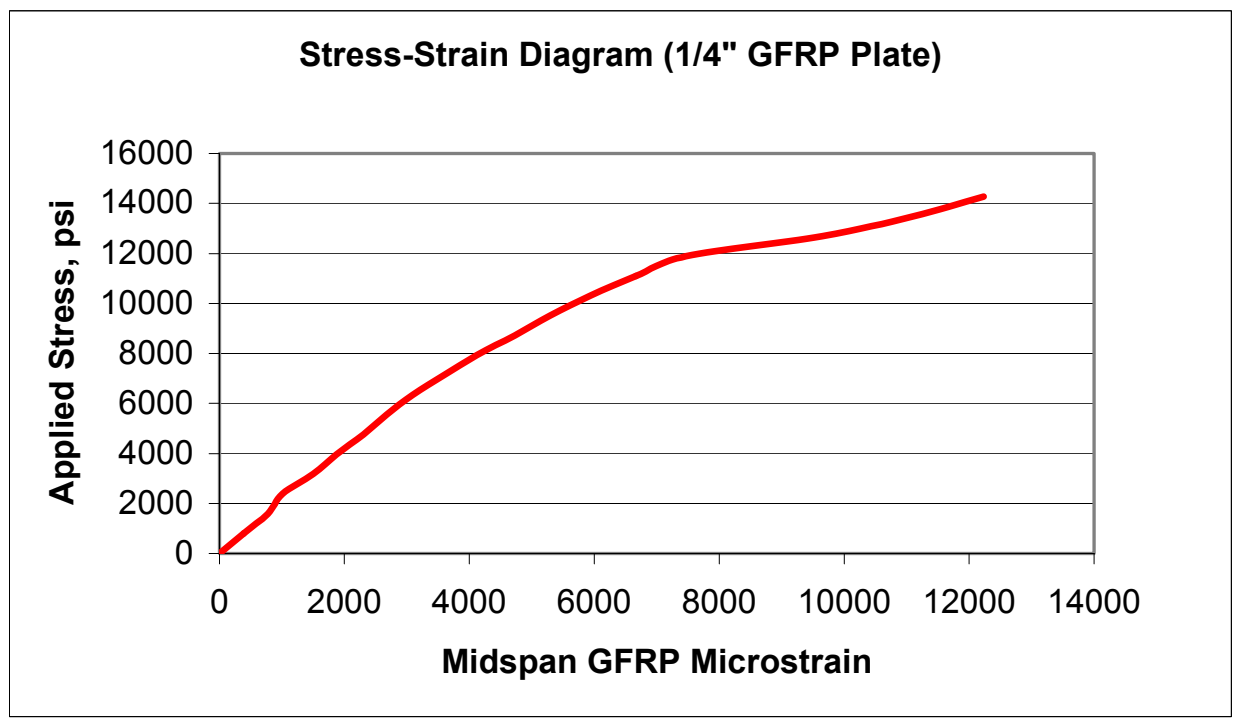

Figure 41. Stress-Strain Diagram for Specimen B-2 
As the load increased, horizontal shear cracks were also first observed at the notched cut-out located at the bottom side of the member below and between the loading points as shown in Figure 42. The first linear part of the stress/strain curve was maintained to a load level of $3800 \mathrm{lbs}$ when it was accompanied by load cracking noise, while the second near linear part of the curve was maintained until a failure load level of $4500 \mathrm{lbs}$. The ultimate failure mode of the specimen was tension a failure of the GFRP plate at both locations of the loads with no bond failure observed as shown in Figure 42.

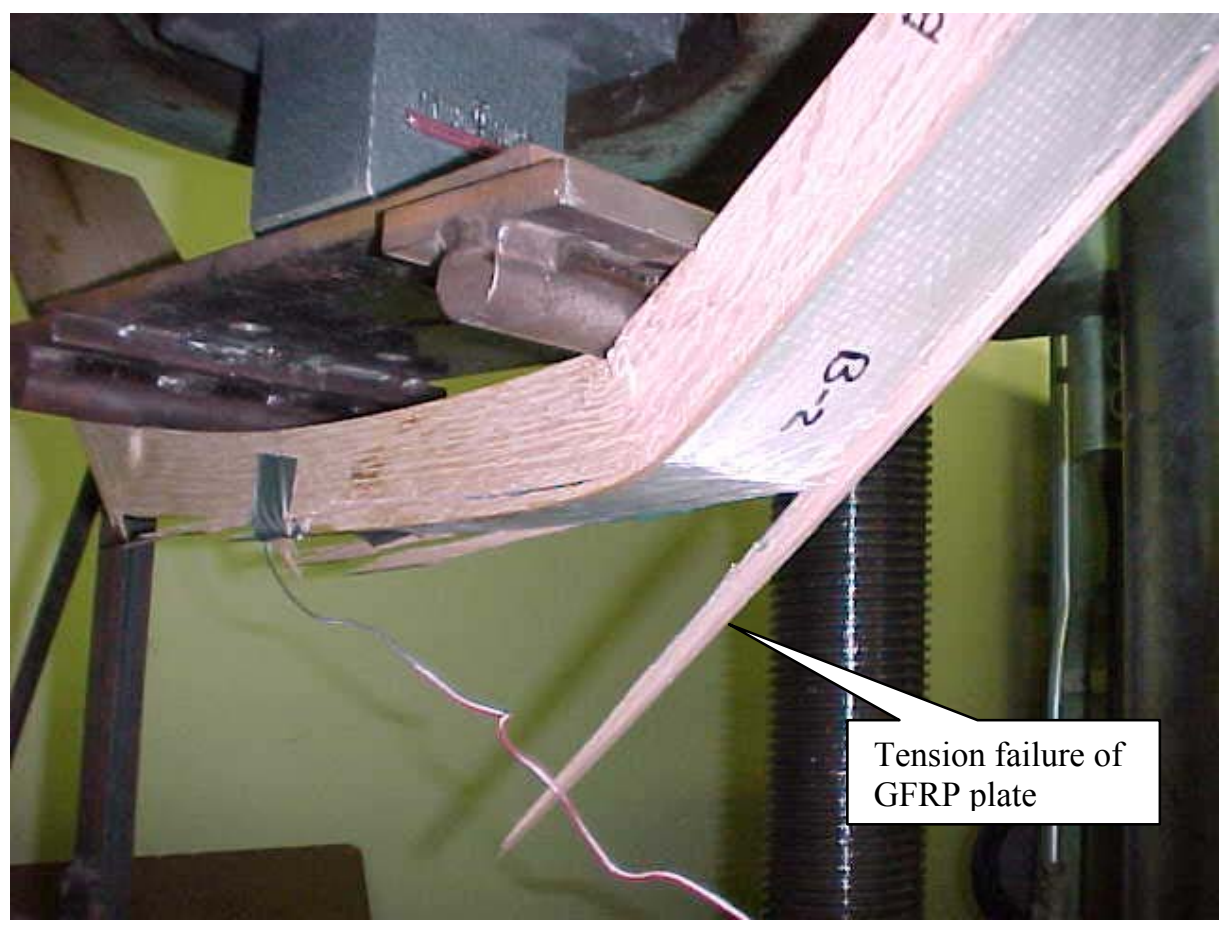

Figure 42. Failure Mode of Specimen B-2

Based on the test results and a transformed section analysis, the ultimate strength or MOR of specimen B-2 is 14,268 psi or an increase of $154 \%$ as compared to the unreinforced control specimen. The initial flexural rigidity (EI) of Specimen B-2 is $1.5 \mathrm{x}$ $10^{6} \mathrm{lb}-\mathrm{in}^{2}$ or a $61 \%$ increase over the unreinforced wood specimen. The strain at failure of the Specimen B-2 measured at the extreme fibers on the GFRP of the midspan tension 
side was 12,231 $\mu$. The transformed and actual section are shown in Figure 43 and the transformed section calculation for B-2 is shown below.

ACTUAL SECTION

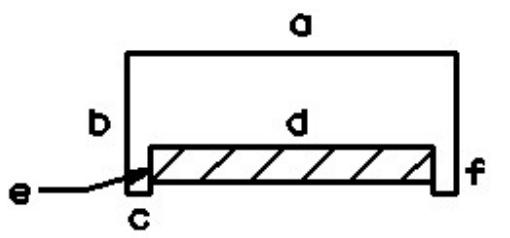

\begin{tabular}{|c|c|}
\hline a & $3.5^{\prime \prime}$ \\
\hline$b$ & $1.5^{\prime \prime}$ \\
\hline c & $3 / 16^{\prime \prime}$ \\
\hline$d$ & $3.0^{\prime \prime}$ \\
\hline e & $1 / 4^{\prime \prime}$ \\
\hline$f$ & $0.5^{\prime \prime}$ \\
\hline c & $7.2^{\prime \prime}$ \\
\hline
\end{tabular}

TRANSFORMED SECTION

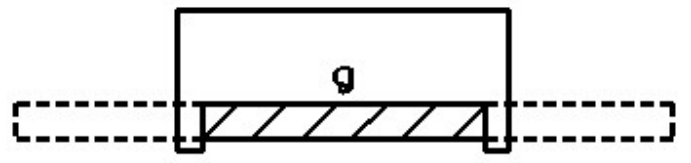

Figure 43. Actual and Transformed Section for B-2

Using the modulus of elasticity of both the wood and GFRP, a modular ratio, $n$, can be found.

$$
\mathrm{n}=\frac{E_{G F R P}}{E_{\text {Wood }}}=2.411 \approx 2.4
$$

The adjusted width for the $1 / 4$ " $\mathrm{x} 3$ " wide GFRP plate is: $\mathrm{n} \times 3=7.2$ ".

The centroid can now be found from the mechanics of materials equation

$$
\bar{y}=\frac{\Sigma y_{i} A_{i}}{\Sigma A_{i}}
$$

Table 4. Centroid Calculation

\begin{tabular}{|c|c|c|c|}
\hline Section & Area & y & yA \\
\hline 1 & 0.09375 & 0.25 & 0.023438 \\
\hline 2 & 0.09375 & 0.25 & 0.023438 \\
\hline 3 & 3.5 & 1 & 3.5 \\
\hline 4 & 1.8 & 0.375 & 0.675 \\
\hline & $\Sigma \mathrm{A}=5.4875$ & & $\Sigma \mathrm{yA}=4.22188$ \\
\hline
\end{tabular}

The centroid is calculated to be $\bar{y}=0.77$ '. 


\section{Moment of Inertia}

$$
\begin{gathered}
I_{X T}=\left\{\frac{(3 / 16)(1 / 2)^{3}}{12}+\left[(3 / 16)(1 / 2)(0.77-0.25)^{2}\right]\right\} \times 2+\left\{\frac{(3.5)(1)^{3}}{12}+(3.5)(1)(1-0.77)^{2}\right\}+ \\
\left\{\frac{(7.2)(1 / 4)^{3}}{12}+(7.2)(1 / 4)(0.77-1 / 4-1 / 8)^{2}\right\} \\
I_{X T}=0.05461+0.47682+0.29022 \\
I_{X T}=0.82 \text { in }^{4}
\end{gathered}
$$

Specimen B-3 was reinforced using a 3/8" thick GFRP plate with vinylester matrix and tested to failure. This specimen exhibited a stiffer behavior than that of Specimen B-2 because of the stiffer GFRP plate used. Specimen B-3 also had a bi-linear behavior as shown on Figure 44.

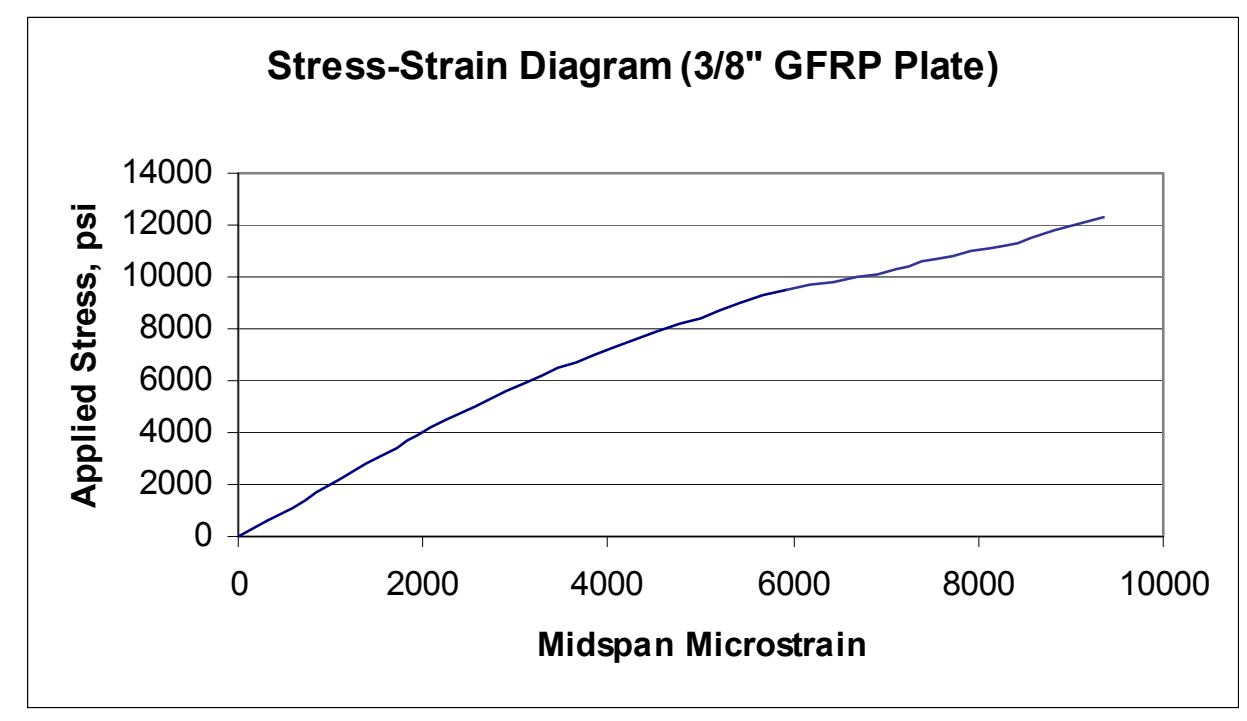

Figure 44. Stress-Strain Diagram for Specimen B-3

As the load increased, horizontal shear cracks were also first observed at the notched cut-out located at the bottom side of the member below and between the loading points as shown in Figure 45. The first linear part of the stress/strain curve was 
maintained to a load level of $4600 \mathrm{lbs}$ when it was also accompanied by load cracking noise, while the second near linear part of the curve was maintained until a failure load level of $5500 \mathrm{lbs}$. The ultimate failure mode of Specimen B-3 was dominated by horizontal shear failure of the wood initiated at the high moment region between the two load points, and wood failure at the bondline leading to the separation of the GFRP plate as shown in Figure 45.

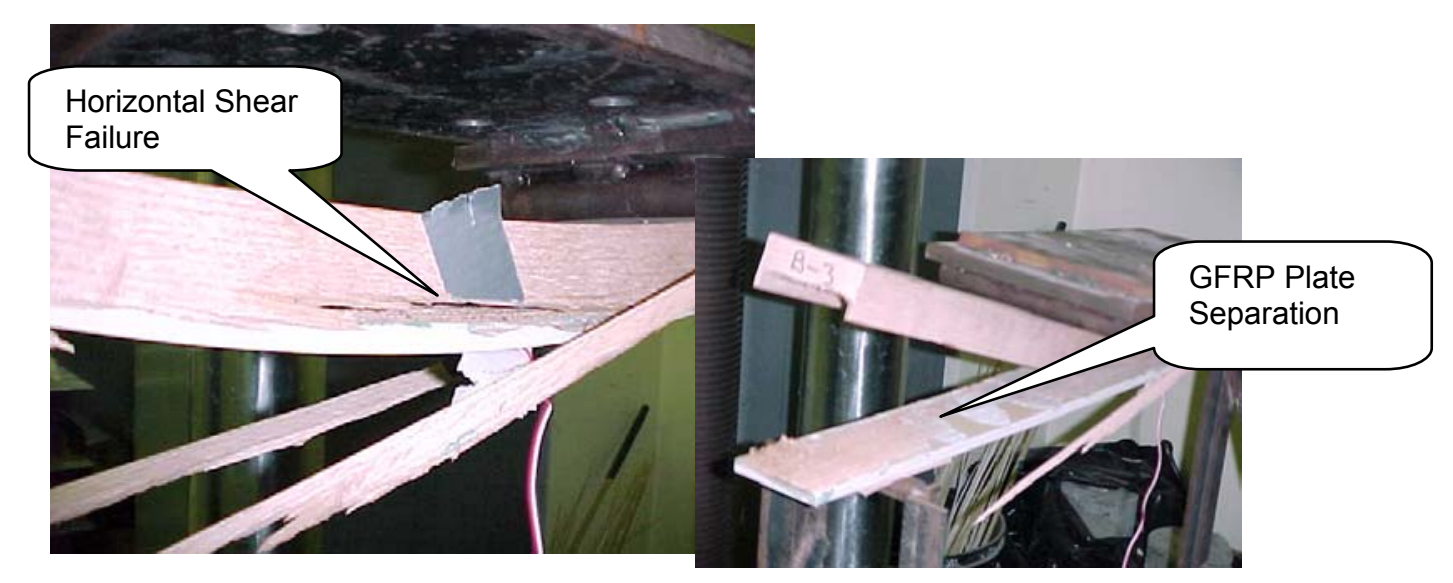

Figure 45. Failure Mode of Specimen B-3

Based on the test results and a transformed section analysis, the ultimate strength or MOR of specimen B-3 is 12,340 psi or an increase of $120 \%$ as compared to the unreinforced control specimen. The initial flexural rigidity (EI) of Specimen B-3 is $2 x$ $10^{6} \mathrm{lb}_{-i n^{2}}$ or a $115 \%$ increase over the unreinforced wood specimen. The strain at failure of the Specimen B-3 measured at the extreme fibers on the GFRP of the midspan tension side was 9,359 $\mu$. The transformed and actual section for B-3 is shown in Figure 46, the method of calculation for the transformed section is the same as that of B-2. 
ACTUAL SECTION

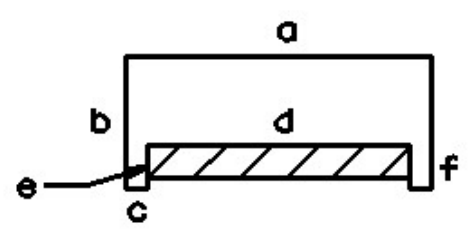

TRANSFORMED SECTION

\begin{tabular}{|c|c|}
\hline$a$ & $3.5^{\prime \prime}$ \\
\hline$b$ & $1.5^{\prime \prime}$ \\
\hline$c$ & $3 / 16^{\prime \prime}$ \\
\hline$d$ & $3.0^{\prime \prime}$ \\
\hline$e$ & $3 / g^{\prime \prime}$ \\
\hline$f$ & $0.5^{\prime \prime}$ \\
\hline$g$ & $7.2^{\prime \prime}$ \\
\hline
\end{tabular}

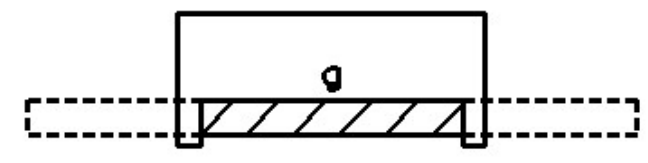

Figure 46. Transformed and Actual Section for B-3

\subsubsection{Summary}

Based on the experimental results, it is evident that the use of GFRP/vinylester matrix composite with PLIOGRIP adhesive has performed very well. Two types of failures were observed. A GFRP plate tensile failure (Specimen B-2) and a horizontal shear failure in the wood (Specimen B-3).

The MOE of the beam with the 3/8" GFRP reinforcement (Specimen B-3) was computed as $1.75 \mathrm{msi}$ (Figure 43), and the MOE of the beam with the 1/4" GFRP reinforcement (Specimen B-2) was computed as $1.82 \mathrm{msi}$. The reason for the lower MOE value appears to be that there was partial $(<100 \%)$ bond between the $3 / 8$ " GFRP plate specimen versus the 1/4" GFRP plate specimen.

The increase in strength of Specimen B-2 (i.e., 154\%) was higher than the increase of strength of Specimen B-3 (i.e., 120\%) as compared to the unreinforced specimen. Also, the failure mode of Specimen B-2 was a tension failure of the GFRP plate, which is more desirable than the horizontal shear failure in the wood of Specimen B-3.

\subsection{Bending Test (6" x $113 / 4$ ") with GFRP Plates}

\subsubsection{Results}

The unreinforced control specimen was tested to failure under four-point bending. Loud checking sounds were heard at the onset of loading. As the load increased horizontal checking first appeared around 25,000 lbs. This checking continued until the 
specimen reached its ultimate load of 33,338 lbs. Once the member reached this load the load then dropped down to $23,000 \mathrm{lbs}$. It then went back up to $31,000 \mathrm{lbs}$ before another loud noise was heard and the load once again dropped off to 23,000 lbs. This behavior continued for several more cycles, the load the member was carrying never went above 23,000 lbs. The ultimate mode of failure was a combination of horizontal shear failure and tension failure due to bending. This can be seen in Figure 45 and can be attributed to a low a/d ratio. This ratio must be greater than 5 to induce a bending failure following ASTM 198, if it is less than 5, horizontal shear will dominate the failure mode. For our test the a/d ratio was approximately 2.7 , which is well below 5 . The initial flexural rigidity (EI) of the control specimen was computed as $429 \times 10^{6} \mathrm{lb}$-in ${ }^{2}$ and the ultimate strength or Modulus of Rupture (MOR) was computed as 3864 psi. The strain at failure of the control specimen measured at the extreme fibers of the midspan tension side was $2536 \mu$. The load vs. deflection curve can be seen in Figure 47.

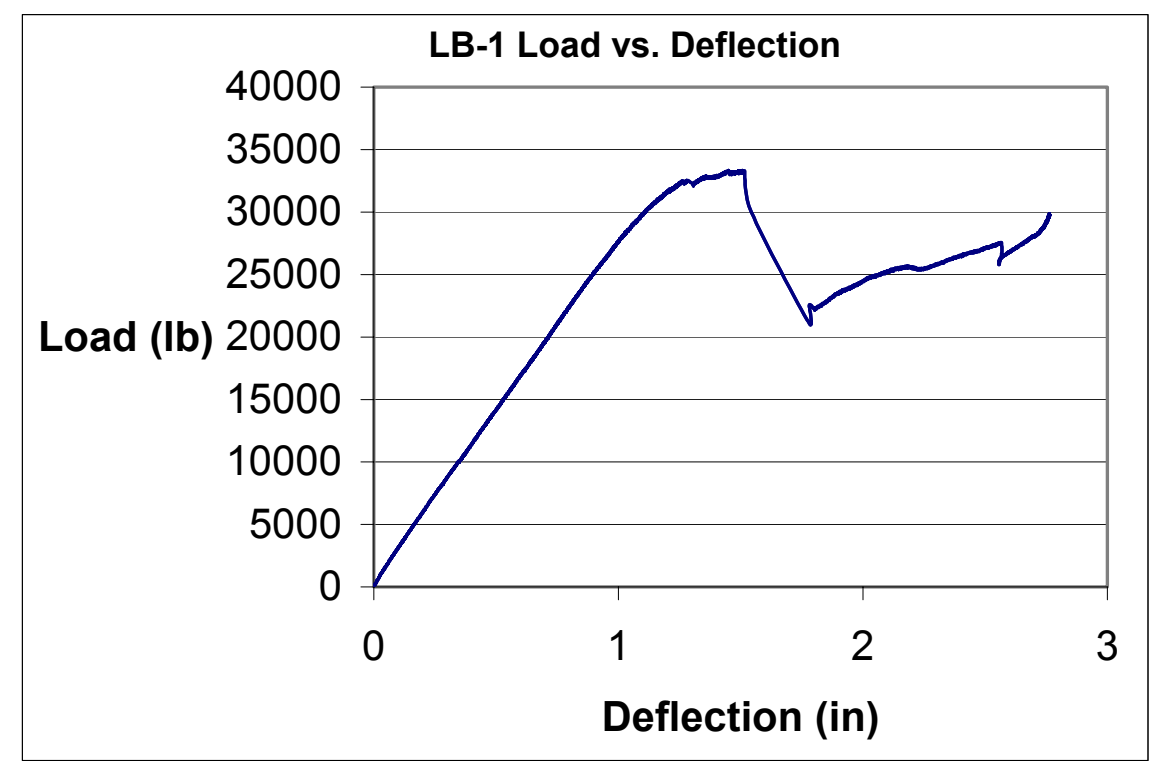

Figure 47. Load vs. Deflection for the Unreinforced Specimen 


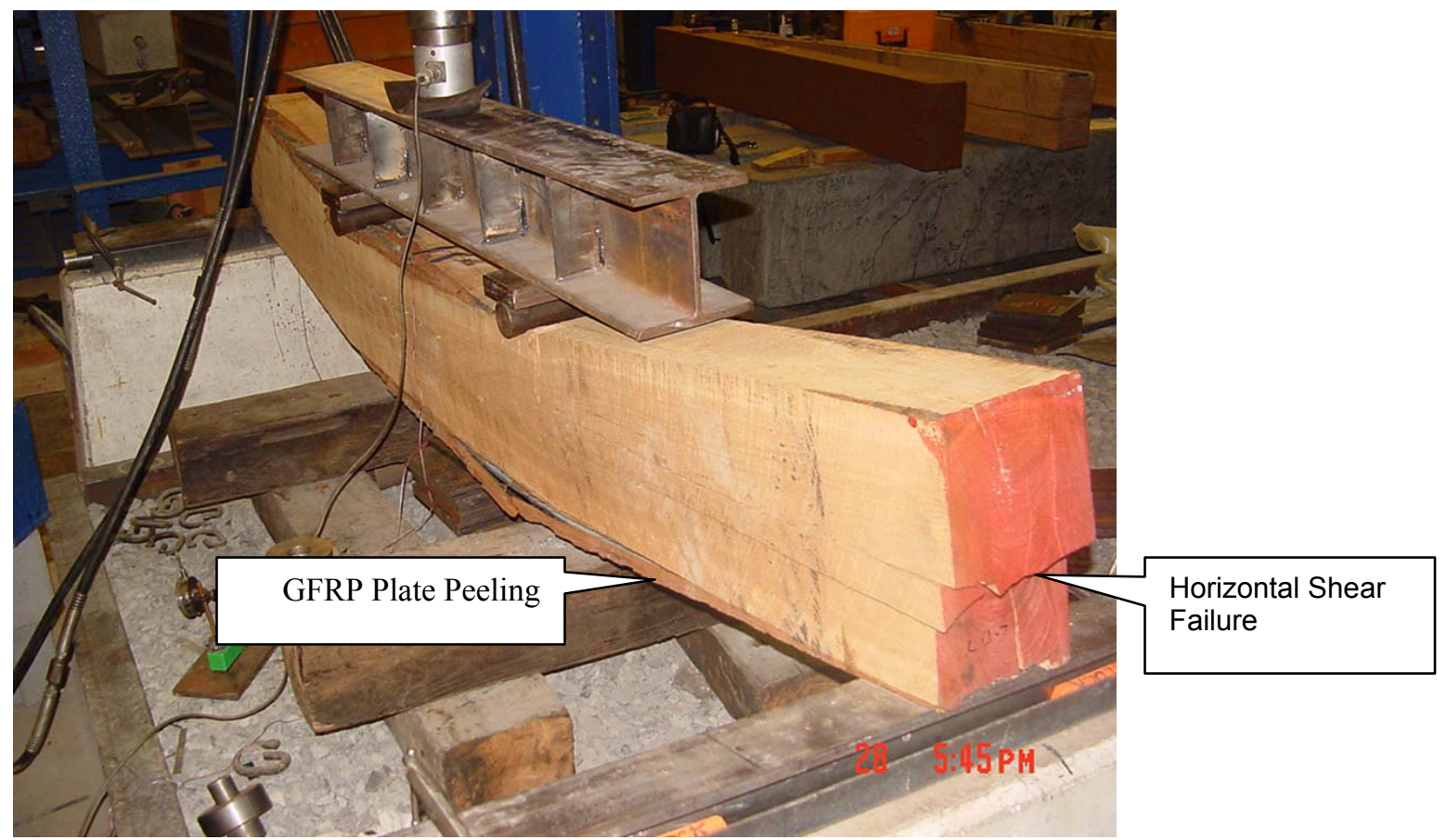

Figure 48. Failure Mode of GFRP Reinforced Beam

As stated earlier two different sizes of GFRP plates were used as reinforcement. Table 5 presents MOR and EI values for all of the specimens that were tested. Table 5 also presents the \% improvement in strength and flexural rigidity between the control unreinforced specimen and GFRP reinforced specimens. Specimens LB-2 and LB-3 were reinforced using the $1 / 4$ " thick plate and specimens LB-4 and LB-5 used the $3 / 8$ " thick plate. The primary mode of failure for specimens LB-2, LB-3, and LB-4 was dominated by horizontal shear failure of the wood and failure in the bondline causing a peeling action at the ends of the GFRP plate, Figure 48.

Table 5. Test Results

\begin{tabular}{|c|c|c|c|c|c|}
\hline Specimen & Plate Thickness & El $\left({\mathrm{Ib}-i{ }^{2}}^{2}\right)$ & $\%$ difference & MOR (psi) & $\%$ difference \\
\hline LB-2 & $1 / 4 "$ & 363902077 & -15.13 & 4291 & 11.05 \\
\hline LB-3 & $1 / 4 "$ & 477985543 & 11.47 & 3785 & -2.04 \\
\hline LB-4 & $3 / 8 "$ & 738056907 & 72.12 & 4913 & 27.15 \\
\hline LB-5 & $3 / 8 "$ & 823140626 & 91.97 & 4827 & 24.92 \\
\hline
\end{tabular}


The following calculation is an example of how EI was determined:

$$
\begin{gathered}
\Delta_{\text {max }}=\frac{P a / 2}{24 E I}\left(3 L^{2}-4 a^{2}\right) \\
E I=\frac{P a}{48 \Delta}\left(3 L^{2}-4 a^{2}\right)
\end{gathered}
$$

The detailed test results for LB-5 are described below since it was the only test specimen to display the desired failure mode. This specimen was tested to failure under four-point bending using the same test setup as the control specimen. Slight checking sounds were heard coming from the specimen at the onset of loading. A loud pop was heard at about 35,000 lbs, the specimen continued to take more loading. At 40,000 lbs a loud pop occurred and the load dropped off to $25,000 \mathrm{lbs}$ just as in the control specimen. A major difference between the reinforced specimen and the control specimen occurred next. The loading on the reinforced specimen continued to increase until it surpassed the point were the loud pop was heard for the control specimen. The specimen took more loading until in it reached 44,100 lbs. The same "load-stepping" behavior that occurred in the control specimen occurred next were the specimen would take load and then a pop would be heard and the load would drop off. This continued to take place until the load reached around 43,000 lbs where delamination of the GFRP plate started to occur. A tension failure occurred in the plate as shown in Figure 49. The specimen continued to take load until it completely failed at $35,000 \mathrm{lbs}$. 


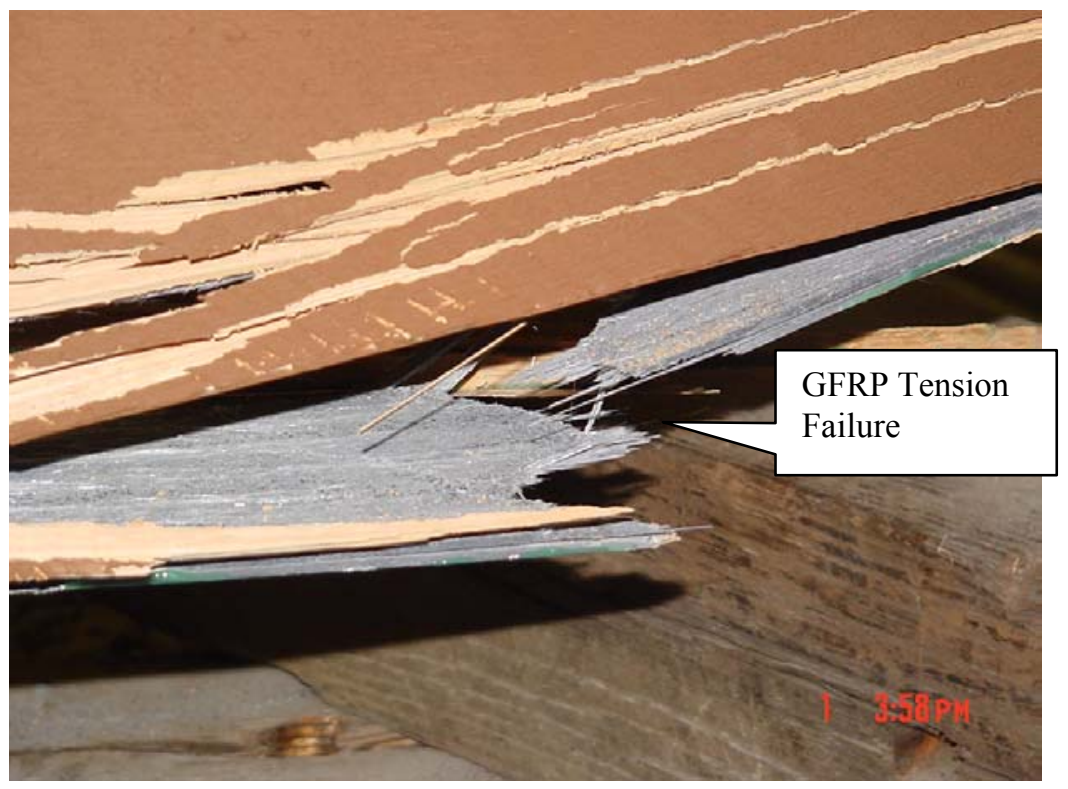

Figure 49. Failure Mode of LB-5

Figure 49 clearly shows the tension failure in the GFRP plate. Also, this specimen did not show any peeling of the GFRP at the ends. After carefully inspecting all the tested specimens it was found that LB-5 was the only specimen that did not have voids in the bonded surface. We believe that a near-perfect bond surface contributed to this failure mode of specimen LB-5.

\subsubsection{Discussion}

Based on the test results and a transformed section analysis (Figure 50), the ultimate strength or MOR of specimen LB-5 is found to be 4827 psi or an increase of $25 \%$ as compared to the unreinforced control specimen. The initial flexural rigidity (EI) of Specimen LB-5 is $823 \times 10^{6} \quad \mathrm{lb}^{-i n^{2}}$ or a $92 \%$ increase over the unreinforced wood specimen. The strain at failure at the extreme fibers of the midspan tension side was $4867 \mu$, A comparison of the load deflection diagram for specimens LB-1 and LB-5 clearly shows the improvement in flexural rigidity, Figure 51. 


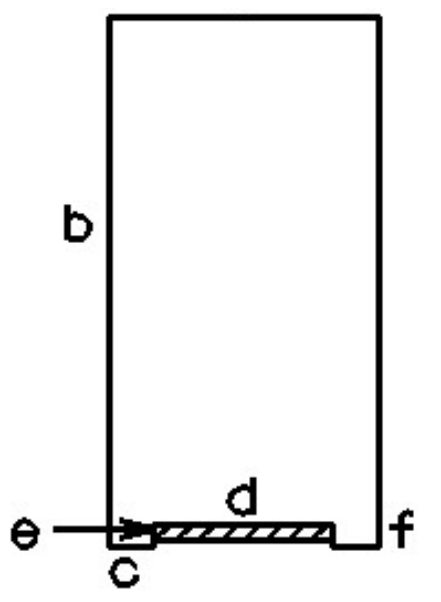

\begin{tabular}{|c|c|}
\hline$a$ & $6^{\prime \prime}$ \\
\hline$b$ & $11^{3 \prime} 4^{\prime \prime}$ \\
\hline$c$ & $1^{\prime \prime}$ \\
\hline$d$ & $4^{\prime \prime}$ \\
\hline$e$ & $3 / 8^{\prime \prime}$ \\
\hline$f$ & $1 / 2^{\prime \prime}$ \\
\hline$g$ & $7.12^{\prime \prime}$ \\
\hline
\end{tabular}

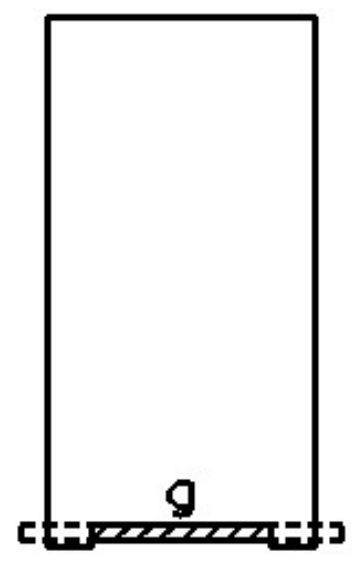

$$
\begin{aligned}
& n=E_{\text {rpp }} / E_{\text {mao }} \\
& n=1.78 \\
& g=n \times 4 "=7.12^{\prime \prime}
\end{aligned}
$$

Figure 50. Transformed Section for LB-5

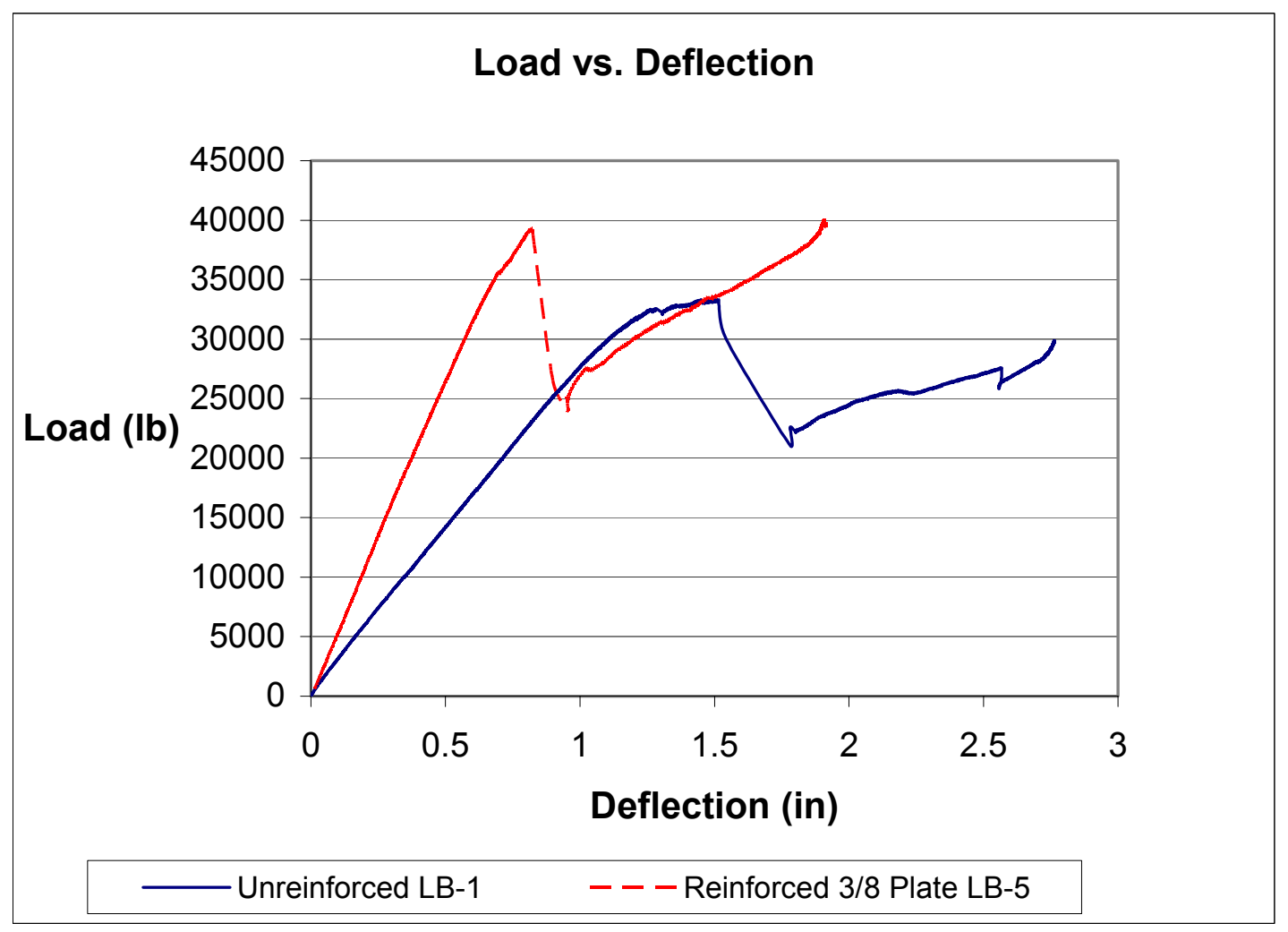

Figure 51. Load vs. Deflection Between Reinforced and Unreinforced Beams 


\subsubsection{Prediction of Flexural Rigidity Using Rule of Mixtures}

Flexural rigidity (EI) was predicted using the rule of mixtures for specimen LB-5. This prediction assumes there is a perfect bond between the GFRP plate, adhesive and the wood. If there is not a perfect bond it will show in a larger percent difference between the $(\mathrm{EI})_{\exp }$ and the $(\mathrm{EI})_{\text {hybrid. }}$ An example of the calculation used to predict the flexural rigidity $(\mathrm{EI})$ using the rule of mixtures can be seen below:

$$
\begin{aligned}
& (\mathrm{EI})_{\mathrm{hybrid}}=(\mathrm{EI})_{\mathrm{wood}}+(\mathrm{EI})_{\mathrm{GFRP}} \\
& (\mathrm{EI})_{\text {hybrid }}=\mathrm{E}_{\mathrm{wood}}\left[\mathrm{I}_{\mathrm{wood}}+\left(\mathrm{n} \times \mathrm{I}_{\mathrm{GFRP}}\right)\right] \\
& \mathrm{E}_{\mathrm{wood}}=1.8 \times 10^{6} \mathrm{psi} \text { (determined from testing) } \\
& \mathrm{I}_{\mathrm{wood}}=\frac{b \times d^{3}}{12}=778 \mathrm{in}^{4} \\
& \mathrm{n}=\frac{E_{\text {GFRP }}}{E_{\text {wood }}}=1.78 \\
& \mathrm{I}_{\mathrm{GFRP}}=\frac{b \times d^{3}}{12}=0.0176 \mathrm{in}^{4} \\
& (\mathrm{EI})_{\mathrm{hybrid}}=1.8 \times 10^{6}[778+(1.78 \times 0.0176)] \\
& (E I)_{\text {hybrid }}=1400 \times 10^{6} \mathrm{lb}^{* \mathrm{in}^{2}} \\
& \% \text { Difference }=\frac{E I_{\text {hybrid }}-E I_{\text {exp }}}{E I_{\text {hybrid }}} \\
& \% \text { Difference }=\frac{1400-823}{1400}=41 \%
\end{aligned}
$$

The percent difference is significant; this is an indication that there was less than a perfect bond in LB-5 between the GFRP plate and the wood member. 


\subsubsection{Summary}

The experimental results of the full scale bending members are a further validation of earlier test on small-scale specimens. As in the small-scale specimens the use of GFRP/vinylester matrix composite with PLIOGRIP adhesive was used successfully to improve the strength and flexural rigidity of wooden members. Two types of failures were observed, horizontal shear failure in the wood and tension failure in the GFRP plate. All test specimens showed an increase in strength or flexural rigidity. Specimen LB-5 showed the most significant increase in both. This can be attributed to larger bond area than the other specimens. This specimen also displayed tension failure in the plate, not horizontal shear failure in either the wood or the GFRP plate peeling at the ends.

\subsection{Bending Specimens with Reinforcing Bars}

\subsubsection{Results}

Both specimens were tested to failure under four-point bending. The load vs. deflection, and load vs. strain behavior were similar to those of earlier tension test specimens' responses. No sounds or checking could be heard throughout the duration of the test. There was no yielding or increase in strain or deflection at constant loading, i.e. no ductility. The members did not immediately fail once the ultimate load was reached; they continued to deflect as the loading continued, but the member could not resist any more additional load, Figure 53. The ultimate mode of failure was bond failure between the PLIOGRIP and wood. The bond between the adhesive and GFRP was still intact, Figure 52. The a/d ratio for these tests was 3.2. This ratio should be above 5 if bending failure is desired and below 5 for shear. This ratio was irrelevant for these tests. The placement of the GFRP reinforcing bars in the specimens inhibited failure induced by horizontal shear failure. 


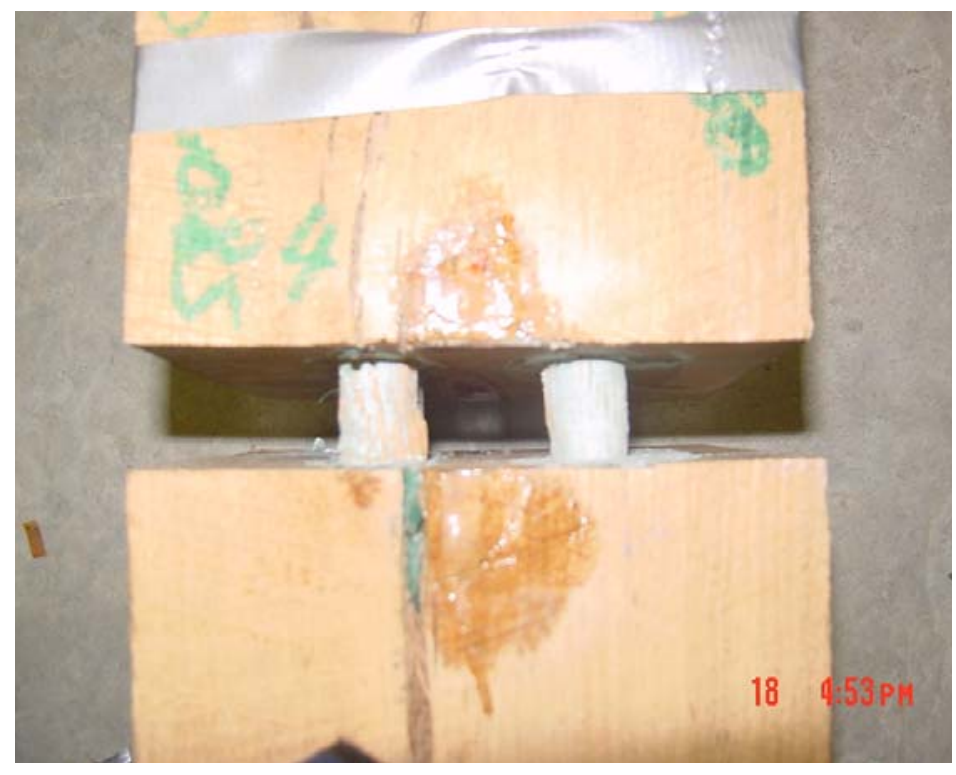

Figure 52. Specimen after Testing

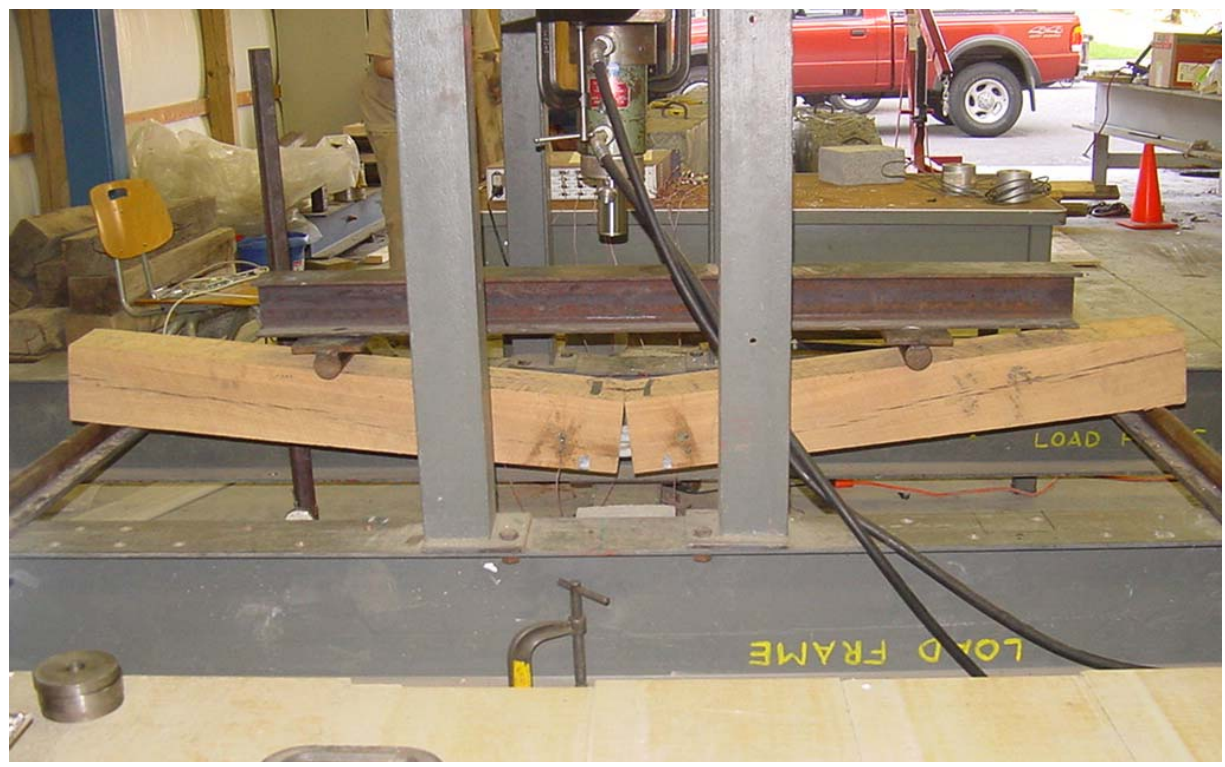

Figure 53. Specimen after Testing

The initial flexural rigidity (EI), MOR, and strain at failure for the test specimens can be seen in Tables 5 and 6. The ultimate load of BB-2 and BB-3 are respectively, $4559 \mathrm{lbs}$ and $6053 \mathrm{lbs}$. 
Table 6. Test Results

\begin{tabular}{|c|c|c|}
\hline Specimen & MOR (psi) & El (lb*in2) \\
\hline BB-2 & 2700 & $4.25 \mathrm{E}+07$ \\
\hline BB-3 & 3208 & $4.54 \mathrm{E}+07$ \\
\hline
\end{tabular}

Table 7. Strain at Failure

\begin{tabular}{|c|c|c|c|c|}
\hline Specimen & \multicolumn{4}{|c|}{ Gage\# Strain @ Failure } \\
\hline & 1 & 2 & 3 & 4 \\
\hline BB-2 & -358 & -1042 & -140 & -248 \\
\hline BB-3 & -3265 & -1966 & -118 & -98 \\
\hline
\end{tabular}

\subsubsection{Discussion}

As can be seen from Table 7, the strain values for gages 1 and 2 are negative; both gages were on the tension side of the specimen. Location of gages can be seen in Figure 29. This could be attributed to the wood pushing against the top of the reinforcing bar and the reinforcing bar pushing down onto the wood in the tension zone causing the strain reading to be negative. The strains at failure were not the maximum. The strains continued to increase even as the specimen could not take any more load. The strains increased to a point and then they went to zero as the sustained load on the specimens went to zero. The sustained load went to zero because of bond failure between the adhesive and wood. The strains also increased and decreased at different times during the test. The strains on the compression side were much higher and increased at a faster rate than those on the tension; but before the ultimate load was reached, the strains on the compression side decreased and the strains on the tension side increased and continued to increase until well after the specimen was unable to sustain any more load. 


\subsubsection{Prediction of Flexural Rigidity Using Rule of Mixtures}

Flexural rigidity (EI) was predicted using the rule of mixtures for specimens BB-2 and BB-3. This prediction assumes a perfect bond between the GFRP reinforcing bars, adhesive and the wood. Lack of a perfect bond will show in a larger percent difference between the $(\mathrm{EI})_{\text {actual }}$ and the $(\mathrm{EI})_{\text {hybrid. }}$ An example of the calculation used to predict flexural rigidity using the rule of mixtures can be seen below:

Calculation of (EI) actual for BB-2 (for 4-point loading, Figure 30):

$$
\begin{aligned}
& \Delta_{\max }=\frac{P a / 2}{24 E I}\left(3 L^{2}-4 a^{2}\right) \\
& E I=\frac{P a}{48 \Delta}\left(3 L^{2}-4 a^{2}\right) \\
& E I=\frac{18 P}{48 \Delta}\left[(3)(78)^{2}-(4)(18)^{2}\right)
\end{aligned}
$$

Simplifying,

$$
E I=\frac{P}{\Delta}(6358.5)
$$

The value of $\mathrm{P} / \Delta$ can be found from the slope and has a value of 6683.7. Using the value in the above equation yields

$$
E I=(6683.7)(6358.5)
$$

producing a value of $E I=4.25 \times 10^{7} \mathrm{lb} \cdot \mathrm{in}^{2}$

Calculation of $(\mathrm{EI})_{\text {hybrid: }}$

$$
(\mathrm{EI})_{\text {hybrid }}=(\mathrm{EI})_{\mathrm{wood}}+(\mathrm{EI})_{\mathrm{GFRP}}
$$




$$
\begin{aligned}
& (\mathrm{EI})_{\mathrm{hybrid}}=\mathrm{E}_{\mathrm{wood}}\left[\mathrm{I}_{\mathrm{wood}}+(\mathrm{n})\left(\mathrm{I}_{\mathrm{GFRP}}\right)\right] \\
& \mathrm{E}_{\mathrm{wood}}=1.8 \times 10^{6} \mathrm{psi} \text { (determined from testing) } \\
& \mathrm{I}_{\mathrm{wood}}=\frac{b \times d^{3}}{12}=83.5 \mathrm{in}^{4} \\
& \mathrm{n}=\frac{E_{G F R P}}{E_{\text {wood }}}=3.11 \\
& \mathrm{I}_{\mathrm{GFRP}}=\frac{\pi \times d^{4}}{4} \times 2=0.157 \text { in }{ }^{4} \\
& (\mathrm{EI})_{\mathrm{hybrid}}=1.8 \times 10^{6}[83.5+(3.11 \times 0.157)] \\
& (\mathrm{EI})_{\text {hybrid }}=151 \times 10^{6} 1 \mathrm{~b}^{*} \mathrm{in}^{2} \\
& \% \text { Difference }(\mathrm{BB}-2)=\frac{E I_{\text {hybrid }}-E I_{\text {actual }}}{E I_{\text {hybrid }}} \\
& \% \text { Difference }(\mathrm{BB}-2)=\frac{151-42.5}{151}=72 \%
\end{aligned}
$$

$(\mathrm{EI})_{\text {hybrid }}$ for BB-3 was calculated in the same manner as BB-2.

$$
\begin{gathered}
(\mathrm{EI})_{\text {hybrid }}=150.3 \times 10^{6} \mathrm{lb}^{*} \mathrm{in}^{2} \\
\% \text { Difference (BB-3) }=\frac{E I_{\text {hybrid }}-E I_{\text {actual }}}{E I_{\text {hybrid }}} \\
\% \text { Difference }(\mathrm{BB}-3)=\frac{150.3-45.4}{150.3}=72 \%
\end{gathered}
$$

The percent difference is significant for both of these specimens; this is another indication that there was a less than perfect bond between the GFRP reinforcing bars, adhesive and the wood member. 
The last measurement that was taken was the joint opening. Measurements were taken on the top of the specimen. Measurements were taken every $500 \mathrm{lbs}$, the same as deflection measurements. The two specimens had about the same separation, with BB-3 having the least amount. This is to be expected since BB-3 had double the amount of reinforcing bars and adhesive. Even though BB-3 had double the reinforcing material, BB-2 did not have double the joint opening distance as that of BB-3. BB-2 only separated about $7 \%$ more than that of BB-3. This is the same phenomenon that was displayed in earlier tension specimens and it was determined from these earlier tension tests that the development length of the sand coated GFRP reinforcing bars inserted into the end of a member could be reached in relatively short length.

The joint opening is shown in Figure 54. The trend of joint opening for both specimens displayed a very similar separation vs. load. The drastic increases in joint opening are due to bond failure between the wood and adhesive.

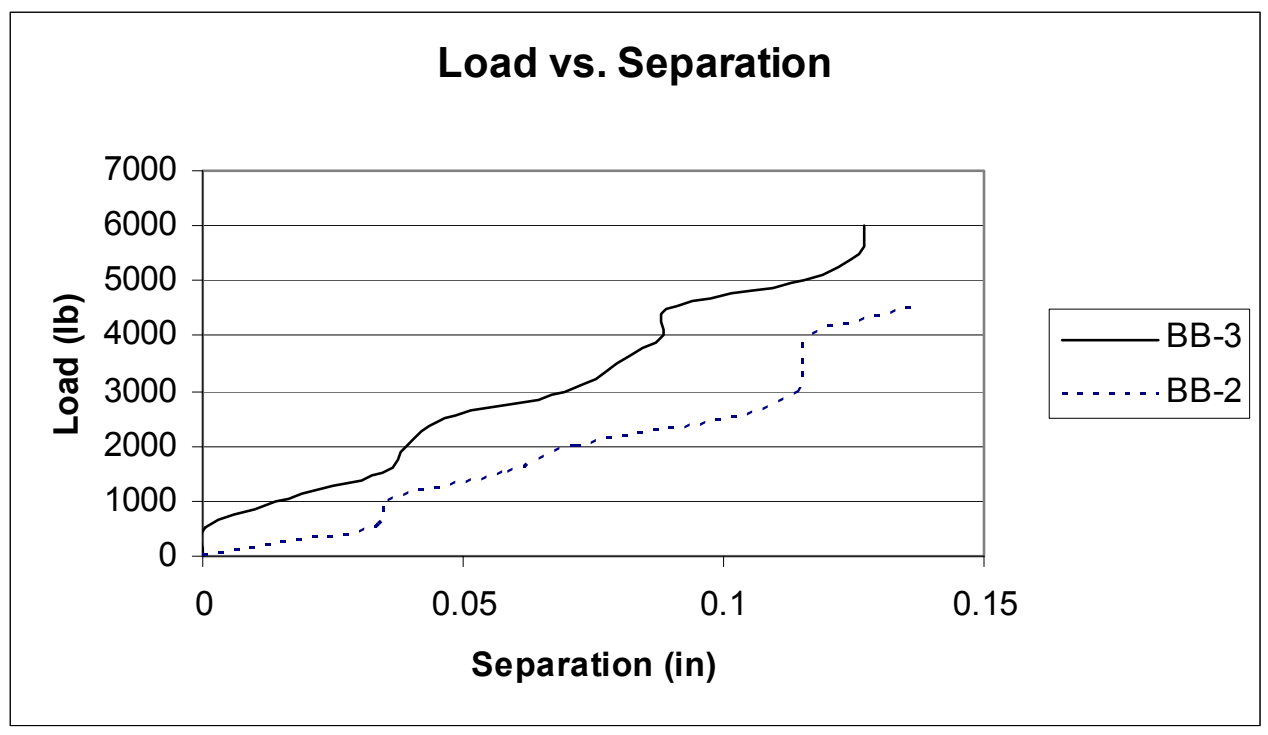

Figure 54. Load vs. Separation

\subsubsection{Summary}

The experimental results of these bending specimens show that this method of strengthening is not suited for bending members. This method would be very useful in 
compression members in a truss. The bars would hold the member in place and keep it from buckling. The constructability is another issue with this method. It was very difficult to drill the holes in both sides in a manner that allowed for perfect alignment. Perfect alignment could not be reached in laboratory setting, but is impossible to achieve in the field.

Figure 55 shows a detail of how a similar repair technique was used on the Barrackville covered bridge, in Barrackville, W.Va.. FRP bars were used as a joint in an arch; to date this repair is performing very well.

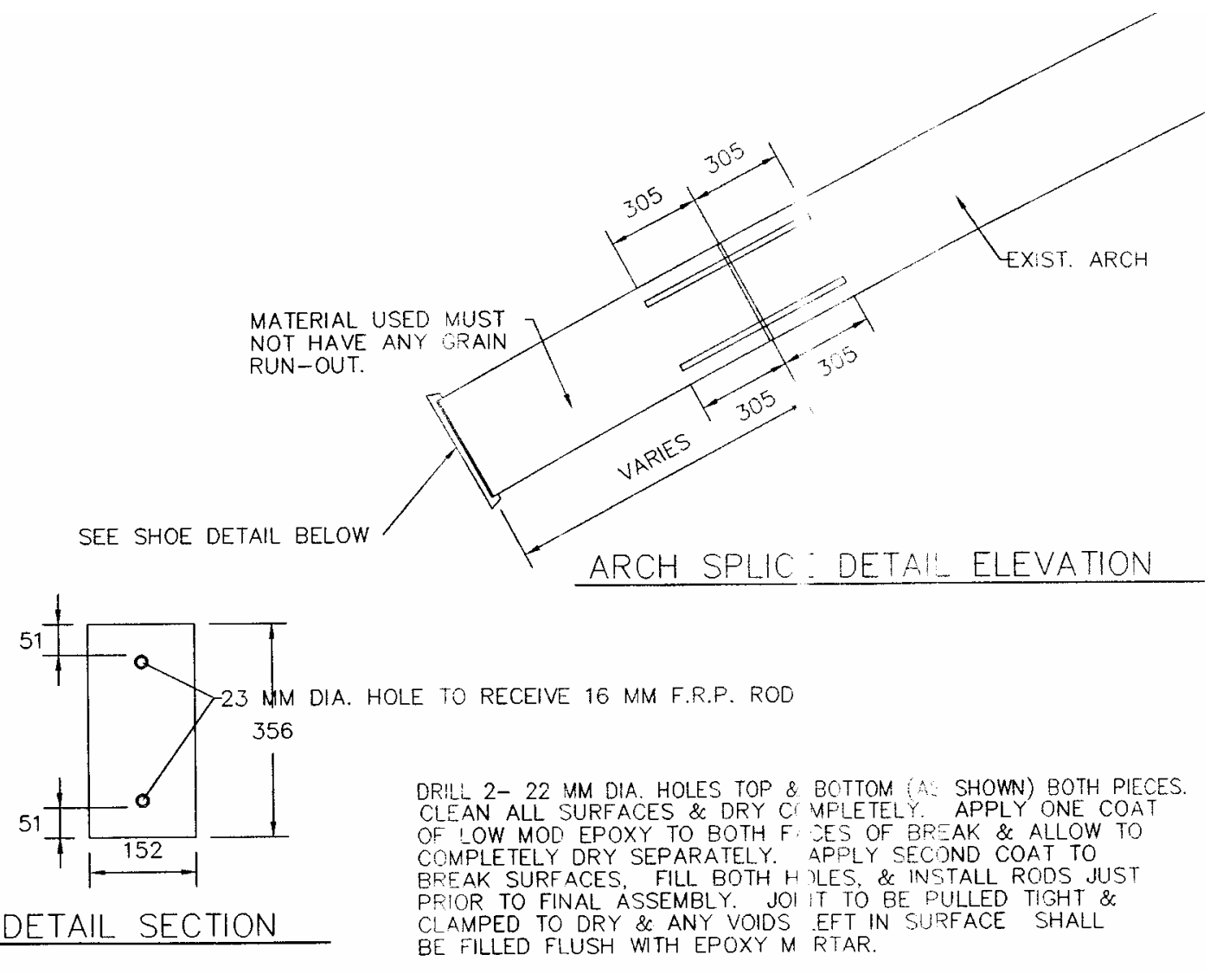

Figure 55. Arch Splice Repair Detail 


\subsection{Bending Tests (6" x 8") with GFRP Plates}

\subsubsection{Results}

The unreinforced control specimen (LB-6) was tested to failure under four-point bending to determine the ultimate moment capacity, flexural rigidity, and to identify the failure mode of the unreinforced member. As the load increased, a checking sound could be heard and a loud popping noise was heard at 11,000 lbs. Horizontal checking first appeared around 13,000 lbs. There was continuous checking until the load reached $18,000 \mathrm{lbs}$. Once the load reached 18,853 lbs another loud pop was heard and the load then dropped down to $18,500 \mathrm{lbs}$. This down and up behavior continued for several more cycles and the load never went back above 18,500 lbs, Figure 56. The shear span to depth $(\mathrm{a} / \mathrm{h})$ ratio for this member was 5 , which is adequate for the evaluation of flexural properties. Figure 57 shows the load vs. deflection plot for this test. The load data in this plot do not exceed 16,000 lbs because the LVDT malfunctioned towards the end of the test. The mode of failure was a combination of horizontal shear failure and bending failure as seen in Figure 58. The initial flexural rigidity (EI) of the control specimen was

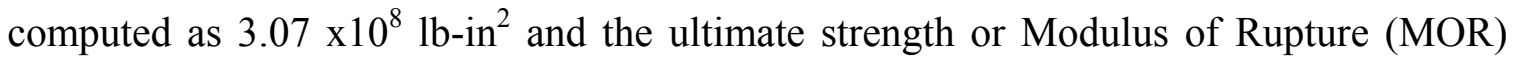
was computed as 5892 psi. The strain at failure of the unreinforced control specimen measured at the extreme fibers of the midspan tension side was $5558 \mu$. The maximum load the member sustained was $18,853 \mathrm{lbs}$. 


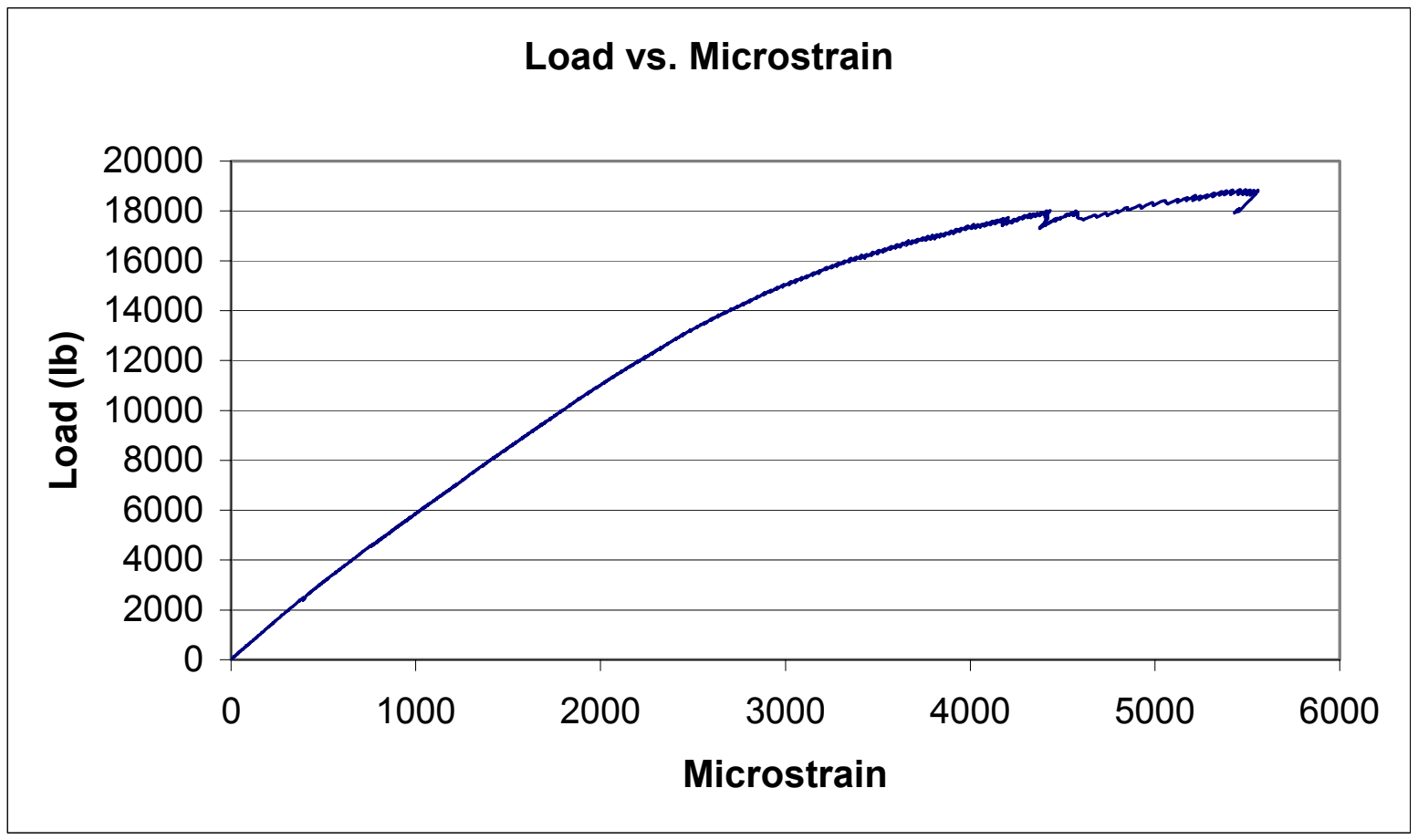

Figure 56. Load vs. Strain for the Unreinforced Specimen

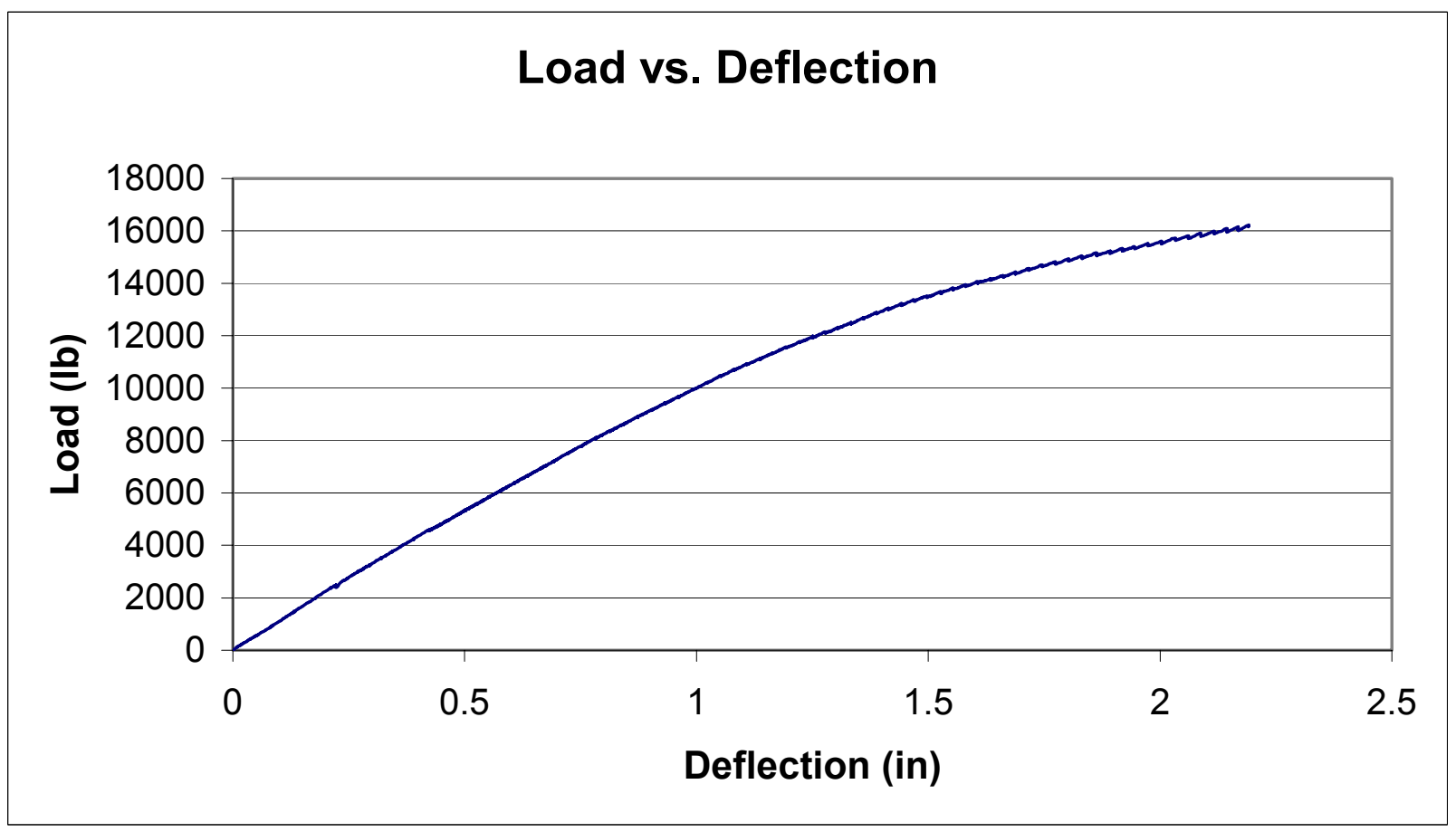

Figure 57. Load vs. Deflection for Unreinforced Specimen 


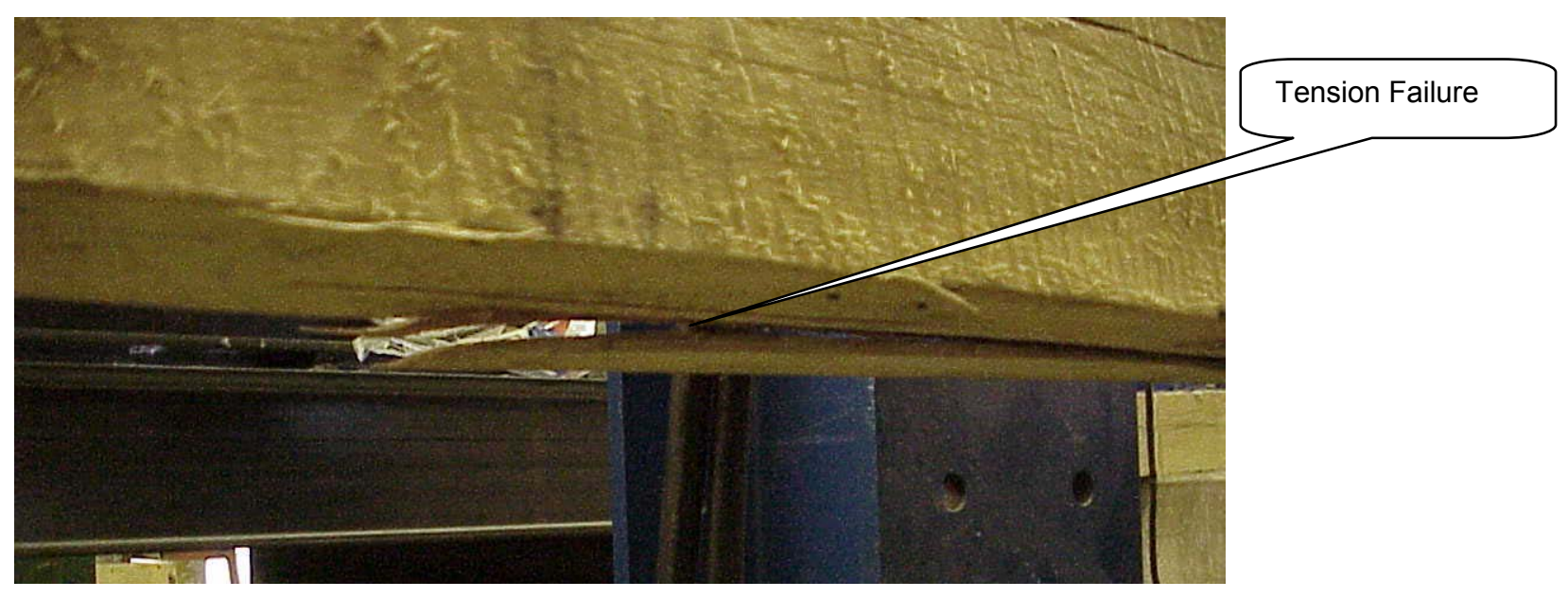

Figure 58. Failure Mode of Unreinforced Beam

The second specimen tested was Specimen LB-8, which was tested in the same manner as LB-6. Checking started at 12,000 lbs. At 13,000 lbs, a loud popping noise was heard and dust could be seen at the same time coming from the bond line. A loud noise was heard at 14,000 $\mathrm{lbs}$ and another loud noise was heard at 14,500 lbs. The maximum deflection of the LVDT (i.e., 3 inches) was reached at 14,800 lbs. The edges of the member on either side of the GFRP broke at 15,600 lbs and complete failure occurred at 16,000 lbs. This beam behaved more consistent with the unreinforced member than the reinforced one. This could be attributed to a less than perfect bond.

The primary mode of failure for LB-8 was dominated by horizontal shear failure of the wood and failure in the bond line causing a peeling action of the GFRP plate. The full capacity of the plate was not reached in these members. The failure of the wood member in horizontal shear and the failure of the bond line occurred before the capacity of the plate could be full utilized. LB-8 results demonstrate the necessity of full bond, Figure 61. A short work time adhesive (i.e., 20 minutes as suggested by the manufacturer, Ashland Chemicals) was used. This short work time adhesive resulted in partial bond between the plate and wood due to the fact that the adhesive started to set up before the plate could be placed in the member. As seen in Figure 59 there are no signs 
of failure in the GFRP plate in this specimen. Also, shown is Figure 60 is the separation of the plate due to partial bond in the GFRP/wood.

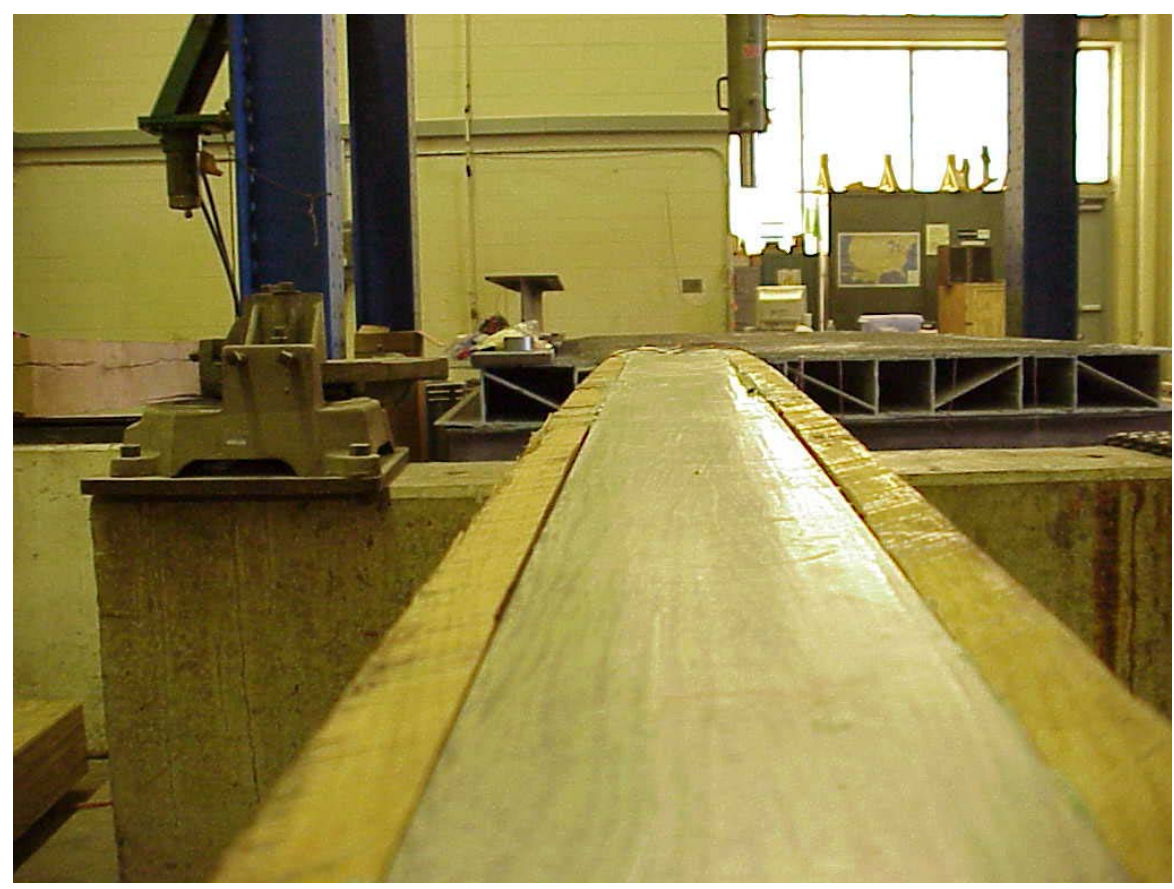

Figure 59. LB-8 after Testing

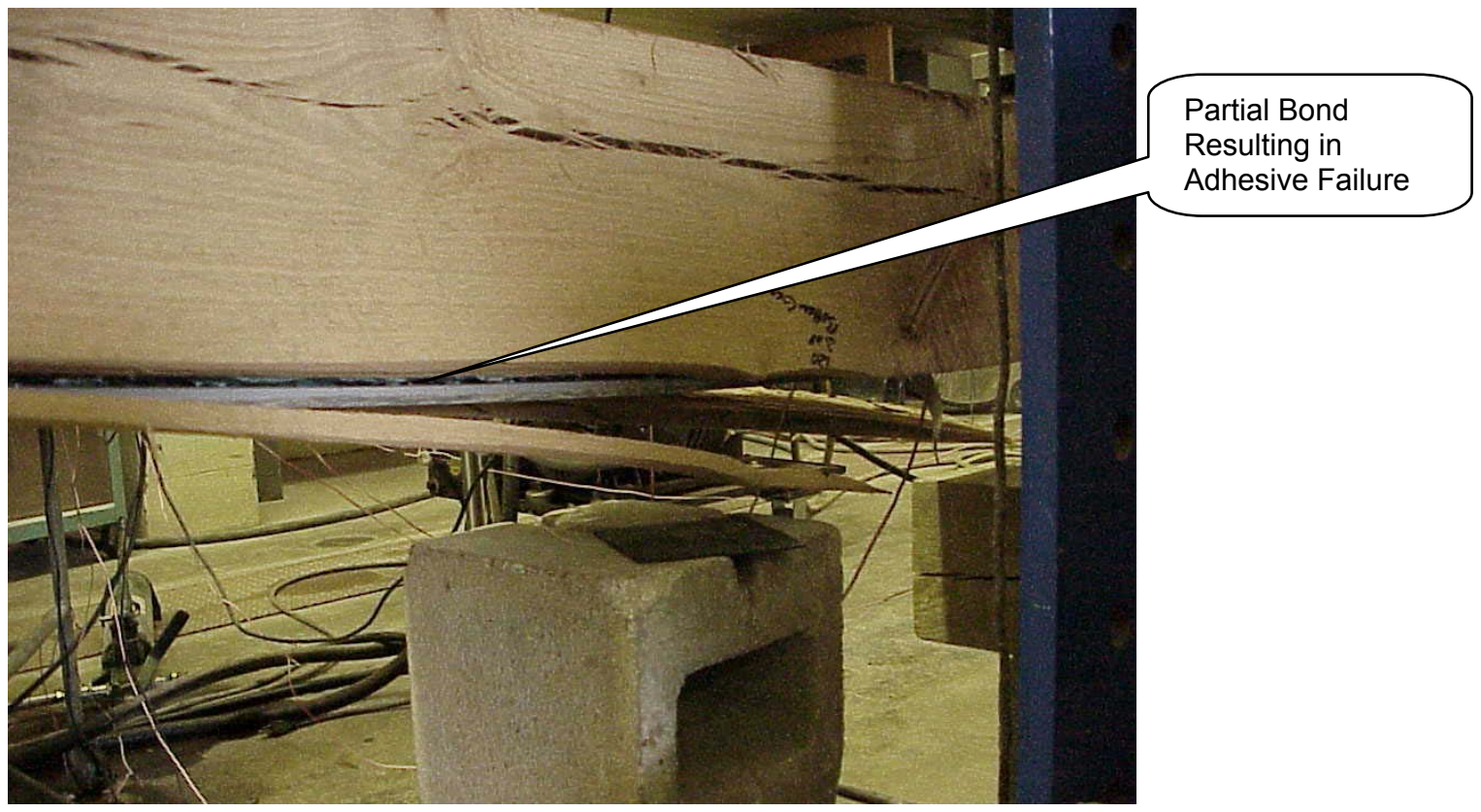

Figure 60. Partial Bond in LB-8 


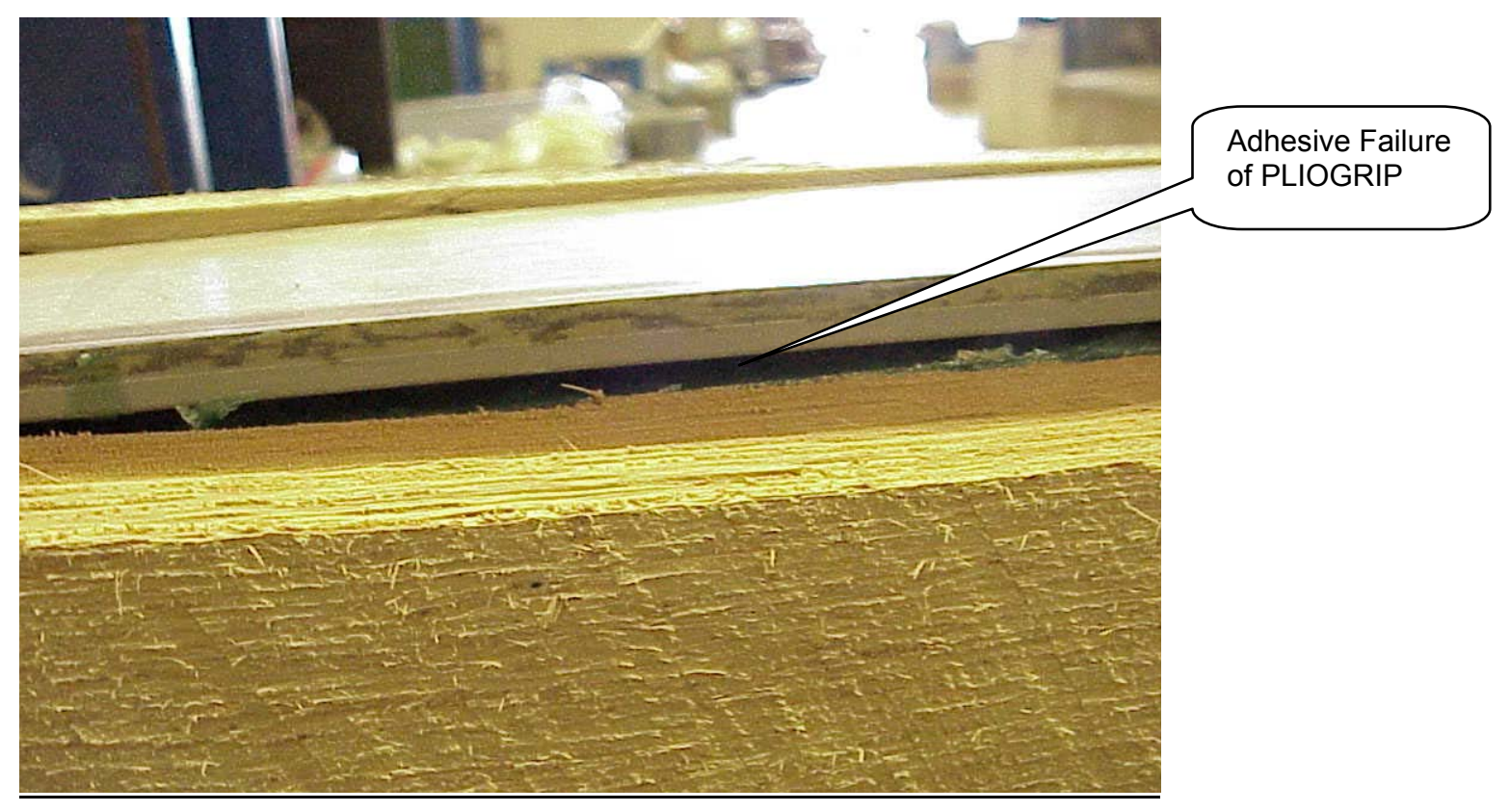

Figure 61. Bond Failure of LB-8

The third specimen tested was Specimen LB-7. This specimen was tested to failure under four-point bending on the same test setup as the other two specimens. There was no checking that could be heard at the onset of loading. As the load was increased it was noticed that the load transfer between the wood member and the GFRP plate was adequate by monitoring the strain values from the gages placed along the length of the member. Nonlinearity between the strain values on the compression and tension sides of the member was observed at approximately 15,000 lbs. At 18,000 lbs the test member started to check and a loud popping noise was heard at 18,800 lbs, the specimen continued to take more loading. The 1-inch wide strips (or notches) on either side of the GFRP plate failed at 20,000 lbs at midspan, Figure 62. Also, at this load level, a horizontal crack could be seen propagating from the center. The load then went up to $22,000 \mathrm{lbs}$ and dropped off to 20,000 lbs. At this time, the loading jack did not have enough travel and the member failed under creep. This specimen also demonstrated the load stepping behavior as seen in the other two specimens. The load stepping behavior can be seen from the load/strain plot shown in Figure 63. The key difference is that once 
the edge notches on this member failed, the load continued to increase. The strain at failure at the extreme fibers of the midspan tension side was $7653 \mu$,.

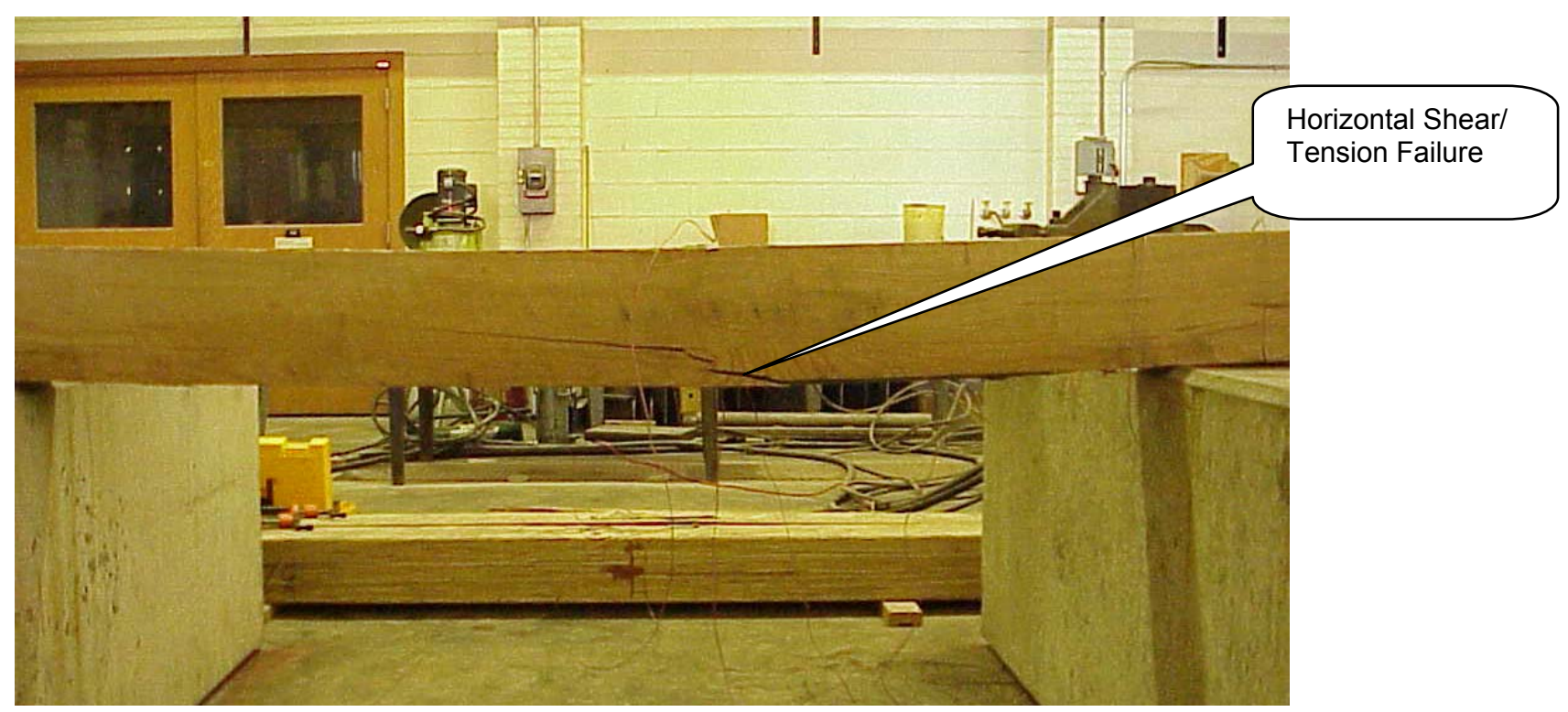

Figure 62. Failure Mode of LB-7, Tension Side Down

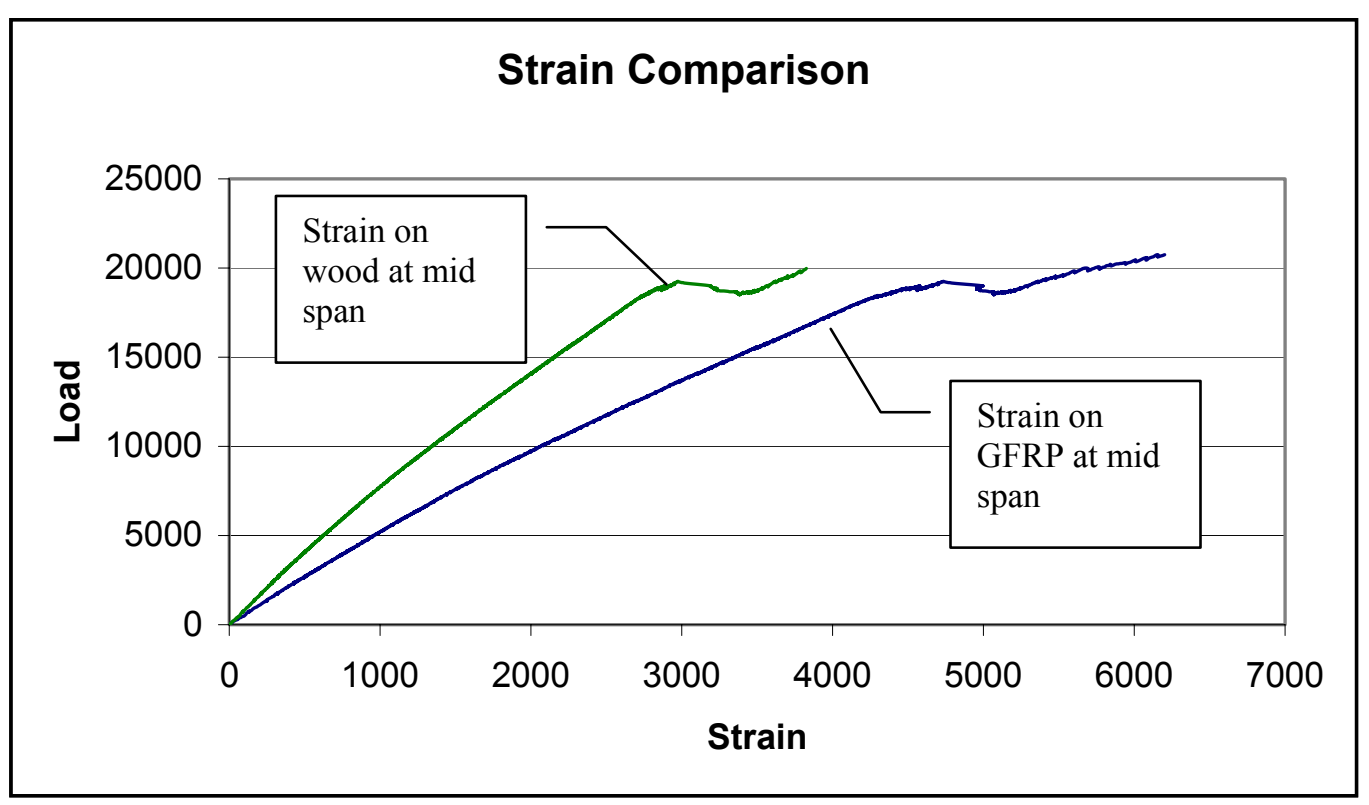

Figure 63. Load vs. Strain Diagram for LB-7 


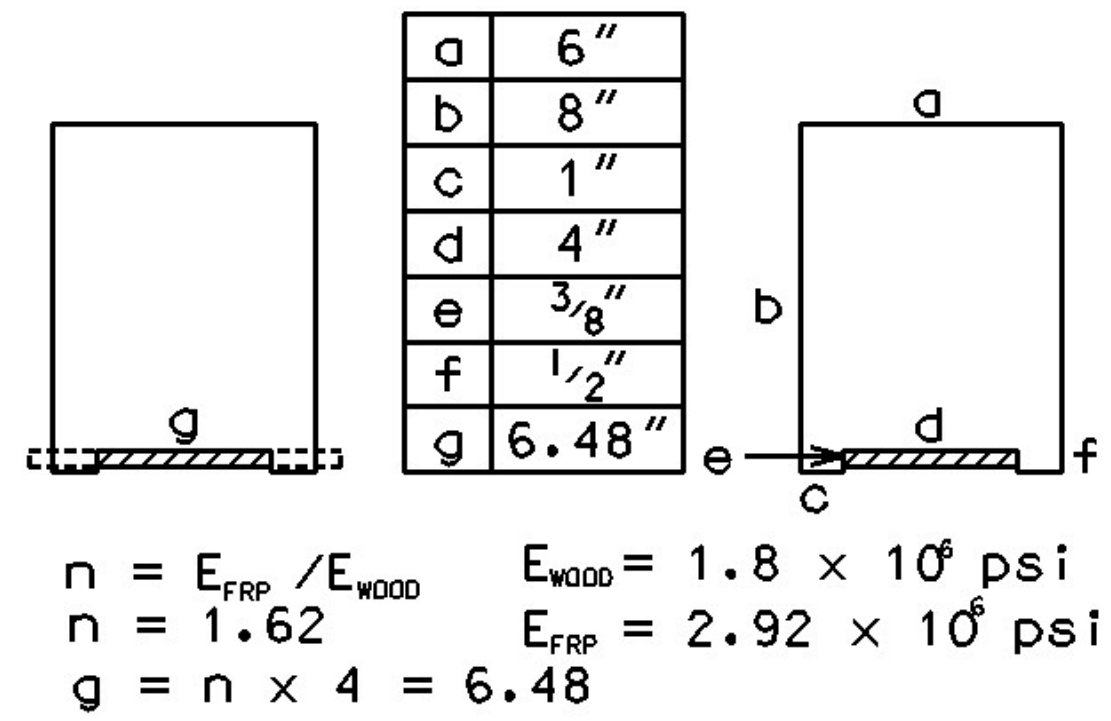

Figure 64. Transformed Section for LB-7

The transformed section for LB-7 is shown in Figure 64 and the following calculation is an example of how the neutral axis and transformed moment of inertia was determined for LB-7:

$\mathrm{n}$ is calculated from the modulus of elasticity values for the wood and FRP and applied to the $\mathrm{x}$ dimension of GFRP plate, the centroid can then be found from the mechanics of materials equation.

$$
\begin{gathered}
\bar{y}=\frac{\Sigma y_{i} A_{i}}{\Sigma A_{i}} \\
\bar{y}=\frac{((6 \times 7.5) \times 4.25)+((1 \times 0.5) \times 2)+((6.48 \times 0.375) \times 0.3125)}{48.43} \\
\bar{y}=3.97 \mathrm{in} \uparrow
\end{gathered}
$$

The transformed moment of inertia ( $\left.\mathrm{I}_{\mathrm{XT}}\right)$ with respect to the $\mathrm{x}$-axis can be calculated using parallel axis theorem. $\mathrm{I}_{\mathrm{XT}}$ should be larger than the $\mathrm{I}_{\mathrm{X}}$ for unreinforced section. So the $\mathrm{I}_{\mathrm{XT}}$ is compared to the $\mathrm{I}_{\mathrm{X}}$ of the unreinforced as a check to ensure that the transformed value is larger. 


$$
\begin{aligned}
\mathrm{I}_{\mathrm{XT}}=\frac{6 \times 7.5^{3}}{12}+\left[6 \times 7.5 \times 0.28^{2}\right]+ & \\
& \frac{1 \times 0.5^{3}}{12}+\left[0.5 \times 1.0 \times 3.72^{2}\right]+ \\
& \frac{1 \times 0.5^{3}}{12}+\left[0.5 \times 1.0 \times 3.72^{2}\right]+ \\
& \frac{6.48 \times 0.375^{3}}{12}+\left[6.48 \times 0.375 \times 3.6575^{2}\right] \\
\mathrm{I}_{\mathrm{XT}}= & 260.86 \mathrm{in}^{4}
\end{aligned}
$$

The moment of inertia of the unreinforced section is:

$$
\begin{aligned}
& \mathrm{I}_{\mathrm{X}}=\frac{6 \times 8^{3}}{12} \\
& \mathrm{I}_{\mathrm{X}}=256 \mathrm{in}^{4} \\
& \mathrm{I}_{\mathrm{XT}}>\mathrm{I}_{\mathrm{X}} \quad \therefore \text { o.k. }
\end{aligned}
$$

\subsubsection{Discussion}

\begin{tabular}{|c|c|c|c|c|}
\hline Specimen & EI $\left(l b-i^{2}\right)$ & $\%$ Difference & $\operatorname{MOR}\left(\mathrm{lb} / \mathrm{in}^{2}\right)$ & $\%$ Difference \\
\hline LB-6 (control) & $3.07 \mathrm{E}+08$ & $\mathrm{~N} / \mathrm{A}$ & 5891.72 & $\mathrm{~N} / \mathrm{A}$ \\
\hline LB-7 & $3.70 \mathrm{E}+08$ & 20.4 & 6600.70 & 12.03 \\
\hline LB-8 (premature failure) & $1.76 \mathrm{E}+08$ & -42.7 & 4534.25 & -23.04 \\
\hline
\end{tabular}

As stated earlier, only one size of GFRP plate was used as reinforcement for both reinforced specimens. Table 8 shows the MOR and EI values for all of the specimens that were tested as compared to the control specimen. As presented in Table 8, the flexural rigidity and strength improvement between the reinforced (LB-7) and unreinforced specimens (LB-6) are 20.4\% and 12.03\%, respectively. Specimen LB-8 failed prematurely due to partial bond as described earlier.

Table 8. Test Results 


\subsection{Theoretical Moment Capacity}

In general, the bending behavior and moment capacity for a wooden beam reinforced with GFRP material can be analyzed using a basic strength of materials approach. A transformed section analysis is used to locate the neutral axis (NA) of the wood/GFRP section. A typical strain compatibility diagram and corresponding forces in tension and compression for moment capacity calculations are shown in Figure 65. Figure 64 shows the transformed section that was used in the analysis of this test specimen. The values for modulus of elasticity for the GFRP plate and the wood member were obtained from test data.

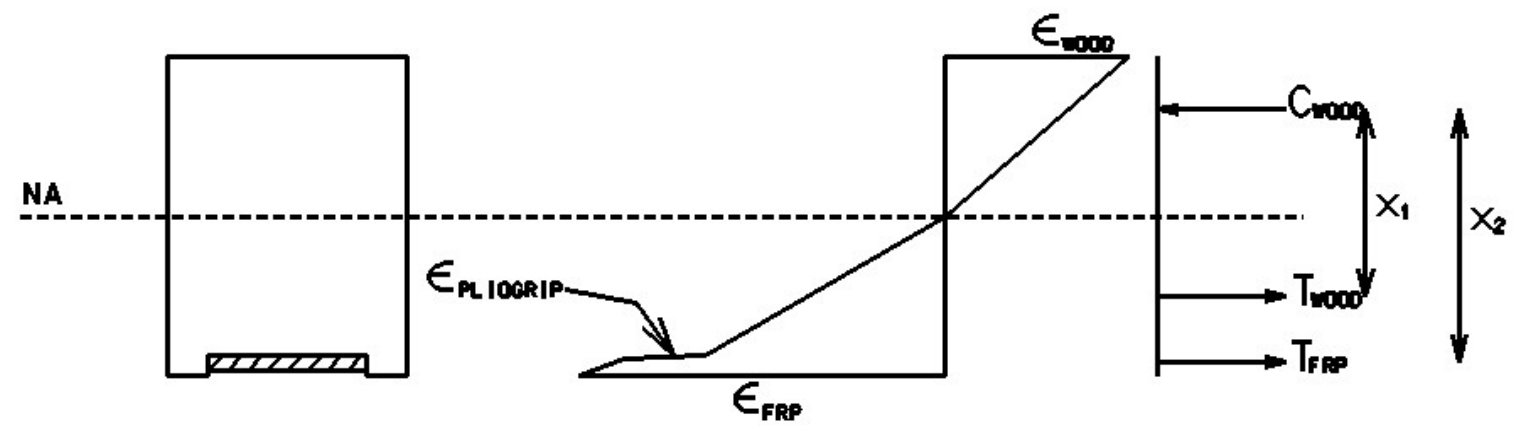

Figure 65. Strain Compatibility and Internal Moment Equilibrium

The theoretical moment capacity $\left(\mathrm{M}_{\text {Theo }}\right)$ computation as described below is compared to the experimental moment capacity $\left(\mathrm{M}_{\mathrm{Exp}}\right)$ to determine if a theoretical moment capacity equation can be developed for design purposes:

\section{Variables}

$\mathrm{T}_{\mathrm{W}}=$ Tension Force of Wood

$\varepsilon_{\mathrm{WT}}=$ Strain in Wood above GFRP (Midspan)

$\mathrm{E}_{\mathrm{W}}=$ MOE of Wood

$\mathrm{A}_{\mathrm{WT}}=$ Area of Wood in Tension 
$\mathrm{T}_{\mathrm{FRP}}=$ Tension Force of GFRP

$\varepsilon_{\mathrm{FRPT}}=$ Strain at Extreme Tension Fiber of GFRP (Midspan)

$\mathrm{E}_{\mathrm{FRP}}=\mathrm{MOE}$ of GFRP

$\mathrm{A}_{\mathrm{FRP}}=$ Area of GFRP Plate

Find Tension Forces

$$
\begin{aligned}
& \mathrm{T}_{\mathrm{W}}=\left(\varepsilon_{\mathrm{WT}} \times \mathrm{E}_{\mathrm{W}}\right) \times \mathrm{A}_{\mathrm{WT}} \\
& \mathrm{T}_{\mathrm{FRP}}=\left(\varepsilon_{\mathrm{FRPT}} \times \mathrm{E}_{\mathrm{FRP}}\right) \times \mathrm{A}_{\mathrm{FRP}}
\end{aligned}
$$

Internal Moment Equilibrium, Figure 65

$$
\mathrm{M}=\left(\mathrm{T}_{\mathrm{W}} \times \mathrm{X}_{1}\right)+\left(\mathrm{T}_{\mathrm{FRP}} \times \mathrm{X}_{2}\right)
$$

Compare to Actual Moment

$$
M=(P / 2) \times a
$$

Below is an example of the theoretical moment capacity calculation using strain compatibility and internal moment equilibrium computed at $7000 \mathrm{lbs}$ :

\section{Moment Capacity at $7000 \mathrm{lb}$}

$\mathrm{a}=40^{\prime \prime}$

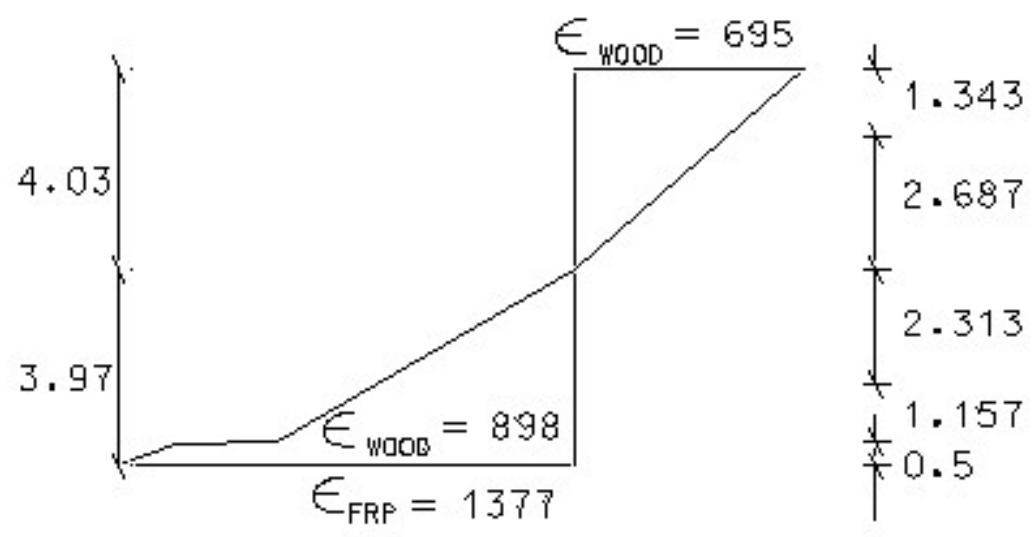


$\mathrm{T}_{\mathrm{W}}=(898 \times 1.8) \times 1 / 2(3.47 \times 6)=16,827 \mathrm{lb}$

$\mathrm{T}_{\mathrm{FRP}}=(1377 \times 2.92) \times(0.5 \times 4)=8,042 \mathrm{lb}$

$\mathrm{M}_{\text {Theo }}=\left(\mathrm{T}_{\mathrm{W}} \times 5.0\right)+\left(\mathrm{T}_{\mathrm{FRP}} \times 6.157\right)=134$ in-kips

$\mathrm{M}_{\mathrm{Exp}}=(\mathrm{P} / 2) \times \mathrm{a}=(7000 / 2) \times 40=140$ in-kips

For a 7,000 lbs load level, the percent difference between $\mathrm{M}_{\text {Theo }} / \mathrm{M}_{\text {Exp }}$ was found to be approximately $4 \%$. For most of the linear range the percent difference is less than $10 \%$. However, between $15,000 \mathrm{lbs}$ to $18,000 \mathrm{lbs}$ the percent difference converges rapidly to less than $1 \%$. Figure 66 shows how the moment capacities vary with load level. As can be seen from Figure 66, the moment capacity values are almost linear up to the point where failure starts to occur, and then the values start to diverge away from each other.

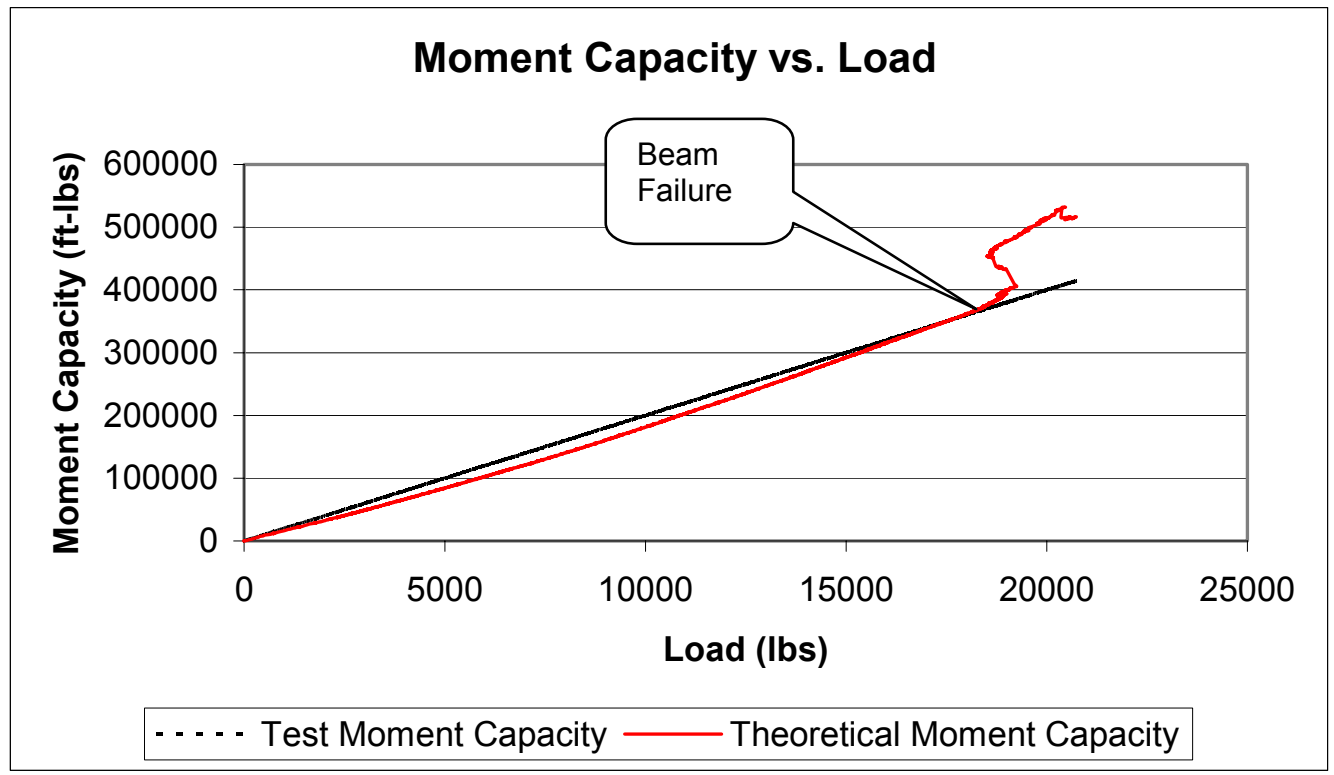

Figure 66. Load vs. $\mathrm{M}_{\text {Theo }} / \mathrm{M}_{\mathrm{Exp}}$ 


\subsection{Bending Member Design Example}

The theoretical moment capacity developed above needs to be taken to the next level. This is the level of the design engineer. Equations need to be presented in a manner that is consistent with existing timber and FRP design equations and standards. The first step in developing a design methodology is to develop a design that can be compared with test data for accuracy. Section 4.8.1 presents a design developed for comparison and Section 4.8.2 is the same design problem only utilizing appropriate reduction factors.

\subsubsection{Bending Member Design without Factors}

This problem will use the same beam size and GFRP type and placement as that used for LB-7 in order to have an accurate comparison to test data. This example is only to see if the approach can be used for a design. A more detailed example will be presented in Section 4.8.2.

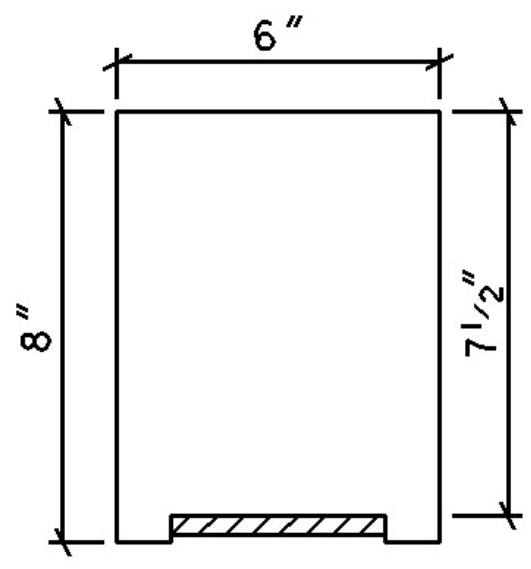

Figure 67. Bending Member Design Example

3/8" x 4" GFRP plate

Select Structural White Oak Floor Beam

$\mathrm{E}=2.92 \times 10^{6} \mathrm{psi}$

For the purposes of this example, neglect the $1 / 2$ " $\mathrm{x} 1$ " strips on either side of the GFRP plate. 
Determine the allowable bending stress of the timber using NDS 1997.

$$
\begin{array}{ll}
\mathrm{F}_{\mathrm{b}}=1200 \mathrm{psi} & \begin{array}{l}
\text { Select Structural } \\
\mathrm{C}_{\mathrm{D}}=1.0
\end{array} \\
\mathrm{C}_{\mathrm{M}}=\mathrm{NA} & \text { Occupancy Live Load } \\
\mathrm{C}_{\mathrm{t}}=0.8 & 100^{\circ} \mathrm{F}<\mathrm{T} \leq 125^{\circ} \mathrm{F} \\
\mathrm{C}_{\mathrm{L}}=\mathrm{NA} & \begin{array}{l}
\text { Assume Supported } \\
\mathrm{d}<12^{\prime}
\end{array} \\
\mathrm{C}_{\mathrm{F}}=1.0 & \\
\mathrm{~F}_{\mathrm{b}}{ }_{\mathrm{b}}=\mathrm{F}_{\mathrm{b}}\left(\mathrm{C}_{\mathrm{D}}\right)\left(\mathrm{C}_{\mathrm{M}}\right)\left(\mathrm{C}_{\mathrm{t}}\right)\left(\mathrm{C}_{\mathrm{L}}\right)\left(\mathrm{C}_{\mathrm{F}}\right) \\
\mathrm{F}^{\prime}{ }_{\mathrm{b}}=1200 \times 1.0 \times 0.8 \times 1.0 \\
\\
\quad=960 \mathrm{psi} &
\end{array}
$$

Determine capacity of timber beam with GFRP plate.

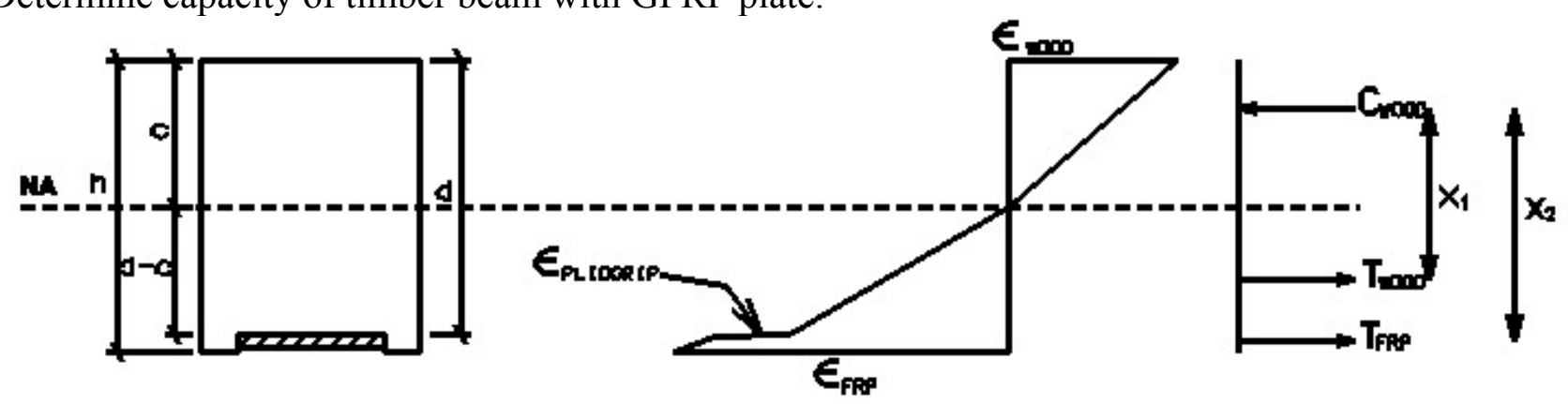

Figure 68. Strain Compatibility and Internal Moment Equilibrium

NA determined using transformed section in section 4.6

$$
\begin{aligned}
& \mathrm{h}-\mathrm{d}=\mathrm{a} \\
& \mathrm{d}-\mathrm{c}=\mathrm{b} \\
& \mathrm{x}_{1}=\mathrm{d}-1 / 3 \mathrm{c}-1 / 3 \mathrm{~b} \\
& \mathrm{x}_{2}=\mathrm{h}-1 / 3 \mathrm{c}-1 / 2 \mathrm{a} \\
& \mathrm{x}_{1}=7.5-1 / 3(4.03)-1 / 3(3.47) \\
& \quad=5.0 ” \\
& \mathrm{x}_{2}=8.0-1 / 3(4.03)-1 / 2(0.5) \\
& =6.41
\end{aligned}
$$

Determine Moment Capacity

$$
\mathrm{M}=\left(\mathrm{F}^{\prime}{ }_{\mathrm{b}} / 2\right)\left(\mathrm{A}_{\mathrm{w}}\right)\left(\mathrm{x}_{1}\right)+\phi\left(\mathrm{A}_{\mathrm{f}}\right)\left(\mathrm{F}_{\mathrm{f}}\right)\left(\mathrm{x}_{2}\right)
$$




$$
\begin{aligned}
\mathrm{A}_{\mathrm{w}} & =\text { Area of wood in tension block } \\
& =3.47 \times 6 \\
& =20.82 \mathrm{in}^{2} \\
\mathrm{~A}_{\mathrm{f}} & =\text { Area of GFRP } \\
& =3 / 8 \times 4 \\
& =1.5 \mathrm{in}^{2} \\
\mathrm{~F}_{\mathrm{f}} & =\text { Stress in GFRP } \\
\varepsilon & \text { value to be used in comparison was obtained from test data at the load before failure } \\
& =\varepsilon \times \mathrm{E} \\
& =.035 \times 2.92 \times 10^{6} \\
& =102,200 \text { psi } \\
\Phi & =\text { Reduction factor to be used since GFRP plate will not be fully utilized } \\
& =0.5 \\
\mathrm{M} & =(960 / 2)(20.82)(5)+0.5(1.5)(02200)(6.41) \\
& =45.1 \mathrm{ft}-\mathrm{kips}
\end{aligned}
$$

Compare to actual max moment

Beam failed at 22 kips

$$
\begin{aligned}
\mathrm{M} & =\mathrm{P} / 2 \times \mathrm{a} \\
& =22 / 2 \times 40 / 12 \\
& =37 \mathrm{ft}-\mathrm{kips}
\end{aligned}
$$

$$
\begin{aligned}
\% \text { Difference } & =\frac{45.1-37}{45.1} \\
& =17.9 \%
\end{aligned}
$$

This is a reasonable \% difference, so it is valid to use this approach in the following design using reduction factors. This approach is not as accurate as the theoretical moment capacity developed in section 4.7. This is attributed to the compositeness of the beam. It is unrealistic to assume that $100 \%$ of the timber beam and $100 \%$ of the GFRP plate's capacities are going to be utilized. They both contribute to the overall capacity, but after limited testing it is impossible to determine the exact percentage of each contribution. 


\subsubsection{Bending Member Design with Factors}

A floor beam in a covered bridge was determined by the use of NDT to be inadequate for the loading required. The original member is a $6 " \mathrm{x} 8$ " sawn white oak cant that has had no significant section loss. Using a moisture meter it was determined that the member is at $16 \%$ moisture content. After a detailed structural analysis it was determined that the beam needed to resist a bending moment of $15 \mathrm{ft}-\mathrm{kips}$.

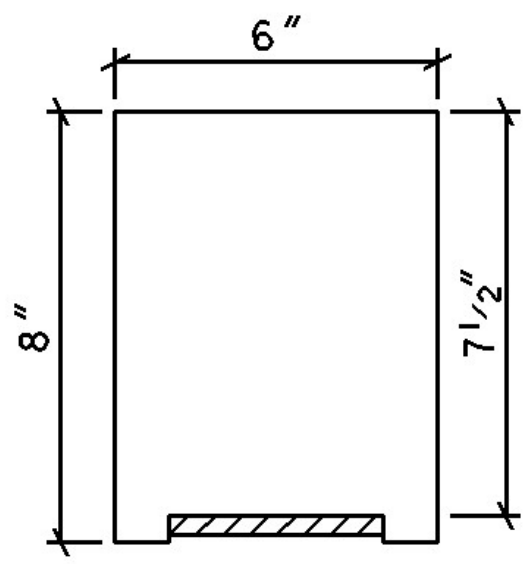

Figure 69. Bending Member Design Example

3/8" x 4" GFRP plate

Select Structural White Oak Floor Beam

$\mathrm{E}=2.92 \times 10^{6} \mathrm{psi}$

For the purposes of this example, neglect the $1 / 2$ " $\mathrm{x} 1$ " strips on either side of the GFRP plate.

Determine the allowable bending stress of the timber using NDS 1997.

$$
\begin{array}{ll}
\mathrm{F}_{\mathrm{b}}=1200 \text { psi } & \text { Select Structural } \\
\mathrm{C}_{\mathrm{D}}=1.0 & \text { Occupancy Live Load } \\
\mathrm{C}_{\mathrm{M}}=\mathrm{NA} & 100^{\circ} \mathrm{F}<\mathrm{T} \leq 125^{\circ} \mathrm{F} \\
\mathrm{C}_{\mathrm{t}}=0.8 & \text { Assume Supported } \\
\mathrm{C}_{\mathrm{L}}=\mathrm{NA} & \mathrm{d}<12^{\prime} \\
\mathrm{C}_{\mathrm{F}}=1.0 & \\
\mathrm{~F}^{\prime}{ }_{\mathrm{b}}=\mathrm{F}_{\mathrm{b}}\left(\mathrm{C}_{\mathrm{D}}\right)\left(\mathrm{C}_{\mathrm{M}}\right)\left(\mathrm{C}_{\mathrm{t}}\right)\left(\mathrm{C}_{\mathrm{L}}\right)\left(\mathrm{C}_{\mathrm{F}}\right)
\end{array}
$$


$\mathrm{F}_{\mathrm{b}}=1200 \times 1.0 \times 0.8 \times 1.0$

$=960 \mathrm{psi}$

Determine capacity of timber beam with GFRP plate.

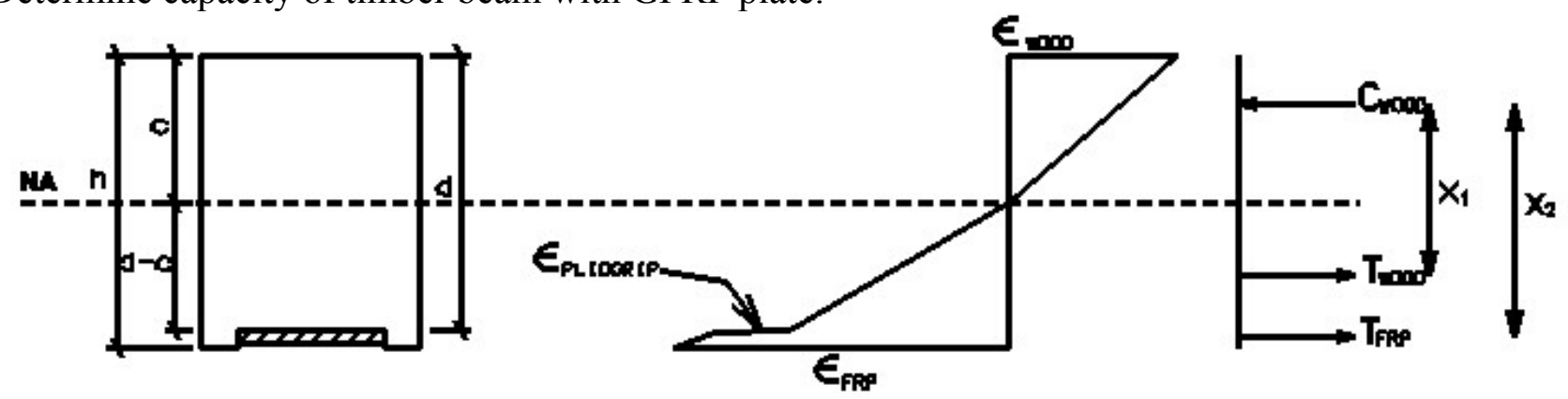

Figure 70. Strain Compatibility Internal Moment Equilibrium

NA determined using transformed section in section 4.6.

$\mathrm{h}-\mathrm{d}=\mathrm{a}$

$\mathrm{d}-\mathrm{c}=\mathrm{b}$

$\mathrm{x}_{1}=\mathrm{d}-1 / 3 \mathrm{c}-1 / 3 \mathrm{~b}$

$\mathrm{x}_{2}=\mathrm{h}-1 / 3 \mathrm{c}-1 / 2 \mathrm{a}$

$\mathrm{x}_{1}=5.0^{\prime \prime}$

$\mathrm{x}_{2}=6.41$

Determine Moment Capacity

$M=\left(F^{\prime}{ }_{b} / 2\right)\left(A_{w}\right)\left(x_{1}\right)+\phi_{b}\left(\psi_{f}\right)\left(A_{f}\right)\left(F_{f}\right)\left(x_{2}\right)$

$\mathrm{A}_{\mathrm{w}}=$ Area of wood in tension block

$=3.47 \times 6$

$=20.82 \mathrm{in}^{2}$

$\mathrm{A}_{\mathrm{f}}=$ Area of GFRP

$=3 / 8 \times 4$

$=1.5 \mathrm{in}^{2}$

$F_{\mathrm{f}}=$ Stress in GFRP

$\mathrm{C}_{\mathrm{E}}=$ Outdoor use reduction factor (Externally Bonded FRP Systems for Strengthening

Concrete Structures, Hota)

$$
=0.65
$$


$\varepsilon$ value to be used in design is reduced from the comparison value to a point in the elastic range

$$
\begin{aligned}
& =\mathrm{C}_{\mathrm{E}} \times \varepsilon \times \mathrm{E} \\
& =.065 \times 0.02 \times 2.92 \times 10^{6} \\
& =37,960 \mathrm{psi}
\end{aligned}
$$

$$
\begin{aligned}
& \phi_{\mathrm{b}}=\text { Reduction factor to be used since GFRP plate will not be fully utilized } \\
& =0.5 \\
& \psi_{\mathrm{f}}=0.85 \\
& \mathrm{M}=(960 / 2 \times 20.82 \times 5)+0.5(0.85 \times 1.5 \times 37,960 \times 6.41) \\
& =203,518 \text { in-lbs } \\
& =16.9 \mathrm{ft}-\mathrm{kips}
\end{aligned}
$$

This is a simplistic design approach that gives a conservative bending capacity estimate, it is an approach that could be easily used by practicing engineers.

\subsection{Tension Member Design Example}

The design of tension members using the methods developed for this project is governed by bond strength. A check of the timbers tension capacity should be made to ensure that it is greater than the bond strength. By checking the tension capacity of the timber it will ensure that a catastrophic failure does not occur.

The design steps should generally be:

Determine capacity needed through structural evaluation of existing structure Choose development length from Table 9

Apply a $\phi_{\mathrm{t}}$ reduction factor to values listed in Table 9. Use $\phi_{\mathrm{t}}=0.85$

Table 9. Tension Member Design Table

\begin{tabular}{|c|c|}
\hline Bar Length (in) & Capacity (Ibs) \\
\hline 2 & 1950 \\
\hline 4 & 2800 \\
\hline 8 & 7300 \\
\hline 16 & 10000 \\
\hline
\end{tabular}

This table is only valid for \#4 Sand Coated GFRP Reinforcing Bars placed with PLIOGRIP adhesive. Bar length refers to total bar length, this assumes that only half of the bar will contribute to the overall capacity. 
Once the bar length is selected the tension capacity of the timber must be checked using NDS. The design must satisfy the following equation and all other timber design provisions including end and edge distances.

$\mathrm{f}_{\mathrm{t}}=\frac{P}{A} \leq \mathrm{F}^{\prime}$

The following example illustrates the simplified design for a typical tension truss member.

A tension member in a truss was determined by the use of NDT to be badly decayed and in need of replacement. The original member is a 4"x 6" sawn white oak cant. Using a moisture meter it was determined that the member is at $16 \%$ moisture content. After a detailed structural analysis it was determined that this member needed to have a tensile capacity of 12 kips.

From Table 9 try two (2) 8" Sand Coated GFRP reinforcing bars with PLIOGRIP adhesive.

Check capacity of two (2) bars

Capacity $=\#$ of bars $\times \mathrm{P} \times \phi_{\mathrm{t}}$

$$
=2 \times 73001 \mathrm{bs} \times 0.85
$$

$=12,410 \mathrm{lbs}$

$12,410>12,000=\mathrm{f}_{\mathrm{t}} \therefore$ o.k.

Check tensile capacity of timber

Determine allowable tension stress using NDS

$$
\begin{array}{ll}
\mathrm{F}_{\mathrm{t}}=700 \text { psi } & \text { Select Structural } \\
\mathrm{C}_{\mathrm{D}}=1.0 & \text { Occupancy Live Load } \\
\mathrm{C}_{\mathrm{M}}=1.0 & \text { Dry Service Conditions } \\
\mathrm{C}_{\mathrm{t}}=1.0 & 100^{\circ} \mathrm{F}<\mathrm{T} \leq 125^{\circ} \mathrm{F} \\
\mathrm{C}_{\mathrm{F}}=1.0 & \text { Sawn Lumber } \\
\mathrm{F}_{\mathrm{t}}=\mathrm{F}_{\mathrm{t}}\left(\mathrm{C}_{\mathrm{D}}\right)\left(\mathrm{C}_{\mathrm{M}}\right)\left(\mathrm{C}_{\mathrm{t}}\right)\left(\mathrm{C}_{\mathrm{F}}\right) &
\end{array}
$$


$\mathrm{F}_{\mathrm{t}}=700 \times 1.0 \times 1.0 \times 1.0 \times 1.0$

$=700 \mathrm{psi}$

Check tensile capacity of timber

$\mathrm{F}_{\mathrm{t}} \times \mathrm{A}_{\mathrm{n}}=\mathrm{P}$

$\mathrm{A}_{\mathrm{n}}=$ net-cross sectional area

$\mathrm{A}_{\mathrm{g}}=$ gross cross sectional area

$A_{h}=$ area of holes

$A_{n}=A_{g}-A_{h}$

$\mathrm{A}_{\mathrm{g}}=4 " \mathrm{x} 6$ "

$=24 \mathrm{in}^{2}$

$$
\begin{aligned}
\mathrm{A}_{\mathrm{h}} & =\# \text { of bars } \times \frac{\pi d^{2}}{4} \\
& =2 \times \frac{\pi \frac{9}{16}^{2}}{4} \\
& =0.25 \mathrm{in}^{2}
\end{aligned}
$$

$\mathrm{A}_{\mathrm{n}}=24-0.25$

$=23.75 \mathrm{in}^{2}$

$\mathrm{P}=700$ psi $\times 23.75$ in $^{2}$

$=16,625 \mathrm{lbs}$

$16,625 \mathrm{lbs}>12,410 \mathrm{lbs}=$ bond strength $\therefore$ o.k.

Determine placement of GFRP bars in the end of the member. The placement of the bars should satisfy the requirements of the NDS. The end, edge, center to center and row spacing of loading parallel are a conservative approach and should be used. These requirements should only be used as a minimum. To maximize the design, the GFRP reinforcing bars need to be placed as close to the center of the member as possible.

End distance $=$ NA, since bars placed in the end of the member Edge distance $=1.5 \mathrm{~d}$ unloaded edge

Center to Center $=3 \mathrm{~d}$ minimum 
Row spacing:

For $l / \mathrm{d} \leq 2.0$ : row spacing $=2.5 \mathrm{~d}$

For $l / \mathrm{d} \geq 6.0$ : row spacing $=5 \mathrm{~d}$

For $2.0<l / \mathrm{d}<6.0$ : row spacing $=$ interpolate between $2.5 \mathrm{~d}$ and $5 \mathrm{~d}$

Edge distance $=1.5 \times \frac{9}{16}$

$$
=0.85 \text { in }
$$

Center to Center $=3 \times \frac{9}{16}$

$$
=1.7 \mathrm{in}
$$

Row Spacing for this example is NA, since only two (2) bars are needed.

The placement of the GFRP reinforcing bars is as shown on Figure 71. The placement and member preparation is the same as described in Chapter 3.
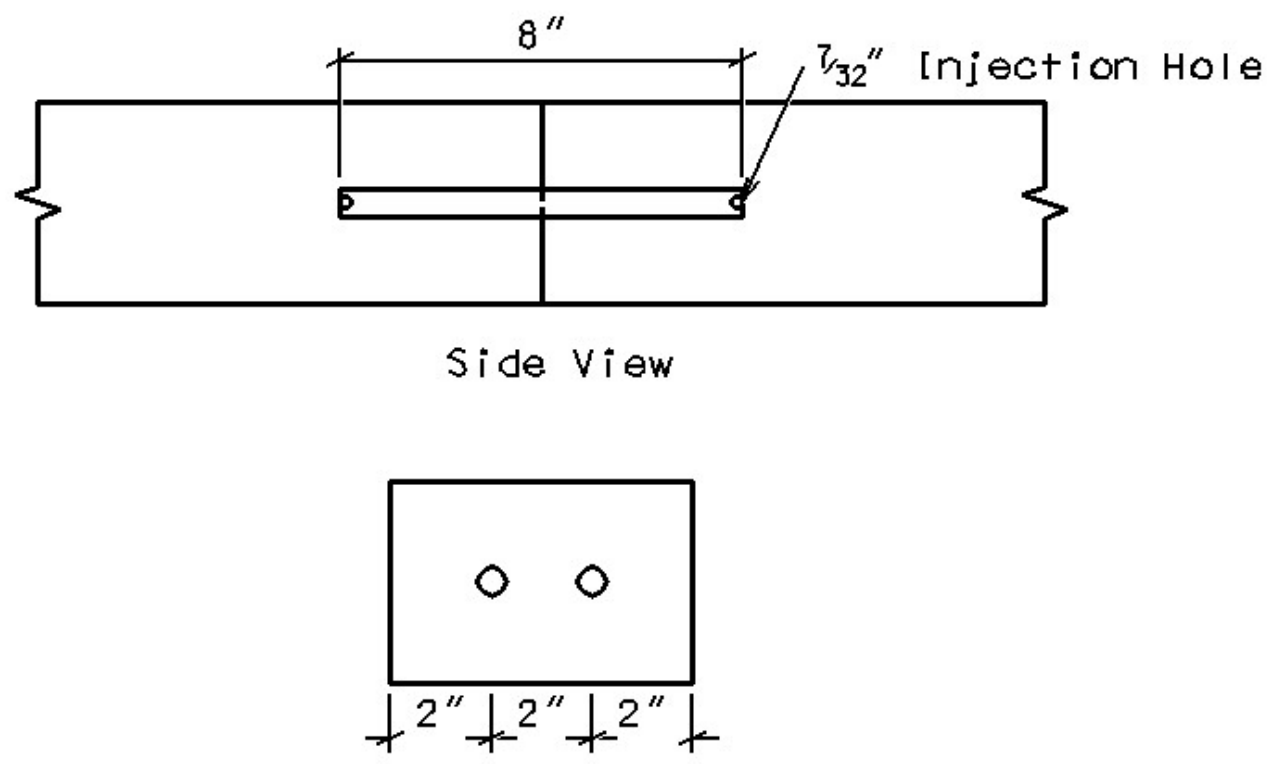

End $V$ iew

Figure 71. Tension Member Design Example

\subsection{Prediction of Flexural Rigidity Using the Rule of Mixtures}

Flexural rigidity (EI) was predicted using the rule of mixtures for specimen LB-7. This prediction assumes there is a perfect bond between the GFRP plate, adhesive and the wood. If there is not a perfect bond it will show in a larger percent difference between 
the $(\mathrm{EI})_{\exp }$ and the $(\mathrm{EI})_{\text {hybrid. }}$. A detailed example of the calculation used to predict flexural rigidity using the rule of mixtures can be seen in Section 4.5.2.1.

$$
\begin{gathered}
\text { EI comparison for LB-7: } \\
(\text { EI })_{\text {hybrid }}=410 \times 10^{6} \mathrm{lb}^{*} \text { in }^{2} \\
\% \text { Difference }=\frac{E I_{\text {hybrid }}-E I_{\text {exp }}}{E I_{\text {hybrid }}} \\
\% \text { Difference }=\frac{410-370}{410}=9.8 \%
\end{gathered}
$$

The percent difference is under $10 \%$ for LB-7; this is an indication that there was close to a perfect bond between the GFRP plate, adhesive and the wood member. This suggests that there was composite action in the specimen. So, the prediction of flexural rigidity using the rule of mixtures is accurate for this specimen.

\subsection{Adhesive Strain}

The strain in the PLIOGRIP adhesive was determined based on the difference between the strains from the strain gage placed on the wood "internally" and the strain gage placed on the GFRP plate, Figure 72. Figure 73 also shows the strain elongation in the PLIOGRIP from the strain profile for a $7000 \mathrm{lbs}$ load level. 

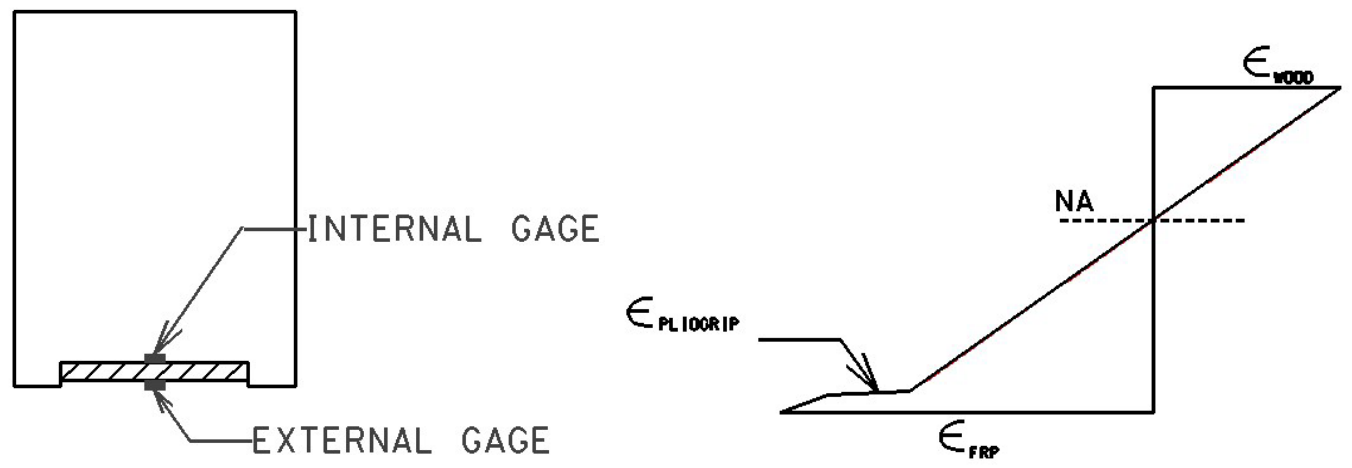

Figure 72. Diagram of Strain Gage Placement and Strain Profile

However, the strain in the PLIOGRIP is linear up to a certain load level (which is about 21,000 lbs) and then yielding of the PLIOGRIP occurs, Figure 73. This behavior of an adhesive is extremely beneficial in terms of transferring the load to the GFRP. Other adhesives like epoxies are typically brittle and fail suddenly.

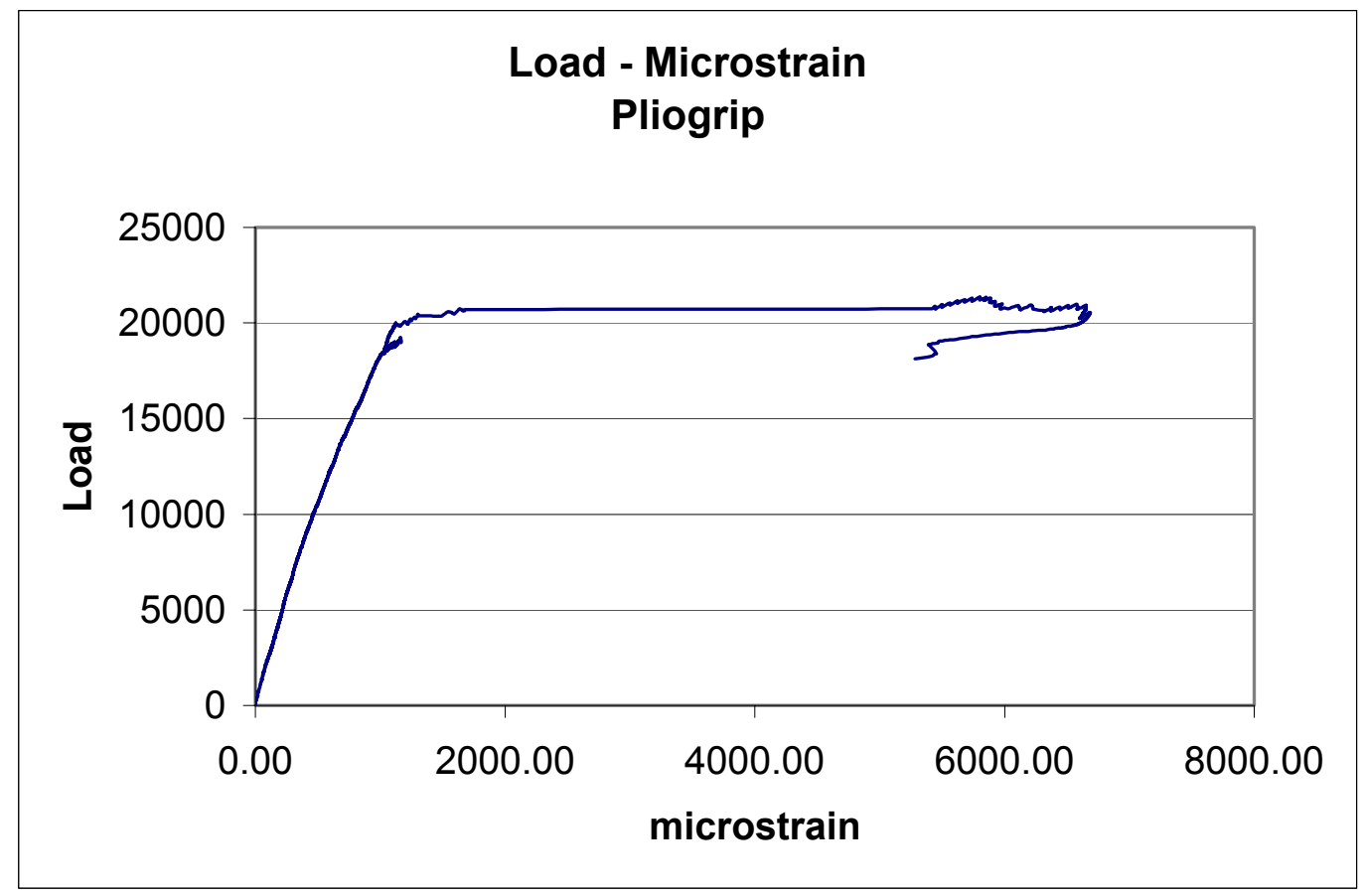

Figure 73. Load vs. Microstrain in PLIOGRIP 


\subsection{Bonding GFRP Plates to Timber Beams}

The process used to repair the bridge in the field is as or more important than the design of the repairs. The use of GFRP plates with timber beams requires knowledge of the materials to be used and limitations of their uses. The following steps will help ensure that the design will reach its full potential.

1. Accounting for material compatibility: This means that the resin and sizings in the GFRP must be compatible with the adhesive that is to be used to bond the GFRP to the timber beam. Like wise, the adhesive must be compatible with the timber beam.

2. Preparing the beam: The process of recessing the beam is described in length at Chapter 3. The surface must be level and free of depressions and bumps. If the surface is not in the above condition it will lead to too little or excess adhesive, leading to premature bond failure. If bumps are present they should be removed and if depressions are present they should be filled and leveled with an epoxy and walnut shell mixture or other material that will bond to both the GFRP and wood and not decrease the capacity of the beam by acting as a bond breaker, to create the surface required for proper bonding.

3. Sanding and bonding of GFRP plate: The plate must be sanded on the side that is to be bonded. The top layer of resin that covers the fibers must be removed to allow the adhesive to bond with the fibers or plate must be pultruded with a peelply which can be removed before bonding. Peel-ply eliminates the need to sand the GFRP plate.

4. Applying adhesive: The work time of the adhesive must be carefully noted. Some adhesives have a short work time, if the adhesive has a short work time it might start to set before the GFRP plate is placed. If this happens, as can be expected, the adhesive will not have adequate cross-linking to the beam. If the adhesive starts to set, it will not be able to transfer, the load from the beam to the GFRP, with no load transfer the GFRP will not contribute to the capacity of the beam. The adhesive should be applied generally to the beam in a manner that once the GFRP plate is added there will be no voids. 
5. Placing weights along the entire length of the GFRP plate: Apply pressure to the plate while the adhesive is curing. The weights must remain in place for 24 hours or at least the clamp time as specified by the manufacturer.

6. Working at moderate temperatures: Higher temperatures will shorten the work time and lower temperatures will increase the viscosity of the adhesive. In lower temperatures, the adhesive might not be able to adequately bond to the timber beam. The work and set times of PLIOGRIOP can be adjusted by the manufacturer from a few minutes to several hours. These times are based on placing and curing at ambient temperatures. Therefore, the times may vary dependent on the temperature. The manufacturer should be consulted prior to work to ensure that the adhesives capabilities will be optimized. 


\section{Chapter 5}

\section{Conclusions and Recommendations}

\subsection{Introduction}

- From the test results for the tension and bending are based on the experimental data. It is evident that the use of GFRP/vinylester matrix composite with PLIOGRIP adhesive has performed very well on bending and tension members. PLIOGRIP was chosen because of the high compatibility to GFRP/vinylester matrix composite and also wood.

- The tension test established a development length for the reinforcement of wood with sand coated GFRP reinforcing bars. The desired bond strength is reached in a relatively short distance, see Figure 39. Based on the preliminary laboratory tests, the bonded-in GFRP reinforcing bar members performed well in terms of pullout force and bond strength. The chosen reinforcing bar diameter and length did not appear to significantly affect the pullout performance and bond strength beyond a bond length of $8 d_{b}$. The bar diameter that was used was $d_{b}=1 / 2$ ", so the bond length was equal to $4 "$.

- As in the small-scale specimens the use of GFRP/vinylester matrix composite with PLIOGRIP was used successfully to improve the strength and stiffness of wooden members; however, some limitations of the strengthening method were observed. The wood surface must prepared so that the surface is level so as to provide a uniform bonding area and that if there is not adequate bond the GFRP plate will peel from the member and possibly lead to a reduction in performance. The surface must be degreased and free from loose material. The surface preparation requirements for PLIOGRIP are not as stringent as those of epoxy. For epoxy the surface temperature must be $50^{\circ} \mathrm{F}$ for all bonding applications.

- The full-scale test specimens showed an increase in strength or stiffness. The results from testing full-scale members indicate that strength and stiffness can be improved significantly, while complying with the Secretary of the Interiors Standards for Historic Preservation. 
- The experimental results conducted on bending members reinforced with bars did not achieve the desired level of performance. This method would be very useful in compression members in a truss. The bars would be to hold the member in place and keep it from buckling. The constructability is another issue with this method. It was very hard to drill the holes in both sides in a manner that allowed for perfect alignment. Perfect alignment could not be reached in a laboratory setting, so it would be difficult to achieve alignment in the field.

- A transformed section analysis, strain compatibility and internal moment equilibrium approach accurately predicted the moment capacity of full-scale members.

- The ductility in the PLIOGRIP was demonstrated experimentally, which is extremely beneficial in terms of transferring the load to the GFRP. Other adhesives like epoxies fail in a brittle fashion, and therefore, may not allow the reinforcement (GFRP) to be used to its full potential.

- Moisture contents and temperature of the test specimens were held as a constant for this research project. All specimens were tested at indoor ambient temperature that had very little variance.

\subsection{Recommendations}

- Performance of GFRP Reinforced Wood Joints

Examine the feasibility of reinforcing wood at jointed connections using GFRP composite materials. Conduct large full-scale trusses, beams tension members to eliminate or reduce the effects of scaling.

- Performance of GFRP Reinforced Wood Members Under Environmental Exposure There is a need to evaluate the long-term performance of bonded-in GFRP reinforcing bars in wood members subjected to tension under several varying environmental conditions.

- Testing needs to be conducted examining the strengthening methods developed for this research project under field application conditions. 
- Performance of GFRP reinforced wood members under exposure to wood preservatives

\begin{abstract}
Although Secretary of the Interior's Standard for the preservation of historic bridges do not allow the use of wood preservatives for restoration work, which alter the color or texture. In some cases replacing a decayed wood member with a GFRP reinforced member that is treated with preservatives is the ideal remedy for a particular location such as, an end post resting on an exposed abutment. Therefore, another recommendation for future research would be to evaluate the long-term performance of GFRP reinforced bridge members exposed to wood preservative chemicals and pressures.
\end{abstract}

- Manual/Chapter on Repair and Strengthening of Historic Covered Bridges

Develop a stand-alone manual or chapter on the preservation and strengthening of historic covered bridges using GFRPs through a step-by-step design procedure including information on types of fibers, adhesives, and installation. 


\section{Bibliography}

${ }^{1}$ Stauch J., "Union County Covered Bridge Rehabilitation - Case History 15.4," "Timber Bridges: Design, Construction, Inspection, and Maintenance," USDA Forest Service, 1990

${ }^{2}$ Kemp, E. L., “Covered Bridge Research,” Restructuring: America and Beyond vol 2, April 2-5 1995

${ }^{3}$ McFeely, D., "Bridges hang in balance Counties debate fate of old spans,"

4 Crowell, A., "Historic bridge can be saved, but is cost too expensive," Kennebec Journal, October 23, 2002

${ }^{5}$ Lichtenstein, A. G., "Historic Bridges: Conflict Ahead," Civil Engineering: vol 57, May 1987, p64-66

${ }^{6}$ Jester, T. C. ,"Preserving Historic Bridges,” CRM, Supplement, vol 15: No. 2

${ }^{7}$ Kemp, K. L., "The Rehabilitation and Restoration of Historic Bridges," Historic Bridge Articles, vol 1, Emory L. Kemp Collection

8 "The Secretary of the Interior's Standards for the Treatment of Historic Properties, with Guidelines for Preserving, Rehabilitating, Restoring \& Reconstructing Historic Buildings", National Park Service

${ }^{9}$ Rogers, D. H., "Reinforcing Historic Covered Bridges," International Bridge Conference, 1987

${ }^{10}$ Rich, S., "Uncovering and American Legacy Kentucky’s Covered Bridges: Preserving Historical and Architectural Value," Structure: September 2001

${ }^{11}$ Michael A. Ritter, "Timber Bridges: Design, Construction, Inspection, and Maintenance," USDA Forest Service, 1990

12 "Stress Wave Timing Nondestructive Evaluation Tools for Inspecting Historic Structures, a guide for use and interpretation," United States Department of Agriculture

${ }^{13}$ Pahel, J. E., "Laser Scanning a Tale of Two Projects," Structural Engineer: March 2002

${ }^{14}$ Pullaro, J. J., "Restoring Historic Bridges Using Modern Methods," Structures Congress, 1999 proceedings 
${ }^{15}$ Davis, A. G.,’Nondestructive Evaluation Helps Maintain Concrete Structures," Structures, September, 2001

${ }^{16}$ Tang, B. T., "Fiber Reinforced Polymer Composites Applications in USA," Korea/USA Workshop, 1997, January 28-29, proceedings

${ }^{17}$ Tech note ETL 1110-2-548, Army Corps of Engineers, 31 March 1997

${ }^{18}$ Neale, K. W., "FRPs for Structural Rehabilitation: A Survey of Recent Progress," Structural Engineering Materials: 2000; 2: 133-138.

${ }^{19}$ Lacroix, S., Johns, K. C., "Composite reinforcement of timber in bending," Canada Civil Engineering, vol 272000

${ }^{20}$ Plevris, N., Triantafillou, T., "Creep Behavior of FRP-Reinforced Wood Members," Journal of Structural Engineering, vol 121, no 2, Feb, 1995

${ }^{21}$ Triantafillou, T. C., "Shear Reinforcement of Wood Using FRP Materials," Journal of Materials In Civil Engineering: May 1997

${ }^{22}$ Griggs Jr., F. E., "Restoration of Cast and Wrought Iron Bridges," Structure, September, 2001

${ }^{23}$ Petrie, Edward M., "Handbook of Adhesives and Sealants", McGraw-Hill, 2000

${ }^{24}$ National Design Specification (NDS), for Wood Construction 1997 Edition 


\section{Appendix A}

\section{Preliminary Testing}

\section{A.1 Introduction}

One possible method for strengthening deteriorated historic wooden members without violating the Secretary of the Interior's Standards for Rehabilitation is to internally reinforce them with Glass Fiber Reinforced Polymer (GFRP) composite bars. To implement such rehabilitation, the nature of the bond between the composite rebar and the wood must be understood. Tension test specimens were developed and tested to determine the bond strength of the GFRP bar adhesively bonded to wood. The development of techniques used to prepare members that are internally reinforced must be developed. Primer/adhesive type, how to cut the wood, injection/pour and bond length needed to be understood to achieve an acceptable bond.

\section{A.2 Void Test for Tension Members}

Void tests were conducted to determine the best method to apply the adhesive to the GFRP. Several different methods were developed and compared. The best method was then used to further develop the techniques to strengthen the tension members.

\section{A.2.1 Preparation of Test Specimens}

Tests were conducted to determine the best method to apply the adhesive. Phenolic formaldehyde resin was used because of its high compatibility with wood and the reinforcing bar was a GFRP with vinylester matrix. Earlier test results showed that there were poor results with the vinylester matrix reinforcing bar and the phenolic matrix. The test results need to be validated to determine if excess voids or a bad method of preparation influenced the test response and data. The following tests were conducted to answer this question, as well as to determine a method to apply the adhesive and maintain 
proper alignment. The combination of resin/adhesive to be used with what type of FRP will be investigated in this section. Three different methods were developed and tested. Wood was white oak and reinforcing bars were 9/16" diameter sand coated GFRP 8" in length. The wood specimens were $2 \times 4$ 's that were 12 " in length. The wood was cut into two pieces and the holes were drilled as specified in the following descriptions of the test specimens (S-1, S-2, and S-3). A two part phenolic resin and GFRP vinlyester reinforcing bar were used for all three (3) specimens.

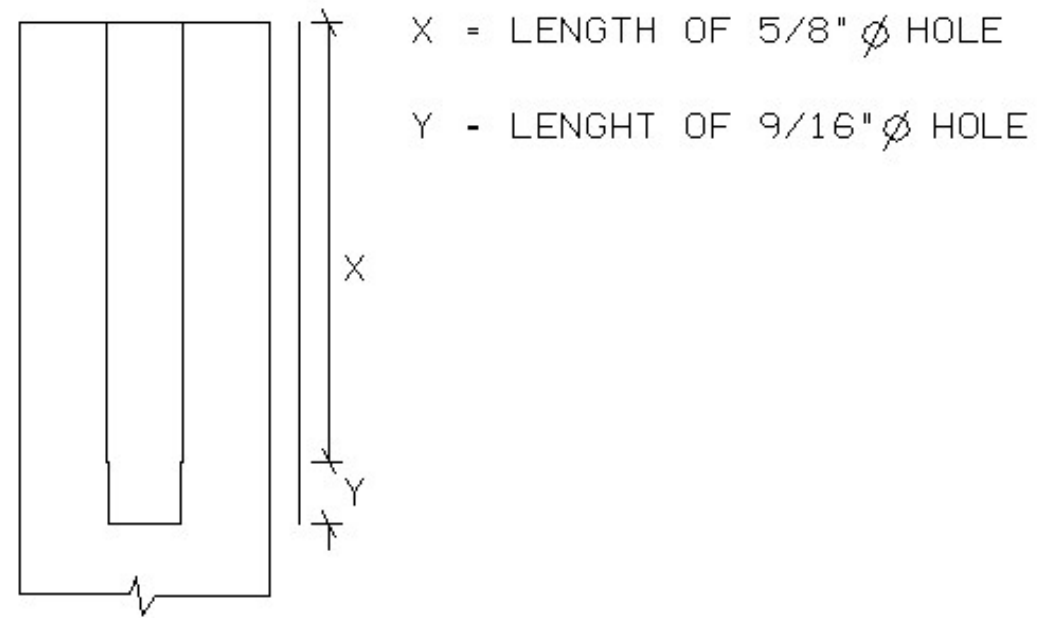

Figure 74. Side View of Test Specimens

Specimen S-1:

$\mathrm{x}=37 / 8^{\prime \prime}$

$\mathrm{y}=1 / 8^{\prime \prime}$

A 7/32" bleeder/injection hole drilled at $33 / 4$ " from the point where the specimen was cut into two pieces on both sides to allow for the injection of resin into the specimen and to allow for the excess to escape. The y dimension was used to maintain proper alignment until the resin has had time to cure. The following steps were used for specimen S-1:

1. Filled from one side of the specimen with resin and hardener combination.

2. Inserted GFRP bar into the side that was full of resin and removed excess resin.

3. Filled the opposite side with resin and hardener combination. 
4. Inserted the side with the bar into the opposite side and clamped the specimen together, then removed excess resin.

5. After the specimen was clamped together $10 \mathrm{ml}$ of resin and hardener was injected into the specimen. Once the resin started exiting from the bleeder hole on the opposite side, injection of the resin was discontinued.

6. Specimen was left for the resin to harden for 1 hour, at that time resin and hardener was injected into the bleeder hole. The specimen took an additional 4 $\mathrm{ml}$ before it started to escape again.

Specimen S-2:

$\mathrm{x}=31 / 2{ }^{\prime}$

$\mathrm{y}=1 / 2 "$

The 7/32" bleeder/injection holes were drilled at $33 / 8$ " from the point where the specimen was cut into two pieces of both sides. The following steps were used for S-2:

1. GFRP bar was inserted into the specimen and both sides were clamped together without any adhesive.

2. Resin and hardener were injected into the through the bleeder hole until the mixture started to escape through the opposite hole. Approximately $12 \mathrm{ml}$ was used to fill the cavity.

3. Specimen was left to harden for 1 hour.

4. No additional resin and hardener were needed. 
Specimen S-3:

$\mathrm{x}=33 / 4 "$

$\mathrm{y}=1 / 4^{\prime \prime}$

The 7/32" bleeder/injection holes were drilled at $31 / 2$ " from the point where the specimen was cut into two pieces of both sides. The following steps were used for S-2:

1. GFRP bar was inserted into the specimen and both sides were clamped together without any adhesive.

2. Resin and hardener were injected into the through the bleeder hole until the mixture started to escape through the opposite hole. Approximately $12 \mathrm{ml}$ was used to fill the cavity.

3. Specimen was left to harden for 1 hour.

4. Approximately $2 \mathrm{ml}$ of resin and hardener were injected into the specimen throught the bleeder hole.

\section{A.2.2 Discussion}

The specimens were allowed to cure for 24 hours. They were then cut into varying lengths ranging from $1 / 2$ " to $13 / 4$ " thick to determine if the GFRP reinforcing bar was aligned on the inside of the specimen and the amount of voids if any. S-1 displayed little to no voids on the cuts that were made on cross section close to the bleeder holes. There were also very few voids between the resin and GFRP. When the cuts were made at the center of specimen voids were present and it was discovered that the bars were not aligned. S-2, on the other hand looked as if the bar was aligned the entire length of the specimen and voids were almost nonexistent. The larger value of y was determined to be the reason the bar was aligned and the placement of the bleeder hole in the y part and not the x part was also desirable to avoid voids. The results of S-3 were very similar to those of S-1. Even though there were no voids in S-2, it did not appear that there was a bond between the GFRP bar and resin.

After these tests were conducted, it was determined that the phenolic formaldehyde is not the most desirable resin to use for this application with the vinlyester 
GFRP bars. The phenolic would be the most desirable if a reinforcing bar made with a phenolic matrix could be used, but they are not readily available on the market. The purpose of developing these methods is to use them in real world applications. Since the vinlyester matrix GFRP reinforcing bars are readily available to the public, a compatible adhesive with vinlyester must be used other than phenolic.

\section{A.3 Preliminary Tension Tests}

The following tension tests were conducted to determine the best material combination and it was developed for S-2 in the previous experiments. The same reinforcing bar was used for all tests. The adhesive was varied to determine which combination is the most desirable for this application.

\section{A.3.1 Preparation of Test Specimens}

The next set of experiments was conducted in order to determine the best material combination and expand upon was developed for S-2 in the previous experiments. Specimens were prepared using urethane, epoxy, and acrylic resins. Wood was white oak and reinforcing bars were $9 / 16$ " diameter sand coated GFRP 6" in length. The wood was approximately $11 / 2$ " x $21 / 2$ " x 12 " long. The wood was cut transversely into two pieces and the holes were drilled as specified in the following descriptions of the test specimens (S-4, S-5, S-6, S-7, S-9, and S-10).

S-4:

The resin used for this specimen was a urethane based two part adhesive called (PLIOGRIP) manufactured by the Ashland Chemical Company. S-4 was drilled and prepared in the same manner as S-2. The GFRP reinforcing bar was inserted into the specimen and it was clamped before the application of the adhesive. The PLIOGRIP was injected into the bleeder holes until it could be seen coming from the opposite bleeder hole.

\section{S-5:}

The same materials and method as used for S-4 was used on this specimen. The PLIOGRIP was inserted into the drilled hole before the GFRP reinforcing bar was 
inserted. It was then clamped and more adhesive was injected until it escaped from the bleeder hole.

S-6:

A 2 part epoxy resin system was used for the adhesive in this specimen. The drilling of the holes was the same as S-2. The primer coat was applied to the GFRP bar and the inside of the holes and allowed to stand for 24 hours. The bar was then inserted and the specimen was clamped without the application of the adhesive. The epoxy was then injected into the specimen by the bleeder holes until it was seen coming from the opposite bleeder hole. The epoxy adhesive used was much more viscous than the PLIOGRIP.

\section{S-7:}

This specimen was done in the same manner as S-6 with the same epoxy system. S-9:

An acrylic resin system was used for this specimen. The specimen was drilled and put together with the same method as S-2. The adhesive did not require a primer coat. S-10:

The urethane based PLIOGRIP was used for this specimen. The holes were drilled in the same manner as S-2. A new method was used for this specimen to keep the bar aligned on the inside of the specimen. A washer with an inside diameter of $9 / 16$ " and outside diameter of 5/8" was placed on the GFRP bar at the middle. The bar was then inserted into the specimen and the same procedure as S-2 was followed.

\section{A.3.2 Discussion}

Uniaxial tension tests were performed on the GFRP reinforced wood samples using a 200 kip capacity Baldwin Universal Testing Machine. No strain data were taken; the only concern was the bond strength. Load values were taken manually from the Baldwin Machine. Bond strength of the specimens was determined. The bond strength or failure was defined as the load divided by the circumferential area of the embedded length of the GFRP rebar in one side (loaded end) of the test specimen, while bond failure was defined as the load at which the specimen could not sustain any additional 
loading. Failure was at the adhesive / timber interface. The bond strengths of the specimens are shown in Figure 75.

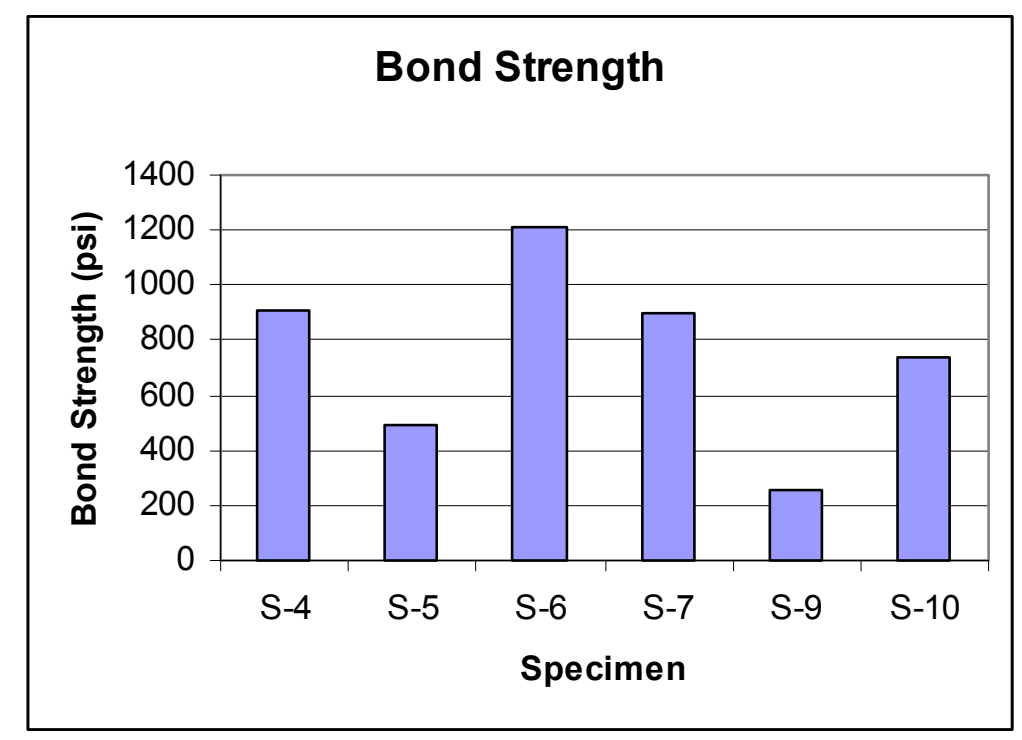

Figure 70. Bond Strength

In Figure 75 it can be seen that both of the specimens prepared with epoxy performed very well. The specimens (S-4 and S-10) that were prepared with PLIOGRIP had adequate strength as well. The acrylic did not perform as well as the PLIOGRIP and the epoxy adhesives. S-10 had near perfect alignment of the bar on the inside of the specimen, but its bond strength was lower than that of S-4. This is because of the fact that the washer did not allow the adhesive to pass freely to allow for equal distribution. S-5 was found to have voids after inspection; the method used for S-5 will not be used again.

\section{A.3.3 Conclusion}

The best method to use is S-10; even though it did not have the highest bond strength it has the most potential for field implementation. If the adhesive can pass freely through the washer while it maintains alignment, the bond strength will be much higher. The resin to be used with the vinlyester matrix sand coated GFRP bars is PLIOGRIP. Although epoxy had the highest bond strength, it was not high enough to warrant its use 
and the reasons will be discussed in the next section. This round of experiments has established the resin/FRP combination to use and the preferred method of application. Further tests will be done to verify these test results. The following section will discuss tension tests conducted on phenolic FRP reinforcing bars with a phenolic resin and vinlyester GFRP reinforcing bars with phenolic resin.

\section{A.3.4 Urethane versus Epoxy}

The urethane adhesive PLIOGRIP was chosen as the adhesive for all strengthening methods developed for this project. Why was PLIOGRIP chosen when the preliminary tension test results showed the greater bond strength was achieved with the epoxy adhesive? Several other factors play a major role in the choice of the right adhesive; strength alone will not achieve desired results. The first decision that needs to be made is which adhesive is most compatible to wood and vinlyester matrix GFRP. In this situation both the urethane and epoxy are compatible. The next comparison that needs to be made is the general properties and which adhesives properties are more closely related to those of wood and the GFRP. Urethanes have higher shear strength, peel strength, and are more flexible. Epoxies have better moisture resistance and solvent resistance. The adhesives have about the same creep resistance and urethanes are slightly better in impact strength. ${ }^{23}$ The nature of the repairs will cause the bond line to be on the order of $1 / 16$ " to $1 / 8$ ". This is acceptable for a urethane adhesive, but will cause a cohesive or brittle failure in the epoxies. Due to the broad range of uses in this project the properties of the urethane are much better suited for use with wood and GFRP.

Considering this is a historic preservation project the impact the adhesive will have on the materials it comes into contact with is a very important factor. The epoxy tested has a very low viscosity and acts almost like paint with what it comes into contact with. The urethane on the other hand has higher viscosity than the epoxy, and is able to be wiped from the material it comes into contact with before it sets. The adhesive cannot ruin the members this research is trying to save. 


\section{A.4 Tension Test}

A final comparison was made between the two most desired adhesive reinforcing bar combinations. The tests were conduct on small scale wood samples that more closely replicate tension members that would be found in a truss on an existing covered bridge.

\section{A.4.1 Preparation of Test Specimens}

The tension members consisted of White Oak at 12\% Moisture Content (MC) that was air-dried at the West Virginia University Forest saw mill. A 12\% MC was selected to replicate MC levels typically found in timber covered bridges (e.g., 12-15\%). The test specimens were cut into a dog-boned shape with dimensions prorated to ASTM test standards for tensile strength parallel to the grain. The ends of the test specimens were 1 $1 / 4 \times 3 \frac{1}{2}$ inches tapering down to a constant cross-section of $1 \frac{1 / 4}{4} 1 \frac{1 / 4}{4} 6$ inches with an overall specimen length of 36 inches.

In order to insert the GFRP bars into the specimens, the specimens were cut transversely in two halves and holes drilled into each end. Two different size diameter holes (1/2 and 5/8 inches) were drilled to accommodate two size diameter bars (\# 3 and \# 4). The sizes of the holes were drilled slightly larger than the diameter of the bar to allow for $1 / 16$ inch of resin on all sides of the composite bar. Two different depths (4 and 8 inches) were also drilled into each end so that two different bond lengths (8 and 16 inches) could be tested.

To prevent premature tensile failure (i.e., grip failure), the ends of the specimens were reinforced using GFRP composite fabrics. Initially, a phenolic resin was used as the adhesive and a GFRP with a vinylester matrix bar as the reinforcement. A primer coat of the phenolic resin (without the hardener or formaldehyde) was applied to the inside of the holes and allowed 24 hours to dry. The drilled holes were filled with the resin and hardener (i.e., phenol formaldehyde in a 5:1 mix ratio, respectively). After the holes were filled, the bars were soaked in the mixture and inserted into each of the cut ends of the specimens. The specimens were then clamped at the joint by a C-clamp and placed into a bar furniture clamp and left for another 24 hours to cure before testing. 


\section{A.4.2 Testing}

Uniaxial tension tests were performed on the GFRP reinforced wood samples using a 200 kip capacity Baldwin Universal Testing Machine. 2-inch long strain gages were mounted on the test specimen at mid height. Initially, strain and load measurements were taken manually every 500 pounds from the Baldwin Machine.

\section{A.4.3 Results}

The results of the tension tests of the GFRP reinforced wood specimens revealed that there was no chemical cross-linking (a.k.a., bond) between the phenolic resin and the vinylester matrix of the GFRP. The specimens simply separated under nominal loads (i.e., less than 500 pounds).

The reason we used the phenolic resin as an adhesive is because of its high chemical cross-linking of the resin/primer combination with wood and resistance to degradation and harsh environment. Also, our own first hand experience and high levels of success in improving the strength, stiffness, and durability of wood railroad ties and wood stringers in three timber railroad bridges, further reinforced our approach that phenolic is an ideal resin/primer system with varying values of viscosity.

However, to develop adequate bond between the Fiber Reinforced Polymer (FRP) rebar and the wood substrate our approach included changing the adhesive type and also changing the rebar matrix type. Two additional tension tests were conducted.

1. GFRP bar with a phenolic matrix and phenolic resin

2. Urethane based adhesive (PLIOGRIP, manufactured by the Ashland Chemical Company) with a GFRP bar with a vinylester matrix 
The results of the second set of tension tests using a different resin and matrix are presented in Table 1. Comparisons of strength and stiffness values are made with an unreinforced (solid) wood specimen.

Table 10. Observed Strength and Stiffness

\begin{tabular}{|c|c|c|c|}
\hline \multicolumn{4}{|c|}{ Table A1. Observed Strength and Stiffness } \\
\hline Specimen & $\begin{array}{c}\text { Tensile Strength } \\
\text { (kip) }\end{array}$ & $\begin{array}{c}\text { Bond Failure } \\
\text { (ksi) }\end{array}$ & $\begin{array}{c}\text { Young's } \\
\text { Modulus (msi) }\end{array}$ \\
\hline $\begin{array}{c}\text { Phenolic resin / } \\
\text { Phenolic matrix }\end{array}$ & 2.1 & 1.35 & N/A \\
\hline $\begin{array}{c}\text { PLIOGRIP resin } \\
\text { / vinylester } \\
\text { matrix }\end{array}$ & 2.6 & 1.66 & 1.7 \\
\hline
\end{tabular}

\section{A.4.4 Discussion}

GFRP bars made with the phenolic matrix and bonded with the phenolic resin exhibited a relatively high tensile strength (tensile force over full cross sectional area of wood/GFRP, i.e., $1.35 \mathrm{ksi}$ ) and eventually leading to bond failure. The $1.35 \mathrm{ksi}$ value can be improved especially since the GFRP bar made with a phenolic matrix was hand manufactured which resulted in an uneven bar preventing an acceptable bond and force transfer. Strength using the PLIOGRIP adhesive with a GFRP bar with a vinylester matrix carried the highest tensile strength and bond failure stress (1.66 ksi). The ultimate tensile strength of the solid wood specimen was found to be $11.54 \mathrm{ksi}$. Allowable design values (e.g., NDS) of tensile strength of wood are of the order of 0.6 to $0.8 \mathrm{ksi}$. Therefore, the GFRP bars with phenolic matrix resulted in wood failure strength of 1.66 ksi which is approximately 2.5 to 3 times higher than the design strength of wood, thus the preliminary tension tests are a success. Upon further examination of the wood member cross section, we noted that the resin bonding and penetration were less than satisfactory, which are being improved in the next series of tests. We believe that further improvements will result in tensile strengths of 3-4 ksi.

The stiffness of the solid wood specimen was measured to be $1.96 \mathrm{msi}$ which is reasonable for White Oak. The stiffness for the PLIOGRIP adhesive with a GFRP bar 
with a vinylester matrix specimen was measured to be $1.7 \mathrm{msi}$ was which slightly lower than the solid wood specimen, as anticipated. 


\section{Appendix B}

\section{Annotated Bibliography}

\section{Table of Contents}

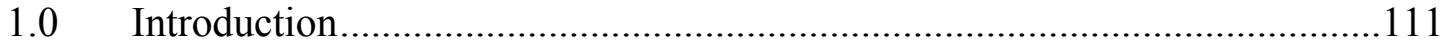

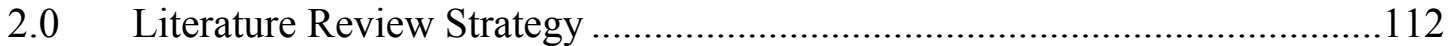

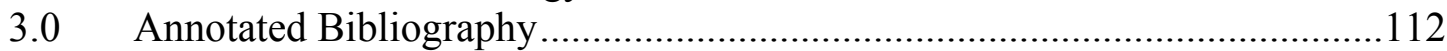

3.1 Composite Reinforcement of Timber Members ..............................113

3.2 Durability of FRP Reinforcement for Wood ....................................117

3.3 Debonding of Beam Reinforced with FRP Plates...............................118

3.4 Timber Joints with Composites ...........................................................118

3.5 FRPs in Bridge Applications ......................................................120

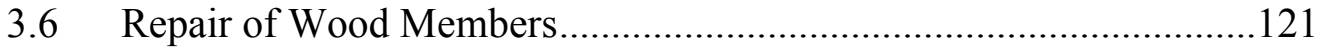

3.7 Nondestructive Evaluation of Timber Bridges ................................122

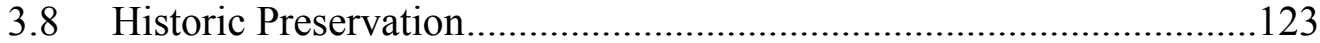

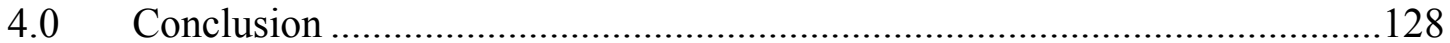




\subsection{Introduction}

The researchers have conducted an intensive search of the available literature relevant to the strengthening historic covered bridges. The literature review was performed from various sources such as books, pamphlets, magazines, journals, Internet sites, reports, agencies, etc. The information gathered from these sources was reviewed, synthesized and compiled with relevance to strengthening of historic covered bridges. The search was performed under the following aspects of the project:

- Composite Reinforcement of Timber Members

- Durability of FRP Reinforcement for Wood

- Debonding of Beams Reinforced with FRP Plates

- Timber Joints with Composites

- FRP's in Bridge Applications

- Repair of Wood Member

- Nondestructive Evaluation of Timber Bridges

- Historic Preservation 


\subsection{Literature Review Strategy}

The literature search document was prepared using keywords on various search databases. The list of keywords is given below:

Covered Bridges

Historic Bridges

Preserving Historic Bridges

Historic Preservation

Historic Preservation Through Modern Methods

Bridges Strengthened with FRP's

Strengthening Historic Bridges

Strengthening Historic Bridges with FRP's

Bridges with Pultruded FRP's

Timber Reinforced with FRP's

Timber with Composites in Bending, Shear

Timber Reinforcement

Timber and Pultruded FRP's

Reinforced Timber Joints

\subsection{Annotated Bibliography}

The annotated bibliography contains information such as title and authors for the source, citation of the source, a brief summary of what the paper deals with, aim, which gives the relevance of the citation, and the pros/cons of the literature reviewed.

In the following section, an annotated bibliography pertinent to strengthening historic covered bridges is presented. The annotated bibliography provides a brief overview of the research conducted by various authors on several aspects related to strengthening historic covered bridges using FRPs and historic preservation. 


\subsection{Composite Reinforcement of Timber Members}

Title: $\quad$ Composite Reinforcement of Timber in Bending

Author: Johns K.C., Lacroix S.

Citation: $\quad$ Canada J, Civil Engineering, Vol 27, 2000

Summary: A promising use for high performance composite materials is to reinforce timber beams. This paper studies the use of carbon and glass fibers to reinforce sawn timber sections. Consideration is given to strength phenomena of commercial timber alone and in reinforced sections in bending and shear. Anchorage length considerations for composite strips applied to the underside of simple beams are discussed. Experimental results are presented for three geometries of reinforcement using matched samples of 25 pairs of beams, reinforced and not. Results established that the wood itself in the composite section shows strength increase, and that the increase in moment resistance of the reinforced beams is far greater than that predicted by simple models.

Source: This paper shows the increases in strength that can be achieved with composite materials.

Pros/Cons: The authors show the increase in externally bonding sawn timber members with glass and carbon fibers which show good results. This method would not be appropriate for use on historic structures and the methods need to be tested full scale members. The member test size was equivalent to a $2 \times 4$.

Title: $\quad$ Strengthening of Wood Beams Using FRP Composites

Author: $\quad$ H.J. Dagher and R. Lindyberg

Citation: $\quad$ Composites Fabricators Association Conference, Sept. 2000

Summary: The paper presents the reason FRP reinforcement should be used over metallic reinforcement to achieve the desired strength, stiffness, and ductility. The paper shows that with as little as $3 \% \mathrm{E}$ glass bonded to the tension side of the beam bending strength in wood laminated beams can be increased by as much as 100\%. By using GFRP reinforcement the wood requirements can be reduced and in some conditions reduce material costs.

Source: $\quad$ This paper shows why FRP's should be used over metallic reinforcement and that high grade glulam can be produced using low grade wood.

Pros/Cons: The research is focused on the use of glulam beams and not sawn timbers.

Title: $\quad$ Strength and Stiffness Performance of FRP Reinforced White Oak Author: $\quad$ Martin, Zeno, A., Stith, Joe K., Tingley, Dan, A. 
Citation: Proceedings, World Conference on Timber Engineering, Whistler Resort, British Columbia, Canada, July 31-August 3, 2000

Summary: The paper presents results of tests that have been conducted to determine the performance characteristics of vertically laminated White Oak, as used in truck trailer decks, reinforced with high strength fiber-reinforced plastic (FRP). Significant strength and stiffness increases have been shown for other such wood-FRP composites, such as FRP reinforced glue laminated timber, although most previous research research has focused on softwoods. Test results indicate that FRP reinforced White Oak decks provide many of the same benefits as FRP reinforced softwoods.

Source: $\quad$ This paper shows that elastic theory is shown to predict stiffness within $15-25 \%$ of actual test data. The test data was higher than the predicted values.

Pros/Cons: The authors use standard data for the properties of the FRP's instead of values supplied by the manufacturer or from test data. All of the members tested showed some increase in performance over an unreinforced specimen.

Title: $\quad$ Timber Beams Strengthened with GFRP Bars: Development and Applications

Author: $\quad$ Chris Gentile, Dagmar Svecova, and Sami H. Rizkalla

Citation: Journal of Composites for Construction, vol. 6, No. 1, Feburary 1, 2002

Summary: Repair and rehabilitation of infrastructure is becoming increasingly important for bridges due to material deterioration and limited capacity to accommodate current load levels. An experimental program was undertaken to study the flexural behavior of creosote treated sawn Douglas fir timber beams strengthened with GFRP bars. Twenty-two half scale and four full scale full scale timber beams strengthened with GFRP bars were tested to failure. The percent reinforcement ratios were between 0.27 and $0.82 \%$. Additional unreinforced timber beams were tested as control specimens. The results have shown that using the proposed experimental technique changed the failure mode from tension to compression failure, and flexure strength increased by 18 to $40 \%$. Research findings indicate the use of near surface GFRP bars overcomes the effect of local defects in the timber and enhances the bending strength of the members. Based on the experimental results, and analytical model is proposed to predict the flexural capacity of both unreinforced and GFRP-reinforced timber beams. 
Source: $\quad$ This paper presents a method for strengthening sawn timber beams using GFRP bars on half and full scale members.

Pros/Cons: The percent reinforcement was only between 0.27 and $0.82 \%$ of the total cross sectional area. So the percent increases in capacity compared to the percent reinforcement are a significant weight to strength increase.

Title: $\quad$ Wood Reinforced with Pultruded Fiber Reinforced Composites

Author: $\quad$ Douglas J. Gardner, Michael P. Wolcott, and Uma M. Munipalle

Citation: $\quad$ Pacific Rim Bio Based Composites Symposium, 9-13 November 1992

Summary: This paper presents a way to increase strength and stiffness of glulam beams using synthetic fiber reinforcement. Pultruded composites can also be laminated with wood in glulam beams using traditional manufacturing techniques. The pultruded composite plates can replace the high quality wood needed for the compression or tension laminates. Several different resin/composite combinations were investigated including: polyester or vinlyester were bonded using epoxy, resorcinol-formaldehyde, and emulsion isocyanate adhesives. The results presented in the paper show that FRP composites can be successfully bonded to wood to increase strength and stiffness.

Source: The paper shows that FRP can be successfully used in glulam beams.

Pros/Cons: Current tests show that phenolic adhesives are the most compatible with wood. The adhesives used for the most part are not very ductile, applications requiring wood to be bonded with vinlyesters will require a ductile adhesive.

Title: $\quad$ Sawn and Laminated Wood Beams Wrapped with Fiber Reinforced Plastic Composites

Author: $\quad$ Hota V. S. GangaRao, P.E.

Citation: $\quad$ Wood Design Focus, Fall 1997

Summary: There are many applications for fiber-reinforced polymer (FRP) composites, such as, reinforcement of wood and creating hybrid structural components. This paper presents strength, stiffness, and accelerated-aging of sawn and laminated wood beams wrapped with woven glass FRP fabric or glass fibers bonded in place with polymeric resins. The methods used to wrap the beams are also presented. The paper shows how the failure of wrapped beams is progressive, unlike the catastrophic failure of unwrapped beams. There is also increased ductility that can be attributed to the glass fibers carrying load past the failure point of the wood core. Emphasis of this method of strengthening wood beams is characterized by 
the selection of wrapping materials. An increase in strength and stiffness of between 40 and $70 \%$ was achieved.

Source: $\quad$ This paper presents a method of rehabilitating and strengthening wood members that can effectively and reliably increase the strength and stiffness.

Pros/Cons: Wrapping is the preferred method for strengthening timber beams, but the drawback is that it diminishes the historical integrity of the member it is reinforcing.

Title: $\quad$ Strength and Stiffness Evaluations of Wood Laminates with Composite Wraps

Author: $\quad$ S.S. Sonti, Hota V. S. GangaRao

Citation: $\quad$ 50th Annual Conference Composites Institute, The Society of the Plastics Industry, Inc. January 30 - February 1, 1995

Summary: This paper discusses the use of composite wrap on wood laminates. As part of the research two different wrapping materials were used; glass and carbon reinforced composites. Test were conducted on six glulam beams of either 10 or 20 feet in length and wrapped with the glass or carbon composite. A "net" like fiber architecture of the glass wrap was compared to the "cloth" fiber architecture. The stiffness increases were found to be relatively low compared to the relatively high increases in strength. The failure modes of the beams tended to be progressive plastic mode. The wrapping material kept the beams from failing catastrophically.

Source: $\quad$ This paper presents a method of rehabilitating and strengthening wood members using different types of fibers and fiber architecture.

Pros/Cons: The stiffness increases for the beams tested in this paper are lower that what would be expected but the increases were very good. As stated earlier wrapping is the preferred method for strengthening timber beams, but the drawback is that it diminishes the historical integrity of the member it is reinforcing. 


\subsection{Durability of FRP Reinforcement for Wood}

Title: $\quad$ Durability of FRP Reinforcement for Wood

Author: $\quad$ Beckry Abdel-Magid, Eoin Battles, Habib Dagher and Mohamed Iqbal

Citation: Proceedings: 1999 International Composites Expo; Cincinnati OH; Session 22-C

Summary: This paper examines a wood-compatible E-glass phenolic FRP system that was designed and fabricated for the reinforcement of glulam beams. In this paper partial results are presented that show that E-glass/phenolic FRP without surface treatment is affected by aggressive media such as: moisture, alkali, and salt water. A total of 34 panels were used. The primary degradation seems to be in the reinforcing fibers rather than in the phenolic matrix. The test presented in the paper were conducted before the FRP's final processing stage, it still retained more than $80 \%$ of its mechanical properties.

Source: $\quad$ This paper shows the durability of wood reinforced with FRP.

Pros/Cons: Although the results presented in the paper show promising results, they were incomplete at the time the paper was published.

Title: $\quad$ Durability of Wood-FRP Composite Bridges

Author: $\quad$ E. Battles, H. G. Dagher and B. Abdel-Magid

Citation: $\quad 5^{\text {th }}$ International Bridge Engineering Conference; Tampa, FL; 3-5 April 2000

Summary: FRP composite materials offer excellent mechanical properties and corrosion resistance their susceptibility to the synergistic effects of stress and environmental weathering is a hindrance to their acceptance as viable alternative to traditional materials. This paper characterizes the durability of a specific formulation of wood-compatible pultruded E-glass/phenolic composite. The test specimens were subjected to durability tests as per ICBO Acceptance Criteria 125. This criteria states that all FRP materials should retain $90 \%$ of their baseline strength after 1000 hours of environmental exposure, and $85 \%$ after 3000 hours. The test specimens narrowly missed this requirement. This indicates that the primary degradation occurred in the fibers and not in the resin matrix.

Source: $\quad$ This paper shows the durability of wood reinforced with FRP needs to be closely examined before its use in a particular project. 
Pros/Cons: The performance of the test specimens did not perform to standard. These needs to be further studied and understood before this combination of FRP and adhesive can be used in a harsh environment

\subsection{Debonding of Beams Reinforced with FRP Plates}

Title: $\quad$ Significance of Midspan Debonding Failure in FRP-Plated Concrete Beams

Author: $\quad$ Sebastian, Wendal M.

Citation: Journal of Structural Engineering, vol 127, No 7, July 2001

Summary: Reinforced concrete beams enhanced in flexure with adhesively-bonded reinforced polymer plates are susceptible to a brittle form of failure, defined by delamination of the cover concrete attached to the adhesive that causes the plates to debond from the beam. Data from large scale experiments are presented to show the midspan debond action is triggered by high shear stresses from the plates transmitted through the adhesive to the cover concrete. These stresses arise initially from the tension stiffening in the cracked concrete. The shear span of the external load and the stiffness of the plate are cited as parameters that may influence whether in practice end peel or midspan debond will occur.

Source: This paper describes and shows how and when midspan debond will occur.

Pros/Cons: $\quad$ The author shows in detail two modes for which FRP plates debond from concrete. This same phenomenon of debonding occurs in timber beams with FRP plates bonded adhesively.

\subsection{Timber Joints with Composites}

Title: $\quad$ Mechanical Behavior of Fiberglass Reinforced Timber Joints

Author: $\quad$ Chen, Chi-Jen

Citation: $\quad$ Proceedings, World Conference on Timber Engineering, Whistler Resort, British Columbia, Canada, July 31-August 3, 2000

Summary: This paper investigates the mechanical performance of dowel-type timber joints reinforced by fiberglass fabrics as reinforcements. Some critical characteristics such as the anisotropy of wood and splitting failure in structures and in joints demand more skill and limit the engineering 
design. According to the paper the fiberglass reinforcements lead to a higher performance and provide a good safety factor to the timber joints.

Source: $\quad$ This paper shows the improvements in timber dowel type joints by using fiberglass fabric

Pros/Cons: $\quad$ Through this paper the author shows how several design parameters can be optimized, such as, edge distance and end distance, while optimizing the capacity of the joint.

Title: $\quad$ Efficient Timber Connections Using Bonded-in GFRP Rods

Author: $\quad$ J.G. Broughton \& A.R. Hutchinson

Citation: $\quad$ Composites in Construction, Figueiras et al 2001, Swets \& Zeitilinger, Lisse, ISBN 9026518587 pp 275-280

Summary: This paper investigates the a comprehensive and experimental and numerical investigation into the fundamental material and joint geometry characteristics of both steel and GFRP rods bonded into structural composite lumber. Joint parameters studied included steel and GFRP rod materials, rod length, rod diameter, bond line thickness, multiple rods with multiple spacing. In addition the adhesive type, its performance and the timber moisture content at the time of bonding were all studied. It was found that GFRP rods performed as well as steel rods, and epoxy adhesives out performed all others tested.

Source: $\quad$ This paper shows that GFRP rods can be used in place of steel rods in timber connections.

Pros/Cons: The paper shows that GFRP performed as well as steel, but several factors were overlooked. The authors do not try to match the properties of the GFRP rods to that of the adhesive. If this were the case the epoxy should not have outperformed the urethane or the phenolic.

Title: $\quad$ Improved Timber Connections Using Bonded-in-GFRP Rods

Author: $\quad$ Harvey, Kim, Ansell Martin P.

Citation: $\quad$ Proceedings, World Conference on Timber Engineering, Whistler Resort, British Columbia, Canada, July 31-August 3, 2000

Summary: $\quad$ This paper presents research that deals with limited technology of bonded in rods in timber connections. In this paper GFRP rods were used in place of steel rods. Pull out test were conducted to characterize the bonded in connection. Initial tests investigated the influence of rod surface preparation, bonded length, glueline thickness, and adhesive type. The results were used to determine standard sample size and fabrication 
method to be used in later tests. These later tests investigated the effect of moisture content, wood type, and bonding the rod perpendicular to the grain. Moment-resisting and shear joints have also been tested using GFRP as the rod material. The rod surface preparation and the thickness of the glueline were found to be very important factors in determining strength of the connection.

Source: $\quad$ This paper shows that GFRP rods are a very good alternate to steel rods in timber connections.

Pros/Cons: The paper shows that GFRP performs very well. The strength of the connection is limited by surface preparation, glueline thickness, bonded length, and moisture content.

\subsection{FRP's in Bridge Applications}

Title: $\quad$ Advanced Fiber-Reinforeced Polymer-Wood Composites in Transportation Applications

Author: $\quad$ Habib J. Dagher, Melanie M. Bragdon, and Robert F. Lindyberg

Citation: $\quad$ Transportation Research Board, 2002

Summary: This paper presents six wood-FRP composite projects that utilize three types of technologies developed at the University of Maine. The three types are: tension-reinforced glulam beams with pre-consolidated E-Glass panels, tension reinforced glumlam beams and panels with wetimpregnated E-glass fabrics, and stress-laminated lumber using GFRP tendons. This paper shows that through these six projects properly designed wood-FRP composites are structurally feasible, durable, and cost effective.

Source: $\quad$ This paper deals with the use of FRP reinforced wood in new construction.

Pros/Cons: In one of the projects highlighted in the paper FRP was used in a stresslaminated bridge. After $2 \frac{1}{2}$ years of service the bridge retained $86 \%$ of its initial prestress.

Title: $\quad$ FRP-Reinforced Wood in Bridge Applictions

Author: $\quad$ H. J. Dagher and Robert F. Lindyberg

Citation: $\quad$ Proceedings $1^{\text {st }}$ Rilem Symposium on Timber Engineering; Stockholm, Sweden; 13-15 September 1999

Summary: This paper describes a probabilistic model that predicts the statistical properties of the strength and stiffness of glulam beams. The program is called ReLAM which stands for Reinforced Laminated Beams. ReLAM also calculates the allowable bending strength and MOE. The input 
required is beam layup, reinforcement tensile strength and stiffness, MOE of the lamstock, the ultimate tensile strength, and the ultimate compression strength. The accuracy of ReLAM was verified through a testing program. The program accurately predicted the allowable strength within $6 \%$ and the allowable strength within $7 \%$

Also as a part of the paper test were conducted on ninety FRP-reinforced glulam beams that were 22 feet in length. The results were to determine the accuracy of ReLAM, but they also showed that with adding $3 \%$ by volume GFRP reinforcement to the tension side can increase allowable bending strength by $100 \%$.

Source: $\quad$ This paper shows that a reliable program can be developed to accurately predict strength and properties of glulam beams reinforced with FRP's.

Pros/Cons: Over 500 simulations were run using ReLAM and showed that it more accurately predicted Western Hemlock glulam than Doug-fir.

\subsection{Repair of Wood Members}

Title: $\quad$ Structural Repair of Timber Using Epoxies

Author: $\quad$ Richard Avent, P.E.

Citation: $\quad$ STRUCTURE Summer 2000

Summary: The paper discusses in detail the development of a successful repair methodology using epoxies. The procedures have been used in both the United States and abroad. The paper presents not only repair methodologies, but also a rational and reliable analysis. The analytical model is developed which corresponds to the procedures by which the structural integrity of the epoxy-repaired timber can be reliably predicted. This method of epoxy repairs has been field verified for 15 years and it is very reliable to predicting the after-repair strength of the member.

Source: $\quad$ This paper is a good source to develop a repair of timber members using epoxy.

Pros/Cons: The paper is gives repair examples that walk the reader through the analytical model 
Title: $\quad$ Nondestructive Evaluation Methods for Highway Bridge Superstructures

Author: $\quad$ Udaya B. Halabe, Samer H. Petro, and Hota V.S. GangaRao

Citation: Manual submitted to the West Virginia Division of Highways

Summary: This manual describes in length several nondestructive evaluation methods that can be used for material inspection, structural components with emphasis on bridge superstructures. The manual presents some common nondestructive methods including: chain drag and rebound hammer. Along with several advanced methods including: dynamic characterization, stress wave techniques, ground penetrating radar, acoustic emissions, and infrared thermography. The manual also presents advantages and limitations of each method as applied to bridge superstructures.

Source: $\quad$ This manual is a good source of nondestructive testing methods that could be applied to historic covered bridges.

Pros/Cons: The manual gives advantages and limitations of each method described.

Title: $\quad$ Ultrasonic Testing of Barackville Timber Bridge Author: $\quad$ Udaya B. Halabe, Hota V.S. GangaRao, V. Rao Hota, and Samer H. Petro Citation: $\quad$ Report submitted to Dr. Emory Kemp

Summary: The report presents results on in-situ ultrasonic testing of Barrackville timber bridge. The field testing was conducted using velocity measurements. The members were tested close to the joints and the results were used to identify deteriorated joints. The identification of the weak joints enabled the contractor to economically plan for the renovation work of the bridge leading to substantial savings.

Source: $\quad$ The report is an example of in-situ testing that was conducted on a historic covered bride that was successfully used to renovate the structure.

Pros/Cons: The report is only of one bridge and only uses one nondestructive testing technique.

Title: $\quad$ Testing Historic Bridges with Ultrasound

Author: $\quad$ David A. Simmons

Citation: $\quad$ Ohio County Engineer, Number 2, Summer 1996 
Summary: This paper describes how ultrasonic testing was utilized on the Salt Creek Covered Bridge rehabilitation project. The bridge was built in 1876 and is one of the only all wooden Warren truss bridge still standing in the U.S.. The past method of testing wood members was to sound them with a hammer which is very unreliable. Researchers at the Constructed Facilities Center at West Virginia University have developed a new ultrasonic technique. The system uses two transducers to send and receive sound waves transversely through the wood. The systems were verified by destructively testing a small portion of the badly deteriorated truss. With this system the researchers were able to effectively locate deteriorated portions of the member.

Source: The paper is an excellent example of ultrasound was used to help rehabilitate a historic covered bridge.

Pros/Cons: The paper gives a good overview of how this nondestructive method can be used on a historic bridge.

\subsection{Historic Preservation}

Title: $\quad$ Historic Preservation, Project Planning \& Estimating

Author: $\quad$ Swanke Hayden Connell Architects

Citation: $\quad$ R.S. Means Company, Inc., 2000

Media: $\quad$ Book, 681p.

ISBN: $\quad 0-87629-573-1$

Summary: This book is a comprehensive source of information that focuses on historic preservation. The unique qualities of historic preservation are covered in-depth. Restoration, conservation, preservation, and rehabilitation of historic buildings are very different from new construction in that they deal with buildings that were designed without the use of building codes and the materials used had no processing guidelines. This leads to a very different approach to the project. This book has chapter dealing with the following: What makes a property historic, the project phases $\&$ design team services, hazardous materials, conformance with codes and standards, restoring archaic materials, and then chapters covering all most all materials that would be found in a historic building and also chapters covering aspects of construction administration. The book is intended to guide a person through a historic project development on schedule and within budget. This is accomplished while maintaining the utmost stewardship. 
Source: $\quad$ This book will allow the engineer to taken the proven methods of planning used by architects in preservation of buildings and apply them to covered bridges.

Pros/Cons: This book is an invaluable source if planning to be apart of a historic preservation project. The book has useful information for all disciplines involved in a project, from the 106 process to the actual technical portions of the project dealing with specific materials. All most any topic dealing with preservation is covered in this book.

Title: $\quad$ A Guide to the Maintenance, Repair, and Alteration of Historic Buildings

Author: $\quad$ Frederick A. Stahl

Citation: $\quad$ Van Nostrand Reinhold Company, 1984

Media: $\quad$ Book, $185 \mathrm{p}$.

ISBN: $\quad 0-442-28105-6$

Summary: This book is as the title suggests a true guide to the maintenance, repair, and alteration of historic buildings. The book is broken down into five parts: custodial and maintenance information; repair, alteration and design information; materials information; building systems information; mechanical systems information; electrical systems information. The book is setup with the topic on the left-hand side of page and the description of what do is on the right-hand side of the page. The topic covered with the most thoroughness in the book is masonry.

Source: This book gives some insight in preservation of buildings that could be applied to bridges.

Pros/Cons: This book is a good source if you have worked in the field before and you need assistance with a particular topic. The book does not give good background information on the topics covered. As the title suggest it is a good guide for a person with knowledge in the field.

Title: $\quad$ Caring for the Past

Author: $\quad$ Technical Preservation Services, National Park Services

Citation: $\quad$ U.S. Department of the Interior, 1996-97

Media: $\quad$ Book, 20p

Summary: This book is simply a list of other books and references. Having enough information is essential to any historic preservation project. This book gives information on all books, or resources published by Technical 
Preservation Services that are available either free or to be purchased. Listings range from standards and guidelines to preservation tax incentives to caring for historic buildings.

Source: $\quad$ This book will allow the preservation engineer to find needed sources of information.

Pros/Cons: This book is an excellence source to find or acquire required information for a historic preservation project.

Title: $\quad$ Metals in America's Historic Buildings

Author: $\quad$ Part I - Margot Gayle and David W. Look AIA

Part II - John G. Waite, AIA

Citation: $\quad$ Preservation Press, National Trust for Historic Preservation, 1984

Media: $\quad$ Book, 167p., 1992

ISBN: $\quad$ 0-16-038073-1

Summary: This book covers metals used in historic buildings. There are at least 15 metallic materials used in construction in the United States. Metals discovered in prehistory are still being used today, i.e., bronze and iron. Part I of this book gives a background of the different metal used in construction, such as: lead, tin, zinc, copper, nickel, iron, and aluminum. Part II gives more detailed information on the preservation and restoration of these materials. Causes of deterioration of each metal are described in great detail. Along with details of deterioration and preservation of each metal, general information is given on preservation of architectural metals, and causes of metal deterioration and failure along with general preservation methods.

Source: This book would be valuable if working on a historic wrought iron or suspension bridge.

Pros/Cons: This book is a very good source for information relating the use of metals in construction. The book is not only a good source for a preservationist, it would also be a good source for anyway rehabilitating any structure.

Title:

Aging Gracefully

Author:

Kerri Westenburg

Citation: $\quad$ Preservation Online, www.nthp.org/magazine Nov. 14, 2001

Summary: This article is a story of a street in Beverly Hills, CA, of duplexes and two - apartment buildings built in the 1920s and 1930s that a group of citizens 
are trying to save from a new condominium. Beverly Hills has no real preservation program and the city is not sensitive to preservation issues. The group fought and was able to have the street nominated to the state register of historic resources as a historic district. Even though the group was able to have the properties added to the register and had an environmental impact report stating that the development would result in significant adverse change a judge still ruled the development could proceed. As of the time of the article the ruling was still pending.

Source: A good article to show how important it is for the engineer and planners to work with the community in preservation projects.

Pros/Cons: $\quad$ This article shows what can happen if the proper planning and work is not put into a community before a project is planned. If the group had of planned ahead and developed a landmarks commission, the end result might have been different.

Title: $\quad$ Skilled Fixes for a Log House

Author: $\quad$ Gordon Bock and Douglas C. Reed

Citation: $\quad$ Old House Online, March - April 2001

Summary: This article describes the restoration process on a $19^{\text {th }}$ century log house. The Noah Rohrbach House is a house within the environs of the Antietam National Battlefield that Gen. George Mead stayed in during the 1860s. During the restoration of the house it was discovered that the framing of the house was not the typical wood framing, it was actually logs from an $18^{\text {th }}$ century structure. Since the structure was uninhabited since the $1970 \mathrm{~s}$ it was suspected that there would be some form of damage. Several of the corner post had termite colonies living in them. The repair method used was to relive the load that the corner posts were carrying and transfer it to new pressure treated wood.

Source: $\quad$ This article shows the need for more advanced methods of preservation for timber structures.

Pros/Cons: This article an example of how a $19^{\text {th }}$ century house was restored. There are several was in which this is not an example of good stewardship. The original members were replaced by new wood; the new wood was not augmented into the original structure to keep the same aesthetics. The structure should have been restored in a way to rehabilitate the original members where possible and incorporate new wood in with old in a way that is inconspicuous.

Title: $\quad$ Preserving Yesterday's View of Tomorrow Author: Judith Collins and Al Nash 
Citation: $\quad$ CRM No $5-2002$

Summary: This article discusses the life of the Century of Progress homes at the Chicago World's Fair. The five houses were built out of futuristic materials and of futuristic designs. The houses were displayed at the World's Fair and then sold to Robert Bartlett who moved the houses to the Lake Michigan shore. He eventually sold the houses to the National Park Service. The homes are now listed in on the register and owned by the National Park Service. All of them except one are under renovation as of the time of publication of this article. The major development in this article is how the National Park Service owns the houses, but allowed the owners to live in the houses for a certain period. Now the National Park Service has found people to lease the houses and renovated them to the 1933 World Fair condition.

Source: This article is a success story of historic preservation.

Pros/Cons: This article gives information on how the Chicago World's Fair Houses were preserved, but now detailed information on the methods used to preserve. The article is a good example of a case history in historic preservation.

Title: $\quad$ The Building Doctor Is In

Author: $\quad$ Mariangela F. Pfister

Citation: $\quad$ CRM No 52002

Summary: This article discusses how the building doctor clinics sponsored by the Ohio Historical Society (OHPO) teach owners of buildings the basics of good preservation and rehabilitation. The OHPO sponsors clinics that start out with presentations the Secretary Standards and the basics of old buildings. The next day of the clinics the Building Doctor's visit the houses of the people in attendance and receive assistance from the Doctor's with a wide range of issues during the renovation. The program has been very successful and is in its $25^{\text {th }}$ season. Through this program OHPO is able to spread the message of good preservation. Since the program started many preservation libraries and preservation review boards have been created in the towns that the held the Building Doctor Program. According to the author the most important benefit of the program is that it helps engage the citizens of Ohio in historic preservation.

Source: $\quad$ This article describes a state program to teach historic preservation that could possibly be used for covered bridges. 
Pros/Cons: This article describes a program that was well received in Ohio and could possibly be used in West Virginia. It is a good source of information on a alternative historic preservation program.

\subsection{Conclusion}

Various issues related to the FRP composites and wood, as published by various researchers are summarized herein, and no in-depth review of the presentations has been conducted. As can be seen from the papers presented in Chapter 2 and in this Annotated Bibliography there is a very limited amount of literature available on the use of FRP composites with sawn wood, and there is almost no documented source that presents results of wood members reinforced with pultruded FRP composites for a historic structure. 